Atmos. Chem. Phys., 19, 12631-12686, 2019

https://doi.org/10.5194/acp-19-12631-2019

(C) Author(s) 2019. This work is distributed under

the Creative Commons Attribution 4.0 License.

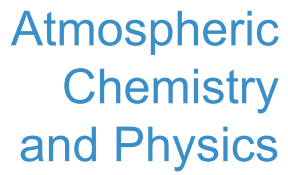

(c) (P)

\title{
A review of experimental techniques for aerosol hygroscopicity studies
}

\author{
Mingjin Tang ${ }^{1}$, Chak K. Chan ${ }^{2}$, Yong $\mathrm{Jie} \mathrm{Li}^{3}$, Hang Su${ }^{4,5}$, Qingxin $\mathrm{Ma}^{6}$, Zhijun Wu ${ }^{7}$, Guohua Zhang ${ }^{1}$, Zhe Wang ${ }^{8}$, \\ Maofa $\mathrm{Ge}^{9}$, Min $\mathrm{Hu}^{7}$, Hong $\mathrm{He}^{6,10,11}$, and Xinming Wang ${ }^{1,10,11}$ \\ ${ }^{1}$ State Key Laboratory of Organic Geochemistry and Guangdong Key Laboratory of Environmental Protection and Resources \\ Utilization, Guangzhou Institute of Geochemistry, Chinese Academy of Sciences, Guangzhou 510640, China \\ ${ }^{2}$ School of Energy and Environment, City University of Hong Kong, Kowloon, Hong Kong, China \\ ${ }^{3}$ Department of Civil and Environmental Engineering, Faculty of Science and Technology, \\ University of Macau, Avenida da Universidade, Taipa, Macau, China \\ ${ }^{4}$ Center for Air Pollution and Climate Change Research, Institute for Environmental and Climate Research, \\ Jinan University, Guangzhou 511443, China \\ ${ }^{5}$ Department of Multiphase Chemistry, Max Planck Institute for Chemistry, Mainz 55118, Germany \\ ${ }^{6}$ State Key Joint Laboratory of Environment Simulation and Pollution Control, Research Center for Eco-Environmental \\ Sciences, Chinese Academy of Sciences, Beijing 100085, China \\ ${ }^{7}$ State Key Joint Laboratory of Environmental Simulation and Pollution Control, College of Environmental Sciences and \\ Engineering, Peking University, Beijing 100871, China \\ ${ }^{8}$ Department of Civil and Environmental Engineering, Hong Kong Polytechnic University, Hong Kong, China \\ ${ }^{9}$ State Key Laboratory for Structural Chemistry of Unstable and Stable Species, Institute of Chemistry, \\ Chinese Academy of Sciences, Beijing 100190, China \\ ${ }^{10}$ University of Chinese Academy of Sciences, Beijing 100049, China \\ ${ }^{11}$ Center for Excellence in Regional Atmospheric Environment, Institute of Urban Environment, \\ Chinese Academy of Sciences, Xiamen 361021, China
}

Correspondence: Mingjin Tang (mingjintang@gig.ac.cn) and Chak K. Chan (chak.k.chan@cityu.edu.hk)

Received: 26 April 2019 - Discussion started: 3 May 2019

Revised: 26 August 2019 - Accepted: 16 September 2019 - Published: 10 October 2019

\begin{abstract}
Hygroscopicity is one of the most important physicochemical properties of aerosol particles and also plays indispensable roles in many other scientific and technical fields. A myriad of experimental techniques, which differ in principles, configurations and cost, are available for investigating aerosol hygroscopicity under subsaturated conditions (i.e., relative humidity below $100 \%$ ). A comprehensive review of these techniques is provided in this paper, in which experimental techniques are broadly classified into four categories, according to the way samples under investigation are prepared. For each technique, we describe its operation principle and typical configuration, use representative examples reported in previous work to illustrate how this technique can help better understand aerosol hygroscopicity, and discuss its advantages and disadvantages. In addition, future directions
\end{abstract}

are outlined and discussed for further technical improvement and instrumental development.

\section{Introduction}

Aerosol particles are airborne solid or liquid particles in the size range of a few nanometers to tens of micrometers. They can be emitted directly into the atmosphere (primary particles) and can also be formed in the atmosphere (secondary particles) by chemical transformation of gaseous precursors such as $\mathrm{SO}_{2}, \mathrm{NO}_{x}$, and volatile organic compounds (Pöschl, 2005; Seinfeld and Pandis, 2016). Aerosol particles are of great concern due to their environmental, health, climatic and biogeochemical impacts (Finlayson-Pitts and Pitts, 2000; 
Jickells et al., 2005; Mahowald, 2011; Mahowald et al., 2011; IPCC, 2013; Pöschl and Shiraiwa, 2015; Seinfeld and Pandis, 2016; Shiraiwa et al., 2017b).

Water, which can exist in gas, liquid and solid states, is ubiquitous in the troposphere. Interactions of water vapor with aerosol particles largely affect the roles that aerosol particles play in the Earth system. When water vapor is supersaturated (i.e., when relative humidity, $\mathrm{RH}$, is $>100 \%$ ), aerosol particles can act as cloud condensation nuclei (CCN) to form cloud droplets and as ice-nucleating particles (INPs) to form ice crystals (Pruppacher and Klett, 1997; Lohmann and Feichter, 2005; Vali et al., 2015; Lohmann et al., 2016; Tang et al., 2016a, 2018; Knopf et al., 2018). Cloud condensation nucleation and ice nucleation activities of aerosol particles, as well as relevant experimental techniques, have been recently reviewed in several books and review papers (Pruppacher and Klett, 1997; Hoose and Moehler, 2012; Murray et al., 2012; Kreidenweis and Asa-Awuku, 2014; Farmer et al., 2015; Lohmann et al., 2016; Tang et al., 2016a; Kanji et al., 2017) and are thus not further discussed in this paper.

When water vapor is unsaturated (i.e., $\mathrm{RH}<100 \%$ ), an aerosol particle in equilibrium with the surrounding environment would contain some amount of absorbed or adsorbed water (Martin, 2000; Kreidenweis and Asa-Awuku, 2014; Cheng et al., 2015; Farmer et al., 2015; Seinfeld and Pandis, 2016; Tang et al., 2016a; Freedman, 2017). The amount of water that a particle contains depends on $\mathrm{RH}$, temperature, and its chemical composition and size. The ability of a substance to absorb/adsorb water as a function of RH is typically termed hygroscopicity (Adams and Merz, 1929; Su et al., 2010; Kreidenweis and Asa-Awuku, 2014; Tang et al., 2016a), and the underlying thermodynamic principles can be found elsewhere (Martin, 2000; Seinfeld and Pandis, 2016). A single-component particle which contains a water-soluble inorganic salt, such as $\left(\mathrm{NH}_{4}\right)_{2} \mathrm{SO}_{4}$ and $\mathrm{NaCl}$, is solid at low $\mathrm{RH}$. When RH is increased to the deliquescence relative humidity (DRH), the solid particle will undergo deliquescence to form an aqueous particle, and the aqueous particle at DRH is composed of a saturated solution (Cheng et al., 2015). Further increase in RH would increase the water content of the aqueous droplet; i.e., the aqueous particle would become more diluted as RH increases. During humidification thermodynamics determines the phase transition and hygroscopic growth of the particle. During dehumidification, an aqueous particle would not undergo efflorescence to form a solid particle when RH is decreased to below DRH; instead, the aqueous particle would become supersaturated (i.e., the aqueous particle becomes a supersaturated solution). Only when RH is further decreased to efflorescence relative humidity (ERH) would the aqueous particle undergo crystallization, leading to the formation of a solid particle. Therefore, efflorescence is also kinetically controlled (in addition to being thermodynamically controlled), and there is a hysteresis between deliquescence and efflorescence. Deliquescence and efflores- cence of multicomponent particles can be more complicated (Seinfeld and Pandis, 2016).

It should be pointed out that not all the single-component particles exhibit distinctive deliquescence and efflorescence. Instead, continuous uptake or loss of liquid water is observed during humidification and dehumidification processes for many inorganic and organic particles (Mikhailov et al., 2009; Koop et al., 2011; Shiraiwa et al., 2011). Particles with extremely low hygroscopicity (e.g., mineral dust) will not be deliquesced even at very high $\mathrm{RH}$; instead, adsorbed water will be formed on the particle surface (Tang et al., 2016a). Furthermore, a multicomponent particle which contains some types of organic materials may undergo liquidliquid phase separation, leading to the formation of two coexisting liquid phases in one particle (Mikhailov et al., 2009; You et al., 2012, 2014; Freedman, 2017; Song et al., 2017, 2018). It is conventionally assumed that hygroscopic equilibrium of aerosol particles can be quickly reached. Nevertheless, recent laboratory, field and modeling studies suggested that atmospherically relevant particles can be semi-solid or amorphous solid (Virtanen et al., 2010; Zobrist et al., 2011; Renbaum-Wolff et al., 2013; Shiraiwa et al., 2017a; Reid et al., 2018). The viscosity of these particles can be high enough such that uptake or release of water is largely limited by diffusion of water molecules in the bulk phase of these particles.

Hygroscopicity determines the amount of water that a particle contains under a given condition and thereby has several important implications. It determines the size and refractive indices of aerosol particles, affecting their optical properties and consequently their impacts on visibility and direct radiative forcing (Malm and Day, 2001; Chin et al., 2002; Quinn et al., 2005; Hand and Malm, 2007; Cheng et al., 2008; Eichler et al., 2008; Liu et al., 2012; Liu et al., 2013b; Brock et al., 2016b; Titos et al., 2016; Haarig et al., 2017). Hygroscopicity is also closely related to the CCN activity of aerosol particles, affecting their impacts on formation and properties of clouds and thus their indirect radiative forcing (McFiggans et al., 2006; Petters and Kreidenweis, 2007; Reutter et al., 2009; Kreidenweis and Asa-Awuku, 2014; Farmer et al., 2015). Aerosol liquid water and/or surface-adsorbed water, largely controlled by hygroscopicity, determine heterogeneous and multiphase reactions of aerosol particles via several mechanisms, as revealed by recent studies (Bertram and Thornton, 2009; Shiraiwa et al., 2011; Rubasinghege and Grassian, 2013; Cheng et al., 2016; Wang et al., 2016; Tang et al., 2017; Mu et al., 2018; Wu et al., 2018). In addition, hygroscopicity significantly impacts dry and wet deposition rates of aerosol particles and thus their lifetimes, spatiotemporal distribution and environmental and health effects (Fan et al., 2004; Q. Q. Wang et al., 2014). For primary biological aerosols in particular, changes in their atmospheric transport behavior have important implications for the spread of plants and microbes and therefore the evolution of ecosystems (Brown and Hovmoller, 2002; Després et al., 2012; Fisher et al., 2012; Fröhlich-Nowoisky et al., 2016). 
Atmospheric aerosol is only one of many fields in which hygroscopicity is of great interest. Hygroscopicity is closely linked to water activities and thermodynamics of solutions (Atkins, 1998). It also determines the amount of surfaceadsorbed water and surface reactivity of various solid materials and has been widely investigated in surface science and heterogeneous catalysis (Miranda et al., 1998; Ewing, 2006; Yamamoto et al., 2010b; Chen et al., 2012; Rubasinghege and Grassian, 2013; Liu et al., 2017). Hygroscopicity is related to the possible existence of liquid water in some hyperarid environments (such as Mars and the Atacama Desert on Earth) (Martin-Torres et al., 2015): while pure liquid water is not stable in these environments, the deliquescence of some salts, such as chlorides and perchlorates, can occur at RH significantly below $100 \%$ and lead to the formation of aqueous solutions (Gough et al., 2011, 2016; Gu et al., 2017a; Jia et al., 2018). Hygroscopic properties significantly affect transport and deposition of inhaled aerosol particles in the respiratory tract, therefore playing an important role in the health impact of ambient aerosols as well as efficacy and side effects of aerosolized pharmaceuticals (Hickey and Martonen, 1993; Robinson and Yu, 1998; Carvalho et al., 2011; Hofmann, 2011; Haddrell et al., 2014; Winkler-Heil et al., 2014, 2017; Darquenne et al., 2016; Davidson et al., 2017). Impacts of moisture and implications of hygroscopicity have been well documented for physical and chemical stability of pharmaceuticals (Ahlneck and Zografi, 1990; Chan et al., 1997; Peng et al., 2000; Newman et al., 2008; Mauer and Taylor, 2010a; Tong et al., 2010a; Feth et al., 2011) as well as food ingredients and blends (Mauer and Taylor, 2010b; Allan and Mauer, 2016), and large efforts have been made in the pharmaceutical and food industries to prevent relevant products from deliquescence. Corrosion and degradation of various constructions and buildings depend largely on RH, and as a result both the chemical inertness and hygroscopicity of materials used should be taken into account (Schindelholz et al., 2014a, b; Vainio et al., 2016); in addition, deposition of particles of different compositions has also been shown to affect the extent of corrosion of steel (Lau et al., 2008).

As summarized in this paper, a number of experimental techniques, which differ largely in principles, configurations and cost, have been developed to investigate hygroscopic properties of atmospherically relevant particles. Hygroscopic properties investigated at $<100 \% \mathrm{RH}$ typically include the amount of water absorbed or adsorbed by particles as a function of RH, as well as DRH and ERH if they exist. Techniques employed to investigate aerosol hygroscopicity under supersaturation, commonly termed CCN activity, are relatively less diverse, and interested readers are referred to the relevant literature (Nenes et al., 2001; Roberts and Nenes, 2005; Kreidenweis and Asa-Awuku, 2014) for further information. In addition, techniques used to study ice nucleation have been discussed in a number of recent papers (DeMott et al., 2011, 2018; Murray et al., 2012; Ladino et al., 2013) and as a result are not further discussed here.
Several review papers and book chapters have discussed some of these techniques used to investigate aerosol hygroscopicity. For example, Kreidenweis and Asa-Awuku (2014) discussed a few widely used techniques for aerosol hygroscopicity measurements, and Tang et al. (2016a) summarized in brief experimental techniques used to investigate water adsorption and hygroscopicity of mineral dust particles. There are also a few review papers focused on a specific technique or a specific category of techniques. For example, Swietlicki et al. (2008) reviewed aerosol hygroscopicity measured in various environments using humidity-tandem differential mobility analyzers and provided a nice overview of this technique; application of single-particle levitation techniques to investigate properties and processes of aerosol particles, including aerosol hygroscopicity, was reviewed by Krieger et al. (2012); Titos et al. (2016) reviewed techniques used to investigate the effect of hygroscopic growth on aerosol light scattering, and Ault and Axson (2017) summarized and discussed recent advancements in spectroscopic and microscopic methods for characterization of aerosol composition and physicochemical properties.

Nevertheless, to our knowledge there is hitherto no paper or book which covers most of (if not all) experimental techniques used for hygroscopicity measurements. This paper aims at providing the first comprehensive review in this field. For each technique, we first introduce its operation principle and typical configurations and then use exemplary results to illustrate how this technique can help better understand hygroscopic properties. According to the way samples under investigation are prepared, experimental techniques covered in this paper are classified into four categories, which are discussed in Sects. 2-5. In Sect. 2, we discuss experimental techniques applied to bulk solutions. Experimental techniques for particles deposited on substrates, levitated single particles and aerosol particles are reviewed in Sects. 3-5, respectively. Remote sensing techniques can also be employed to retrieve aerosol hygroscopicity (Ferrare et al., 1998; Feingold and Morley, 2003; Pahlow et al., 2006; Schuster et al., 2009; Li et al., 2013; Lv et al., 2017; Bedoya-Velasquez et al., 2018; Fernandez et al., 2018); however, they are not covered in this paper because we intend to focus on in situ techniques, and application of remote sensing to investigate aerosol hygroscopicity has been discussed very recently in a book chapter (Kreidenweis and Asa-Awuku, 2014). In addition, techniques for measuring $\mathrm{CCN}$ and $\mathrm{IN}$ activities of aerosol particles are not covered in the present paper, and interested readers are referred to the relevant literature (Roberts and Nenes, 2005; Lance et al., 2006; Petters et al., 2007; Good et al., 2010a; DeMott et al., 2011; Lathem and Nenes, 2011; Hiranuma et al., 2015; Wex et al., 2015). 


\section{Bulk solution-based techniques}

In principle, the hygroscopicity of a compound can be determined by measuring the water vapor pressure of air over (i.e., in equilibrium with) the aqueous solution at a given concentration (Pitzer, 1991; Rard and Clegg, 1997). Experimental data can then be used to derive water-to-solute ratios as a function of RH for aqueous solutions, and the RH over the saturated solution can generally be regarded as the DRH. Experimental methods based on this principle have been widely used since the early 20th century (or probably even earlier) (Adams and Merz, 1929; Hepburn, 1932) and are still being used (Königsberger et al., 2007; Sadeghi and Shahebrahimi, 2011; Golabiazar and Sadeghi, 2014) to investigate thermodynamic properties of aqueous solutions. In general, these methods can be further classified into two categories, i.e., isopiestic and nonisopiestic methods (Rard and Clegg, 1997).

\subsection{The isopiestic method}

The isopiestic method was described in a number of previous studies (Spedding et al., 1976; Rard and Miller, 1981; Pitzer, 1991; Hefter et al., 1997; Rard and Clegg, 1997; Königsberger et al., 2007), and a brief introduction is provided herein. For a typical experiment, two open vessels which contain a reference solution and a sample solution are housed in a sealed chamber with temperature being well controlled, and water vapor will be transferred between the two solutions until an equilibrium is reached. For the reference solution, its water activity should be well documented as a function of concentration. When the equilibrium is reached, the water activity of the sample solution is equal to that of the reference solution. If we measure the concentrations of the two solutions in equilibrium, the water activity of the sample solution at a given concentration can then be determined.

\subsection{Nonisopiestic techniques}

The water vapor pressure over (or the water activity of) an aqueous solution can be determined using a number of methods (Rard and Clegg, 1997), including but not limited to (i) the static vapor pressure method, i.e., direct measurement of the vapor pressure over a solution after being degassed (Adams and Merz, 1929; Jakli and Vanhook, 1972; Apelblat, 1992); (ii) the dynamic vapor pressure method, i.e., measurements of the amount of water vapor from an aqueous solution required to saturate a given volume of air (Bechtold and Newton, 1940); (iii) measurements of the boiling temperature of an aqueous solution; (iv) measurements of the dew point or RH of the air over an aqueous solution (Hepburn, 1932); and (v) the vapor pressure osmometry (Amdur, 1974; Sadeghi and Shahebrahimi, 2011). These techniques are described elsewhere (Pitzer, 1991; Rard and Clegg, 1997), and interested readers are referred to the two papers (and references therein) for more information. A few recent studies are

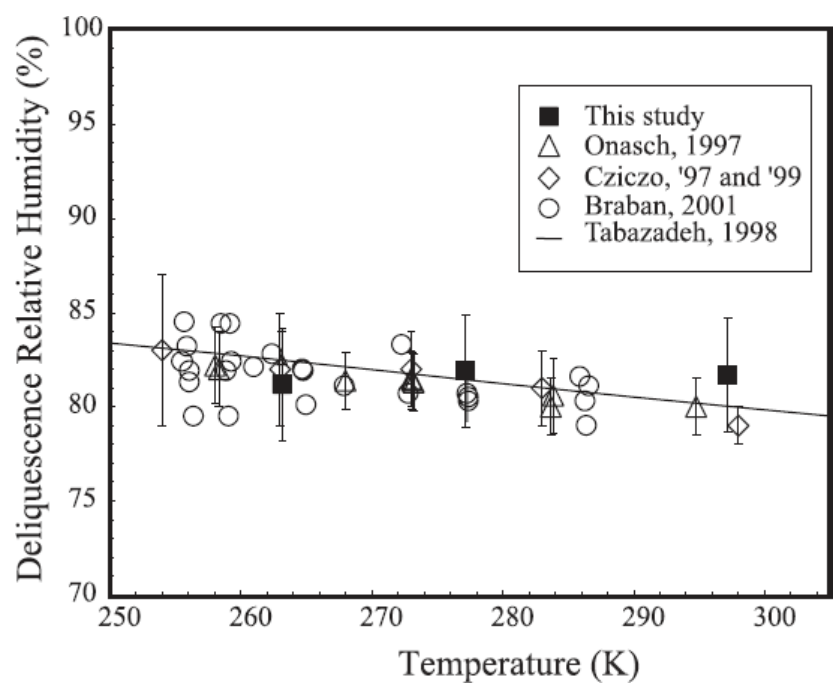

Figure 1. Comparison of DRH values as a function of temperature (250-300 K) measured by different studies, including Onasch, 1997 (Onasch et al., 1997), Cziczo, '97 and '99 (Cziczo et al., 1997; Cziczo and Abbatt, 1999), Braban, 2001 (Braban et al., 2001), and Tabazadeh, 1998 (Tabazadeh and Toon, 1998). Reprint with permission by Brooks et al. (2002). Copyright 2002 John Wiley \& Sons, Inc.

discussed below to illustrate how nonisopiestic techniques could be used to investigate hygroscopic properties of compounds relevant for atmospheric aerosols.

The $\mathrm{RH}$ of air over $10 \mathrm{~mL}$ aqueous solutions which were contained in sealed test tubes kept at constant temperatures was measured by Tolbert and co-workers (Brooks et al., 2002; Wise et al., 2003) to investigate water activities as a function of solution concentration. In the first study (Brooks et al., 2002), $\mathrm{RH}$ over saturated solutions was measured for $\left(\mathrm{NH}_{4}\right)_{2} \mathrm{SO}_{4}$, several dicarboxylic acids, as well as mixtures of $\left(\mathrm{NH}_{4}\right)_{2} \mathrm{SO}_{4}$ with individual dicarboxylic acids to determine their DRH. As shown in Fig. 1, the DRH values of $\left(\mathrm{NH}_{4}\right)_{2} \mathrm{SO}_{4}$ measured by Brooks et al. (2002) agreed well with those reported in previous studies (Cziczo et al., 1997; Tabazadeh and Toon, 1998; Cziczo and Abbatt, 1999; Onasch et al., 1999; Braban et al., 2001) for temperature ranging from $\sim 250$ to $\sim 300 \mathrm{~K}$, confirming that the simple technique could determine DRH in a reliable manner. It was further found that the presence of water-soluble dicarboxylic acids would reduce the DRH of $\left(\mathrm{NH}_{4}\right)_{2} \mathrm{SO}_{4}$, whereas the presence of less soluble dicarboxylic acids had no measurable effects (Brooks et al., 2002). In a following study (Wise et al., 2003), RH of air over eutonic mixtures of $\left(\mathrm{NH}_{4}\right)_{2} \mathrm{SO}_{4} /$ dicarboxylic acids was measured at $25^{\circ} \mathrm{C}$ to investigate the effect of organic acids on hygroscopic growth of $\left(\mathrm{NH}_{4}\right)_{2} \mathrm{SO}_{4}$. The presence of water-soluble dicarboxylic acids reduced hygroscopic growth of $\left(\mathrm{NH}_{4}\right)_{2} \mathrm{SO}_{4}$, while the effect of less soluble dicarboxylic acids was found to be negligible (Wise et al., 2003). 
Water activity meters, which measure the dew point temperature of the air in equilibrium with an aqueous sample, are commercially available (Maffia and Meirelles, 2001; Marcolli et al., 2004; Salcedo, 2006). For example, water activity meters were employed by Salcedo (2006) and Maffia and Meirelles (2001) to study hygroscopic properties of organic acids and their mixtures with $\left(\mathrm{NH}_{4}\right)_{2} \mathrm{SO}_{4}$ and $\mathrm{NH}_{4} \mathrm{HSO}_{4}$ at $25^{\circ} \mathrm{C}$.

\subsection{Discussion}

Bulk solution-based techniques have the advantage of being inherently accurate and very simple, while one major drawback is that these measurement cycles can be very timeconsuming, typically taking days up to months to reach the equilibrium (Königsberger et al., 2007). Particle water content can be quantitatively determined for unsaturated solutions, whereas no information can be provided for supersaturated solutions. Bulk solution-based methods do not require particle sphericity assumption to derive particle water content, but cannot be used to study water adsorption. Generally speaking, while these techniques are useful for understanding properties of deliquesced particles, they are not applicable for direct measurements of ambient aerosol particles.

\section{Particles deposited on substrates}

In this section we review and discuss techniques which can be used to investigate hygroscopic properties of particles (either particle ensembles or individual particles) deposited on substrates. This section is further divided into five parts: techniques for which changes in water vapor and particle mass are measured to investigate particle hygroscopicity are reviewed in Sect. 3.1 and 3.2, and microscopic and spectroscopic tools employed to investigate particle hygroscopicity are reviewed in Sect. 3.3 and 3.4. Measurements of change in electrical conductivity for understanding hygroscopic properties of particles are briefly discussed in Sect. 3.5.

\subsection{Measurement of water vapor}

Particles would absorb/adsorb water vapor from the gas phase to reach a new equilibrium as RH increases, while water vapor will be released if RH decreases. Measurement of change in water vapor can be used to investigate hygroscopic properties. Exposure of water vapor to particles can be achieved in either a static cell or a flow cell.

\subsubsection{Physisorption analyzer}

When exposed to water vapor, particles will absorb/absorb water vapor, leading to depletion of water vapor in the system. The amount of water absorbed/adsorbed by particles can be determined from the measured change in water vapor pressure (if the volume remains constant), and the $\mathrm{RH}$ can

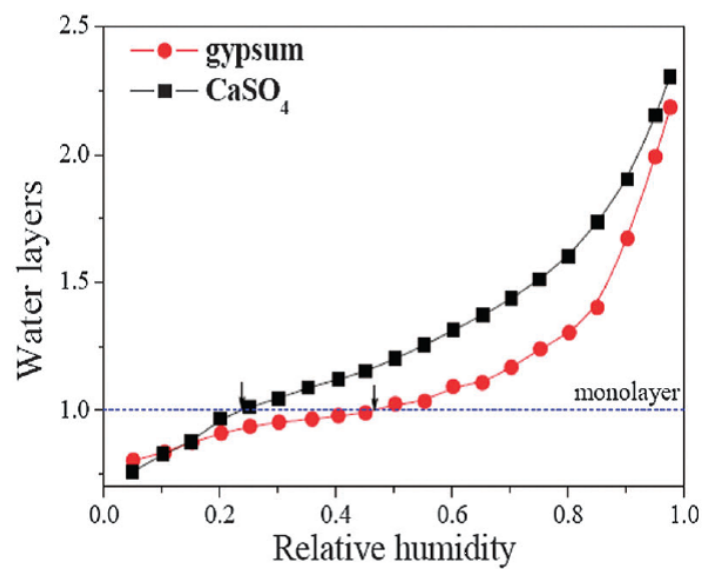

Figure 2. Water adsorption isotherms of $\mathrm{CaSO}_{4}$ (black square) and gypsum $\left(\mathrm{CaSO}_{4} \cdot 2 \mathrm{H}_{2} \mathrm{O}\right.$, red circle $)$ at $278 \mathrm{~K}$. Reprinted with permission by Q. Ma et al. (2013). Copyright 2013 PCCP Owner Societies.

be calculated from the final water vapor pressure when the equilibrium is reached. The amount of water associated with particles can be determined as a function of RH by varying the initial water vapor pressure.

Commercial instruments, usually designed to measure the Brunauer-Emmett-Teller (BET) surface areas using nitrogen or helium (Torrent et al., 1990), have been utilized to investigate hygroscopic properties of atmospherically relevant particles (Ma et al., 2010b, 2012b; Hung et al., 2015). For example, Ma et al. (2010b) integrated an AUTOSORB-1-C instrument (Quantachrome, US) with a water vapor generator and employed this apparatus to investigate hygroscopic properties of $\mathrm{NaCl}, \mathrm{NH}_{4} \mathrm{NO}_{3}$ and $\left(\mathrm{NH}_{4}\right)_{2} \mathrm{SO}_{4}$. The measured $\mathrm{DRH}$ values and mass hygroscopic factors were found to agree very well with those reported in the literature (Ma et al., 2010b). This method has proven to be very sensitive; as shown in Fig. 2, change in adsorbed water as small as the $<0.5$ monolayer can be reliably quantified (Q. Ma et al., 2013). In addition to $\mathrm{CaSO}_{4}$ and gypsum, this instrument was also employed to investigate hygroscopic properties of fresh and aged $\mathrm{Al}_{2} \mathrm{O}_{3}, \mathrm{MgO}$ and $\mathrm{CaCO}_{3}$ particles (Ma et al., 2012a).

A similar instrument (Micromeritics ASAP 2020) was employed by Hung et al. (2015) to examine the hygroscopicity of black carbon, kaolinite and montmorillonite particles at $301 \mathrm{~K}$, and a sensitivity of sub-monolayers of adsorbed water could be achieved. Assuming a dry particle diameter of $200 \mathrm{~nm}$, the single hygroscopicity parameters, $\kappa$, were determined to be $\sim 0.002$ for montmorillonite and $<0.001$ for both black carbon and kaolinite (Hung et al., 2015).

This technique is able to quantify particle water content for unsaturated samples and is sensitive enough to measure adsorbed water; however, it cannot be (at least has not been) used to examine supersaturated samples. This technique, which is independent of particle size and morphology, 
can also be used to investigate hygroscopic properties of ambient aerosol particles in an offline manner. For example, a physisorption analyzer was used to study hygroscopic properties of ambient aerosol particles collected in Beijing during an Asian dust storm, and one monolayer of adsorbed water was formed on these particles at $46 \%$ RH (Ma et al., 2012b).

\subsubsection{Katharometer}

The katharometer, also known as the thermal conductivity detector, can be used to measure water vapor concentration. Lee and co-workers employed a katharometer to investigate liquid water content of aerosol particles collected on filters (Lee and Hsu, 1998, 2000; Lee and Chang, 2002). In this setup (Lee and Chang, 2002), aerosol particles were collected on a Teflon filter and then equilibrated with a helium flow at a given RH; after the equilibrium was reached, the particleloaded filter was purged with a dry helium flow, which was subsequently directed to a katharometer to measure the water vapor concentration. As a result, the liquid water content associated with particles at a given RH could be quantified. The performance of this new method was systematically examined (Lee and Hsu, 1998, 2000; Lee and Chang, 2002), and the measured water-to-solute ratios at different $\mathrm{RH}$ during both humidification and dehumidification processes were found to agree well with those reported in the literature for several compounds, including $\mathrm{NaCl}, \mathrm{NH}_{4} \mathrm{Cl}$, $\mathrm{Na}_{2} \mathrm{SO}_{4},\left(\mathrm{NH}_{4}\right)_{2} \mathrm{SO}_{4}$ and $\mathrm{NH}_{4} \mathrm{NO}_{3}$.

Mikhailov et al. (2011, 2013) also developed a katharometer-based method to investigate aerosol hygroscopicity. The instrument, called a filter-based differential hygroscopicity analyzer (FDHA), is described elsewhere (Mikhailov et al., 2011), and a brief introduction is provided here. In this apparatus, a humidified helium flow was split into two identical flows which were then passed through a pair of differential measurement cells: the reference cell contained a blank filter, and the sample cell contained a filter laden with particles (typically less than $0.1 \mathrm{mg}$ ). The difference in water vapor concentrations in these two cells, caused by absorption/adsorption of water by particles loaded on the filter, was measured using a differential katharometer, and the amount of water taken up by particles could be quantified by integration of the katharometer signals over time. This instrument could measure hygroscopic growth at very high RH (up to $99 \%$ ).

Hygroscopic properties of $\left(\mathrm{NH}_{4}\right)_{2} \mathrm{SO}_{4}, \mathrm{NaCl}$, levoglucosan, malonic acid, and mixed $\left(\mathrm{NH}_{4}\right)_{2} \mathrm{SO}_{4}-$ malonic acid particles were examined using FDHA at different RH during humidification and dehumidification (Mikhailov et al., 2013), and the measured mass growth factors agreed well with those reported in the literature. This instrument was further employed to investigate hygroscopic properties of particles collected from a pristine tropical rainforest (near Manaus, Brazil) (Mikhailov et al., 2013), a suburban boreal forest site (near the city of St. Petersburg, Russia) (Mikhailov et al.,
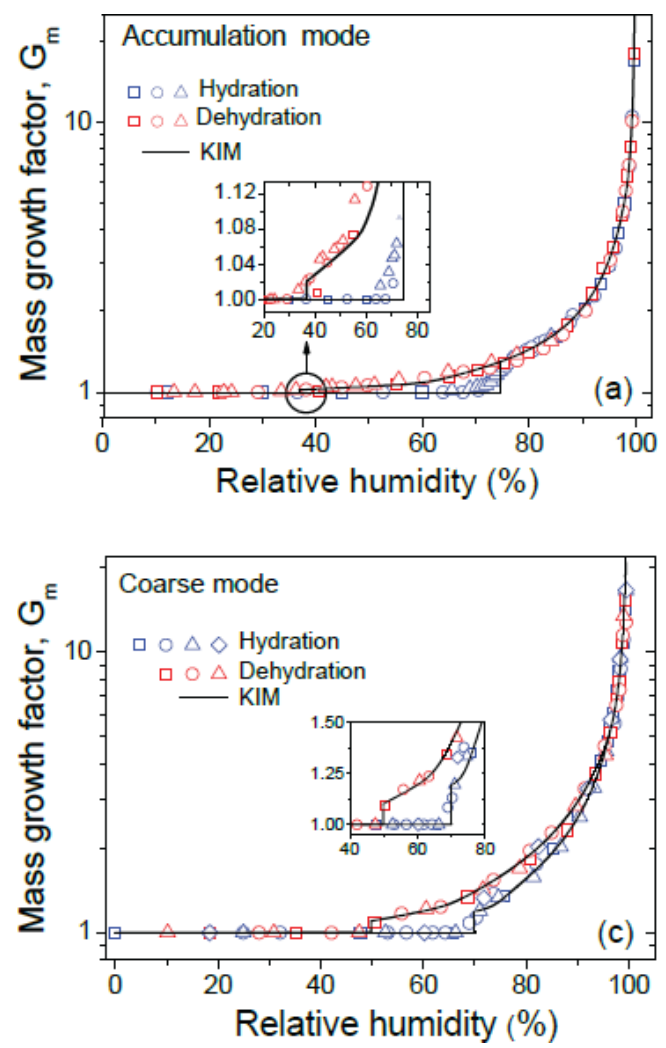

Figure 3. Mass growth factors of particles collected at the ZOTTO site in Serbia in June 2013: (upper panel) accumulation mode; (lower panel) coarse mode. The solid curves represent simulations using the $\kappa_{m}$-interaction model (KIM). Reprinted with permission by Mikhailov et al. (2015).

2013) and a remote boreal site (the Zotino Tall Tower Observatory, ZOTTO) in Siberia (Mikhailov et al., 2015). Figure 3 displays the measured hygroscopic properties of aerosol particles collected at the ZOTTO site. As shown in Fig. 3, both supermicrometer and submicrometer particles started to uptake a substantial amount of water at $\sim 70 \% \mathrm{RH}$; nevertheless, efflorescence took place at different RH, with ERH being $\sim 35 \%$ RH for submicrometer particles and $\sim 50 \% \mathrm{RH}$ for supermicrometer particles (Mikhailov et al., 2015). It was suggested that the observed difference in ERH could be explained by the difference in organic contents in submicrometer and supermicrometer particles (Mikhailov et al., 2015): submicrometer particles contained larger fractions of organic materials, consequently leading to the reduction of ERH.

The katharometer-based technique can be used to determine particle water content for unsaturated and supersaturated samples, independent of particle size and morphology (Lee and Chang, 2002; Mikhailov et al., 2013). It has also been successfully used as an offline method to investigate hygroscopic properties of ambient aerosol particles (Mikhailov et al., 2013, 2015). It remains to be tested whether this tech- 
nique is sensitive enough to investigate water adsorption of a few monolayers or less.

\subsubsection{Knudsen cell reactor}

Knudsen cell reactors are low-pressure reactors widely used to investigate heterogeneous uptake of trace gases (AlAbadleh and Grassian, 2000; Karagulian and Rossi, 2005; Karagulian et al., 2006; Wagner et al., 2008; Liu et al., 2009; Zhou et al., 2012). This technique was also employed in several studies to explore water adsorption by particles with atmospheric relevance (Rogaski et al., 1997; Seisel et al., 2004, 2005). For example, the initial uptake coefficient was reported to be $0.042 \pm 0.007$ for uptake of water vapor by Saharan dust at $298 \mathrm{~K}$ (Seisel et al., 2004). Another study (Rogaski et al., 1997) found that pretreatment with $\mathrm{SO}_{2}$, $\mathrm{HNO}_{3}$ and $\mathrm{H}_{2} \mathrm{SO}_{4}$ could significantly increase water uptake by amorphous carbon. Knudsen cell reactors are normally operated in the molecular flow regime, and thus water vapor pressure used in these experiments is extremely low. As a result, although these measurements can provide mechanistic insights into the interaction of water vapor with particles at the molecular level, limited information on aerosol hygroscopicity under atmospheric conditions can be provided.

\subsection{Measurement of sample mass}

Aerosol hygroscopicity can be quantitatively determined by measuring the mass of particles as a function of RH under isothermal conditions. This can be achieved by several types of experimental techniques, as introduced below.

\subsubsection{Analytical balance}

In a simple manner, the change in particle mass due to water uptake can be measured using an analytical balance under well-controlled conditions (Hänel, 1976; McInnes et al., 1996; Hitzenberger et al., 1997; Diehl et al., 2001). For example, Diehl et al. (2001) investigated hygroscopic properties of 10 pollen species at room temperature, using an analytical balance housed in a humidification chamber. The masses of pollen samples were measured at $0,(73 \pm 4)$ and $(95 \pm 2) \%$ RH. The average ratios of the mass of adsorbed water to dry mass increased from around 0.1 at $73 \% \mathrm{RH}$ to $\sim 1$ at $95 \%$ RH (Diehl et al., 2001), suggesting that pollen samples can adsorb a substantial amount of water at elevated RH.

Analytical balance was also employed to investigate hygroscopic properties of ambient aerosol particles. McInnes et al. (1996) employed an analytical balance to explore the hygroscopic properties of submicrometer marine aerosol particles collected on filters and found that liquid water accounted for up to $9 \%$ of the dry particle mass at $35 \% \mathrm{RH}$ and up to $29 \%$ of the dry particle mass at $47 \%$ RH. In another study (Hitzenberger et al., 1997), size-segregated aerosol particles were collected on aluminum foils using a nine-stage cascade impactor in downtown Vienna, and their hygroscopic properties were examined using an analytic balance. Aerosol hygroscopicity was found to be strongly size dependent (Hitzenberger et al., 1997), and the mass ratios of particles at $90 \% \mathrm{RH}$ to those at dry conditions were found to be 2.35-2.6 for particles in the accumulation mode and 1.16-1.33 for those in the coarse mode.

\subsubsection{Thermogravimetric analysis}

Similarly to humidity-controlled analytical balance, thermogravimetric analyzers (TGAs) can directly measure the mass change in particle samples at different temperatures to investigate aerosol hygroscopicity. Commercial TGA instruments are typically integrated with automated systems for humidity generation and control. They can control temperature and RH very precisely and are very sensitive in mass measurement (typically down to $1 \mu \mathrm{g}$ or even better).

Thermogravimetric analyzers, sometimes also called vapor sorption analyzers (VSAs), have been employed by several groups to investigate hygroscopic properties of atmospherically relevant particles. For example, water uptake by $\mathrm{CaCO}_{3}$ and Arizona test dust was measured at room temperature using a Mettler-Toledo TGA with an accuracy of $1 \mu \mathrm{g}$ in mass measurement (Gustafsson et al., 2005), and about four monolayers of adsorbed water were formed at $80 \% \mathrm{RH}$ for both mineral dust samples. A similar instrument was utilized to determine the DRH of dicarboxylic acids and their sodium salts at different temperatures (Beyer et al., 2014; Schroeder and Beyer, 2016), and the DRH was found to decrease with temperature for malonic acid, from $80.2 \%$ at $277 \mathrm{~K}$ to $69.5 \%$ at $303 \mathrm{~K}$ (Beyer et al., 2014). This method was also used to probe water adsorption by different soot particles (Popovitcheva et al., 2001, 2008a, b), although no details of the instrument used were provided. It is worth noting that TGA and/or VSA have been widely used to investigate hygroscopic properties of pharmaceutical materials. For example, at room temperature anhydrous theophylline was observed to transform to hydrate at $62 \% \mathrm{RH}$, and its DRH was determined to be $99 \%$ (Chen et al., 2010).

Very recently, Tang and co-workers systematically evaluated the performance of a vapor sorption analyzer to investigate hygroscopic properties of particles of atmospheric relevance (Gu et al., 2017b). The instrument, with its schematic diagram shown in Fig. 4, has two sample crucibles housed in a temperature- and humidity-regulated chamber, and one crucible is empty so that the background is simultaneously measured and subtracted. DRH values of six compounds, including $\left(\mathrm{NH}_{4}\right)_{2} \mathrm{SO}_{4}$ and $\mathrm{NaCl}$, were determined at different temperatures $\left(5-30^{\circ} \mathrm{C}\right)$ and found to agree well with literature values. In addition, the mass change as a function of $\mathrm{RH}$ (up to $90 \%$ ), relative to that at $0 \% \mathrm{RH}$, was also found to agree well with those calculated using the E-AIM model (Clegg et al., 1998) for $\left(\mathrm{NH}_{4}\right)_{2} \mathrm{SO}_{4}$ and $\mathrm{NaCl}$ at 5 and $25^{\circ} \mathrm{C}$. Therefore, it can be concluded that the vapor sorption ana- 


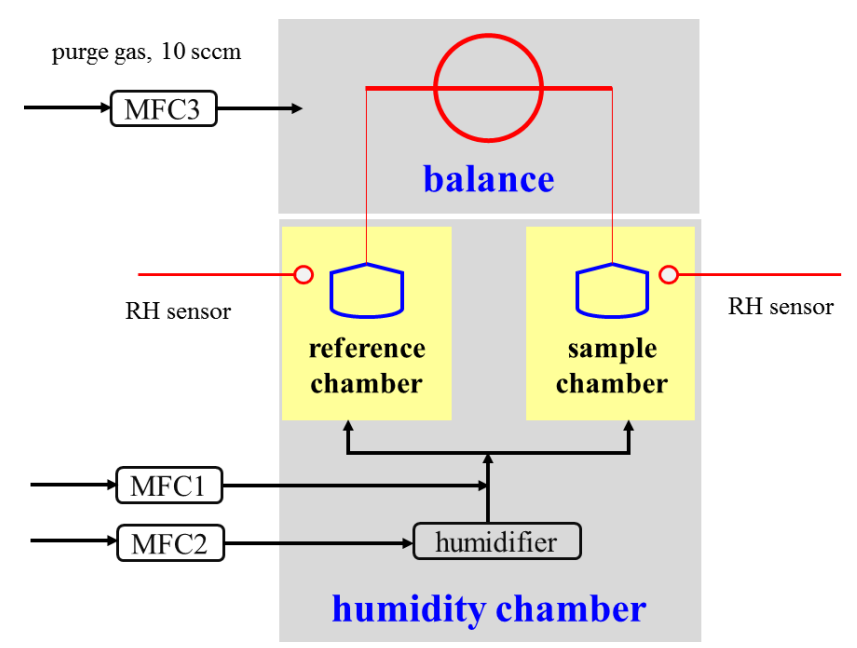

Figure 4. Schematic diagram of a vapor sorption analyzer (Q5000SA, TA Instruments, New Castle, DE, USA). Three mass flow controllers were used (MFC1: the dry flow; MFC2: the humidified flow; MFC3: the dry flow to purge the balance). Reprint with permission by $\mathrm{Gu}$ et al. (2017b).

lyzer is a reliable technique to study hygroscopic properties of atmospherically relevant particles.

The vapor sorption analyzer was used to examine hygroscopicity of $\mathrm{CaSO}_{4} \cdot 2 \mathrm{H}_{2} \mathrm{O}$ at $25^{\circ} \mathrm{C}$ (Gu et al., 2017b), and the results are displayed in Fig. 5. The hygroscopicity of $\mathrm{CaSO}_{4} \cdot 2 \mathrm{H}_{2} \mathrm{O}$ was found to be very low, and the sample mass was only increased by $<0.5 \%$ when $\mathrm{RH}$ was increased from $0 \%$ to $95 \%$. This instrument was very sensitive to the change in sample mass due to water uptake; for example, as shown in Fig. 5b, a relative mass change of $<0.025 \%$ within $6 \mathrm{~h}$ could be accurately determined. This instrument was further employed to investigate hygroscopic properties of perchlorates (Gu et al., 2017a; Jia et al., 2018), Ca- and Mg-containing salts (Guo et al., 2019), and primary biological particles (Tang et al., 2019), which play significant roles in the environments of the Earth and Mars. To our knowledge, the VSA technique has not yet been used to explore hygroscopic properties of ambient aerosol particles.

\subsubsection{Quartz crystal microbalance}

It was proposed in 1959 (Sauerbrey, 1959) that a film attached to the electrodes of a piezoelectric quartz resonator would cause a decrease in the resonance frequency, given by Eq. (1):

$$
\Delta f=-C_{f} \cdot \Delta m
$$

where $\Delta f$ is the change in resonance frequency, $\Delta m$ is the mass of the film, and $C_{f}$ is a constant specific to the quartz resonator that can be experimentally calibrated. Equation (1), known as the Sauerbrey equation, forms the basis for using the piezoelectric quartz resonator as a microbalance, which
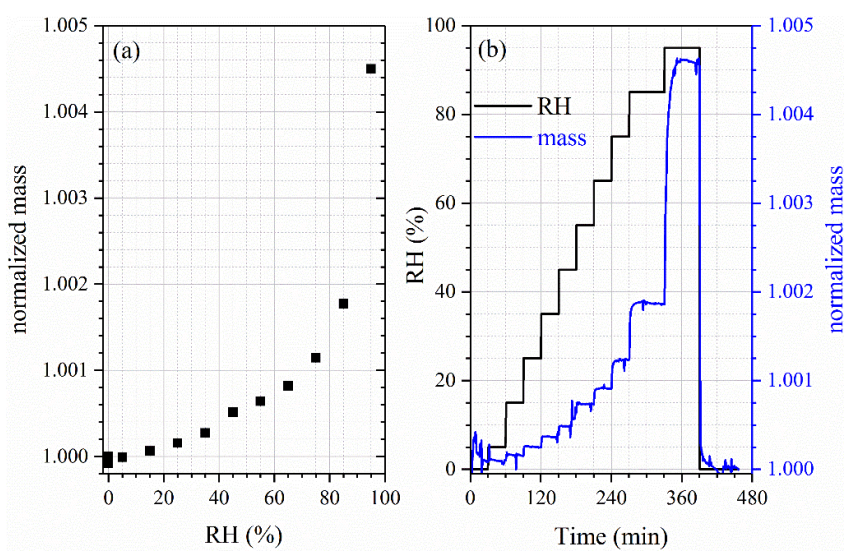

Figure 5. Sample mass of $\mathrm{CaSO}_{4} \cdot 2 \mathrm{H}_{2} \mathrm{O}$ (relative to that of $0 \% \mathrm{RH}$ ) as a function of $\mathrm{RH}$ at $25^{\circ} \mathrm{C}$, measured using a vapor sorption analyzer. (a) Change in sample mass with RH up to $95 \%$; (b) change in sample mass and $\mathrm{RH}$ with experimental time. Reprint with permission by $\mathrm{Gu}$ et al. (2017b).

is usually called quartz crystal microbalance (QCM). QCM is a highly sensitive technique for particle mass measurement and could be extended to investigate aerosol hygroscopicity. In a typical experiment, a particle film is first coupled to the quartz crystal, and RH is then varied, with the resonance frequency being simultaneously recorded. According to Eq. (1), change in the mass of the particle film, due to change in RH, is proportional to the change in resonance frequency. Hygroscopicity measurements only need the information of relative mass change (relative to that under dry conditions), and as a result, knowledge of $C_{f}$ is not required. QCM has a very high sensitivity in mass measurement, and it has been reported that the change in mass on the order of a few percent of a monolayer can be reliably determined (Tsionsky and Gileadi, 1994).

A QCM was used to measure the DRH of a number of inorganic and organic salts, including $\mathrm{NaCl},\left(\mathrm{NH}_{4}\right)_{2} \mathrm{SO}_{4}$, $\mathrm{CH}_{3} \mathrm{COONa}$ and $\mathrm{CH}_{3} \mathrm{COOK}$ (Arenas et al., 2012), and the measured values agreed very well with those reported in previous work. Several studies (Thomas et al., 1999; Demou et al., 2003; Asad et al., 2004; Liu et al., 2016) have utilized QCM to explore hygroscopic properties of organic compounds of atmospheric interest. For example, Demou et al. (2003) quantitatively determined the amount of water taken up by dodecane, 1-octanol, octanoic acid, 1,5pentanediol, 1,8-octanediol and malonic acid at room temperature. The DRH was measured to be $\sim 72 \%$ for malonic acid and $\sim 95 \%$ for 1,8-octanediol, and in general compounds with higher oxidation state showed higher hygroscopicity (Demou et al., 2003). Another study (Asad et al., 2004) found that exposure to $\mathrm{O}_{3}$ would substantially increase the hygroscopicity of oleic acid. Using a QCM, Zuberi et al. (2005) explored the effect of heterogeneous reactions on hygroscopic properties of soot particles. As shown 


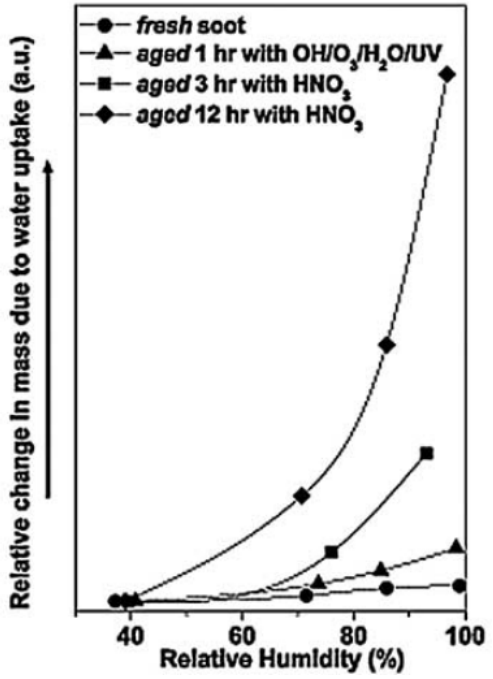

Figure 6. Water uptake (quantified as the ratio of mass of water taken up to the dry particle mass) of fresh and aged soot particles. Reprinted with permission by Zuberi et al. (2005). Copyright 2005 John Wiley \& Sons, Inc.

in Fig. 6, while water adsorption was very limited for fresh soot particles, hygroscopicity of soot particles was significantly increased after heterogeneous reactions with $\mathrm{OH} / \mathrm{O}_{3}$ and $\mathrm{HNO}_{3}$ (Zuberi et al., 2005).

QCM has also been applied to study hygroscopic properties of mineral dust particles, including oxides (Schuttlefield et al., 2007a), clay minerals (Schuttlefield et al., 2007b; Yeşilbaş and Boily, 2016) and authentic dust samples (Navea et al., 2010; Yeşilbaş and Boily, 2016). For example, Yeşilbaş and Boily (2016) measured the amount of water taken up by 21 different types of mineral particles up to $70 \% \mathrm{RH}$ at $25^{\circ} \mathrm{C}$ and found that particle size played a critical role in water adsorption by these minerals. At $70 \% \mathrm{RH}$, submicrometersized particles could adsorb up to $\sim 5$ monolayers of water, while the amount of water adsorbed by micrometer-sized particles can reach several thousand monolayers (Yeşilbaş and Boily, 2016). Another study (Hatch et al., 2008) suggested that $\sim 3$ monolayers of adsorbed water were formed on $\mathrm{CaCO}_{3}$ particles at $78 \% \mathrm{RH}$, and internal mixing with humic and fulvic acids could substantially increase the hygroscopicity of $\mathrm{CaCO}_{3}$.

It should be pointed out (as this is often not fully considered) that a few assumptions are required for the Sauerbrey equation to be valid (Rodahl and Kasemo, 1996), including that (i) the film deposited on the quartz crystal is rigid, i.e., internal friction is negligible; and that (ii) the film is perfectly coupled to the quartz crystal, i.e., there is no slip between the film and the crystal. The Sauerbrey equation may not hold if these conditions are not fulfilled, and the stiffness of the particle film would significantly affect the quartz resonator response (Dybwad, 1985; Pomorska et al., 2010; Vittorias et al., 2010; Arenas et al., 2012). Rodahl and Kasemo (1996) suggested that the Sauerbrey equation can offer reliable mass change measurement only if the film is thin enough and does not slide on the QCM electrode. In addition, as supersaturated films formed on the quartz crystal are unstable, QCM may not be able to explore hygroscopic properties of supersaturated samples.

Piezoelectric bulk wave resonators, which work in a way similar to the QCM, have been used for monitoring aerosol mass concentrations (Thomas et al., 2016; Wasisto et al., 2016). When particles are deposited onto the resonator surface, the resonance frequency will be linearly reduced with the particle mass. Very recently, a new method based on piezoelectric bulk wave resonators was developed to investigate aerosol hygroscopicity (Zielinski et al., 2018). Aerosol particles were first collected on the resonator surface and then exposed to changing RH. Measured DRH and ERH values were found to agree with the literature for $\mathrm{NaCl}$ and $\left(\mathrm{NH}_{4}\right)_{2} \mathrm{SO}_{4}$; in addition, good consistency between experimentally measured and E-AIM predicted hygroscopic growth curves was found for $\mathrm{NaCl},\left(\mathrm{NH}_{4}\right)_{2} \mathrm{SO}_{4}$ and $\mathrm{NaCl} /$ malonic acid mixture (Zielinski et al., 2018). Therefore, this technique appears to be a very promising method for aerosol hygroscopicity measurements.

\subsubsection{Beta gauge and TEOM}

In addition to the gravimetric method, the beta gauge method is widely used to measure aerosol mass concentrations in a semi-continuous way (Courtney et al., 1982; Chow, 1995; McMurry, 2000; Solomon and Sioutas, 2008; Kulkarni et al., 2011). A beta gauge measures the attenuation of beta particles emitted from a radioactive source through a particleloaded filter, and if properly calibrated, attenuation of beta particles through the filter can be used to quantify the mass of particles loaded on the filter (McMurry, 2000). The mass of aerosol particles, after being collected on a filter, was measured at different $\mathrm{RH}$ in a closed chamber using a beta gauge to determine the aerosol liquid water content (Speer et al., 1997). Laboratory evaluation showed that the liquid water content of $\left(\mathrm{NH}_{4}\right)_{2} \mathrm{SO}_{4}$ determined using this method agreed well with those measured gravimetrically (Speer et al., 1997), and when compared to humidification, a hysteresis was found during dehumidification for $\left(\mathrm{NH}_{4}\right)_{2} \mathrm{SO}_{4}$. The ability to observe hysteresis is related to the use of hydrophobic substrate (for example, Teflon is usually a good option) in particle sampling. In addition, the beta gauge method was preliminarily employed to explore hygroscopic properties of submicrometer ambient aerosol particles (Speer et al., 1997). Further tests with other compounds, in addition to $\left(\mathrm{NH}_{4}\right)_{2} \mathrm{SO}_{4}$, are required to validate the robustness and reliability of this method.

Another widely employed semi-continuous technique for aerosol mass measurement is tapered-element oscillating microbalance (TEOM) (Patashnick and Rupprecht, 1991; Chow et al., 2008; Solomon and Sioutas, 2008; Kulkarni et al., 
2011). In a typical TEOM instrument, the wide end of a tapered hollow tube is mounted on a base plate, and its narrow end is coupled to a filter used to collect aerosol particles (Kulkarni et al., 2011). The oscillation frequency of the tapered hollow tube depends on the mass of particles collected on the filter and can be used to measure particle mass if properly calibrated (Kulkarni et al., 2011). Rogers et al. (1998) explored the possibility of using TEOM to measure aerosol liquid water content. Increase in particle mass was observed when a humid particle-free air flow was passed through a particle-loaded filter in the TEOM, and the particle mass started to decrease after a dry particle-free air was introduced (Rogers et al., 1998). This suggested that TEOM had the potential to examine hygroscopic properties of aerosol particles, though further experimental evaluation is needed to assess its performance.

\subsubsection{Discussion}

All the techniques discussed in Sect. 3.2 determine particle water content through direct measurement of sample mass or properties that are related to the sample mass, and hence there is no requirement on particle shape. Some of these techniques, such as thermogravimetric analysis (Gustafsson et al., 2005) and quartz crystal microbalance (Schuttlefield et al., 2007a; Yeşilbaş and Boily, 2016), are sensitive enough to investigate water adsorption down to one or a few monolayers, while other techniques, such as the analytic balance, may not be sensitive enough for this application. If particles are supported on proper substrates (such as hydrophobic films), these techniques can be used to investigate hygroscopic properties of supersaturated samples, as demonstrated for the beta gauge method (Speer et al., 1997) and the piezoelectric bulk wave resonators (Zielinski et al., 2018). Nevertheless, supersaturated solutions formed in the majority of these applications may not be stable enough for hygroscopic growth measurements, and as a result measurements have been rarely reported for supersaturated samples. In principle these techniques can all be used offline to investigate ambient aerosol particles if samples with enough mass can be collected. Analytical balance (McInnes et al., 1996; Hitzenberger et al., 1997) and the beta gauge method (Speer et al., 1997) have been used to explore hygroscopic properties of ambient aerosols; to our knowledge, application of thermogravimetric analysis, quartz crystal microbalance, TOEM and piezoelectric bulk wave resonators to ambient samples is yet to be demonstrated.

\subsection{Microscopic techniques}

Deliquescence and efflorescence can be monitored using a number of microscopic methods, as discussed in this section. Furthermore, change in particle size at different RH, as measured microscopically, can be used to determine hygroscopic growth factors. (a)

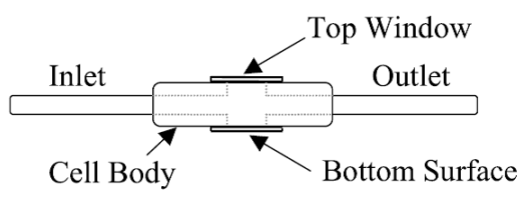

(b)

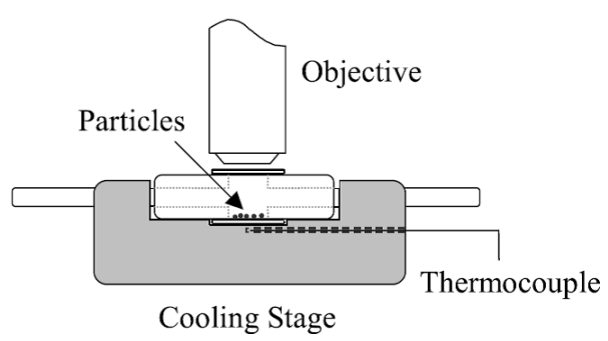

Figure 7. Schematic diagram of the flow cell-optical microscope apparatus developed by Bertram and co-workers to investigate particle-phase transitions: (a) side view of the flow cell; (b) side view of the entire apparatus. Particles were deposited on a glass slide placed on the bottom of the flow cell, which was mounted on a cooling stage. Objective: objective lens of the microscope. Reprint with permission by Parsons et al. (2004b). Copyright 2004 John Wiley \& Sons, Inc.

\subsubsection{Optical microscopy}

Optical microscopy was employed to investigate phase transition of atmospheric particles as early as in the $1950 \mathrm{~s}$ (Twomey, 1953, 1954). In these two studies (Twomey, 1953, 1954), a large number of aerosol particles collected in Sydney were found to deliquesce at $71 \% \mathrm{RH}-75 \% \mathrm{RH}$, implying that they consisted mainly of sea salt. Since then, optical microscopy has been widely used to study hygroscopic properties of atmospherically relevant particles, and herein we only introduce representative studies conducted in the last 2 decades.

Bertram and co-workers (Parsons et al., 2004a, b, 2006) developed a flow cell-optical microscope apparatus to investigate phase transitions of individual particles deposited on glass slides coated with hydrophobic films. As shown in Fig. 7 , the glass slide was placed in a flow cell mounted on a cooling stage for temperature regulation. A dry nitrogen flow was mixed with a humidified nitrogen flow and then delivered into the flow cell through the inlet, and the two flows were regulated using two mass flow controllers to adjust water vapor pressure (and thus RH) in the flow cell. Phase transitions of particles deposited on the glass slide were monitored using a microscope, and particle images were recorded using a CCD camera.

The performance of this apparatus was evaluated by measuring the DRH of $\left(\mathrm{NH}_{4}\right)_{2} \mathrm{SO}_{4}$ particles from $\sim 260$ to $300 \mathrm{~K}$ (Parsons et al., 2004b), and the measured DRH agreed well 
with those reported in the literature. This setup was then used to investigate the deliquescence of malonic, succinic, glutaric and adipic acid particles from 243 to $293 \mathrm{~K}$ (Parsons et al., $2004 \mathrm{~b})$ and deliquescence and crystallization of $\left(\mathrm{NH}_{4}\right)_{2} \mathrm{SO}_{4}$ and $\mathrm{NaCl}$ particles internally mixed with organic compounds (Pant et al., 2004; Parsons et al., 2004a). It was found that if $\left(\mathrm{NH}_{4}\right)_{2} \mathrm{SO}_{4}$ or $\mathrm{NaCl}$ particles contained substantial amounts of organic materials, their DRH would be significantly reduced, and these particles were more likely to be aqueous in the troposphere (Pant et al., 2004). A similar instrument was employed to investigate deliquescence and efflorescence of $\mathrm{HIO}_{3}$ and $\mathrm{I}_{2} \mathrm{O}_{5}$ particles (Kumar et al., 2010), and the DRH at $293 \mathrm{~K}$ was reported to be $81 \%$ for $\mathrm{HIO}_{3}$ and $85 \%$ for $\mathrm{I}_{2} \mathrm{O}_{5}$. Li and co-workers employed an optical microscope to investigate hygroscopic properties of individual particles emitted from residential coal burning (Zhang et al., 2018), collected over the Arctic (Chi et al., 2015) and collected during haze events at an urban site in northern China (W. J. Li et al., 2014; Sun et al., 2018). It was found that during hydration urban haze particles typically had core-shell structure at $60 \% \mathrm{RH}-80 \% \mathrm{RH}$ and fully deliquesced at $>80 \% \mathrm{RH}$, while during dehydration most of these particles remained aqueous at $>50 \%$ RH (Sun et al., 2018).

As illustrated by Fig. 8a, besides deliquescence and efflorescence, atmospheric aerosols can also undergo liquidliquid phase separation (LLPS), leading to coexistence of two liquid phases (Bertram et al., 2011; You et al., 2012, 2014; Freedman, 2017). LLPS can impact the direct and indirect radiative forcing of atmospheric aerosol particles as well as their heterogeneous reactivity, and therefore has received increasing attention in the last several years (You et al., 2012; Freedman, 2017). Optical microscopy has played an important role in understanding LLPS of atmospherically relevant particles (Bertram et al., 2011; You et al., 2012, 2014). Figure $8 \mathrm{~b}$ shows optical microscopic images of an internally mixed particle during an experiment in which RH was decreased while temperature was kept at $\sim 291 \mathrm{~K}$ (Bertram et al., 2011), and the particle contained $\left(\mathrm{NH}_{4}\right)_{2} \mathrm{SO}_{4}$ and 1,2,6trihydroxyhexane with a mass ratio of $1: 2.1$. As shown in Fig. 8b, at high RH the particle existed as an aqueous droplet, and LLPS happened when RH was decreased, leading to the formation of two liquid phases; efflorescence took place with further decrease in $\mathrm{RH}$, leading to the formation of a solid $\left(\mathrm{NH}_{4}\right)_{2} \mathrm{SO}_{4}$ core coated with an organic liquid layer.

In addition to identification of phase transitions, analysis of optical microscopic images recorded can also be used to determine particle size change and, as a result, hygroscopic growth factors (Ahn et al., 2010; Eom et al., 2014; Gupta et al., 2015). For instance, Ahn et al. (2010) employed an optical microscope to investigate hygroscopic properties of $\mathrm{NaCl}, \mathrm{KCl},\left(\mathrm{NH}_{4}\right)_{2} \mathrm{SO}_{4}$ and $\mathrm{Na}_{2} \mathrm{SO}_{4}$ particles collected on TEM grids and found that their measured hygroscopic growth factors agreed well with those reported in the literature for all four types of particles examined. A following study (Eom et al., 2014) compared the influence of six types

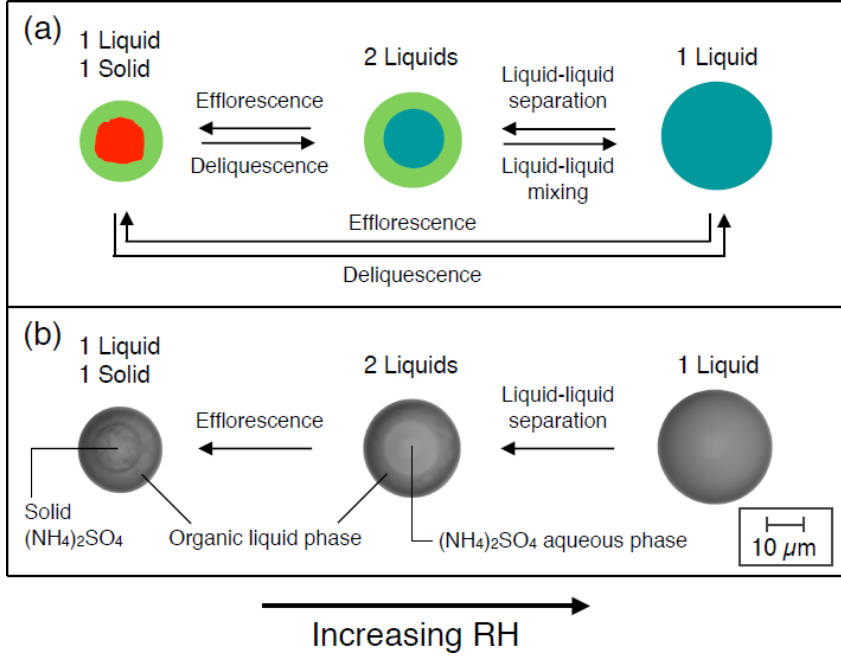

Figure 8. (a) Some of the phase transitions which may occur for internally mixed atmospheric particles consisting of $\left(\mathrm{NH}_{4}\right)_{2} \mathrm{SO}_{4}$ and organic materials. Aqua represents an aqueous phase, green represents a liquid phase of organic material, and red presents a solid phase of $\left(\mathrm{NH}_{4}\right)_{2} \mathrm{SO}_{4}$. (b) Optical microscopic images of a particle which contained $\left(\mathrm{NH}_{4}\right)_{2} \mathrm{SO}_{4}$ and 1,2,6-trihydroxyhexane with a mass ratio of $1: 2.1$, during an experiment in which temperature was kept at around $291 \mathrm{~K}$, while RH was decreased. Reprint with permission by Bertram et al. (2011).

of supporting substrates (including TEM grid, Parafilm-M, aluminum foil, Ag foil, silicon wafer and cover glass) on hygroscopicity measurements using optical microscopy and concluded that TEM grids were the most suitable substrate for this application. Optical microscopy was also used to study hygroscopic properties of $\mathrm{MgCl}_{2}$ and $\mathrm{NaCl}-\mathrm{MgCl}_{2}$ mixed particles (Gupta et al., 2015), and hygroscopic properties (including DRH and growth factors) of these particles were found to differ significantly from $\mathrm{NaCl}$. Since $\mathrm{MgCl}_{2}$ is an important component in sea salt aerosol, this work can have significant implications for hygroscopicity and thus climatic impacts of sea salt aerosol (Zieger et al., 2017).

Optical microscopy can be (and has been widely) coupled to suitable spectroscopic techniques such as FTIR (Liu et al., 2008b), Raman spectroscopy (Liu et al., 2008c) and fluorescence (Montgomery et al., 2015), and if so chemical information can be simultaneously provided.

\subsubsection{Electron microscopy}

Electron microscopy has been widely used in laboratory and field studies to examine composition, mixing state and morphology of atmospheric particles, as summarized by a few excellent review articles (Prather et al., 2008; Posfai and Buseck, 2010; Li et al., 2015; Ault and Axson, 2017). Herein we discuss exemplary studies to illustrate how electron microscopy can help improve our knowledge of aerosol hygroscopicity. This section is further divided into two parts, i.e., 
scanning electron microscopy (SEM) and transmission electron microscopy (TEM).

\section{SEM}

Ebert et al. (2002) developed an environmental scanning electron microscope (ESEM) technique to explore hygroscopic properties of individual particles, and the instrument they used had a spatial resolution of $8-15 \mathrm{~nm}$. Changes in particle morphology could be used to identify phase transitions (deliquescence and efflorescence), and growth factors could be derived from observed change in particle size at different RH. Their measured DRH and hygroscopic growth factors (Ebert et al., 2002) were in good agreement with results reported by the previous literature for $\mathrm{NaCl}$, $\left(\mathrm{NH}_{4}\right)_{2} \mathrm{SO}_{4}, \mathrm{Na}_{2} \mathrm{SO}_{4}$ and $\mathrm{NH}_{4} \mathrm{NO}_{3}$. However, ERH could not be accurately determined due to the influence of the substrate onto which particles under investigation were deposited (Ebert et al., 2002).

ESEM, coupled to energy disperse X-ray analysis (EDX), was employed to investigate hygroscopic properties of a wide range of atmospheric particles, including $\left(\mathrm{NH}_{4}\right)_{2} \mathrm{SO}_{4}$ (Matsumura and Hayashi, 2007), sea spray (Hoffman et al., 2004), aerosol particles collected in nickel refineries (Inerle-Hof et al., 2007), agricultural aerosol (Hiranuma et al., 2008), pollen (Pope, 2010; Griffiths et al., 2012) and protein (Gomery et al., 2013). For example, Hoffman et al. (2004) found that both $\mathrm{NaNO}_{3}$ and $\mathrm{NaNO}_{3} / \mathrm{NaCl}$ particles existed as amorphous solids even at very low RH and exhibited continuous hygroscopic growth, instead of having clear DRH; furthermore, $\mathrm{EDX}$ analysis showed that $\mathrm{Cl}$ was enriched in the core of dried $\mathrm{NaCl} / \mathrm{NaNO}_{3}$ particles (Hoffman et al., 2004), implying that during dehumidification $\mathrm{NaCl}$ started to crystallize first because of its lower solubility. This finding may have important implications for chemical and radiative properties of marine aerosol particles (Quinn et al., 2015). In another study (Pope, 2010), ESEM observations revealed that birch pollen gains swelled internally but did not take up water on the surface significantly, even at $93 \% \mathrm{RH}$; however, liquid water could be observed on the particle surface when RH was $>95 \%$. Hiranuma et al. (2008) found that most aerosol particles collected at a cattle feedlot in Texas did not take up a significant amount of water at $96 \% \mathrm{RH}$, though a small fraction of coarse particles became deliquesced at $\sim 75 \% \mathrm{RH}$ and their sizes were doubled at $96 \% \mathrm{RH}$ compared to their original sizes.

SEM/EDX was utilized by Krueger et al. (2003) to monitor changes in phase, morphology and composition of individual mineral dust particles after heterogeneous reaction with gaseous $\mathrm{HNO}_{3}$. For the first time, laboratory work showed that solid mineral dust particles could be transformed to aqueous droplets due to heterogeneous reactions (Krueger et al., 2003). As displayed in Fig. 9, solid $\mathrm{CaCO}_{3}$ particles were converted to spherical droplets as heterogeneous reaction with gaseous $\mathrm{HNO}_{3}$ proceeded (Krueger et al., 2003),
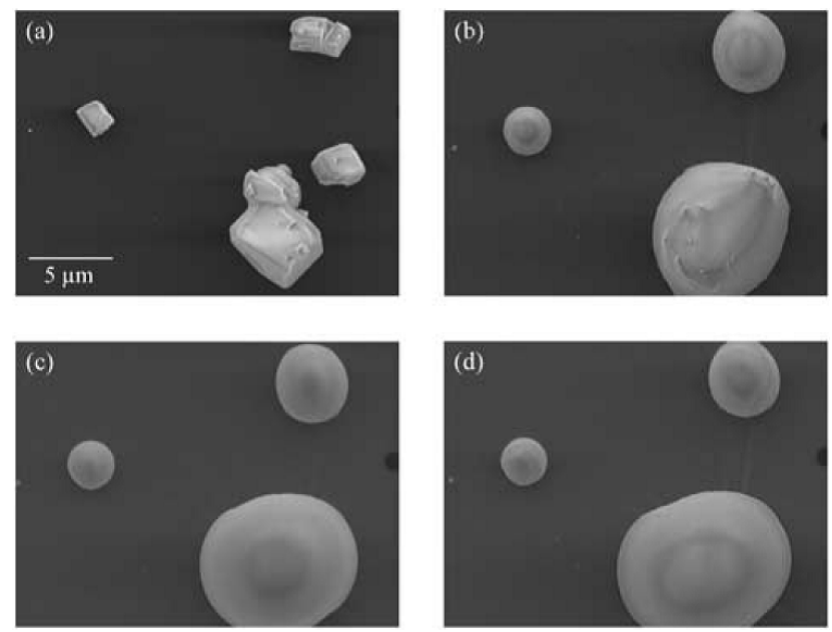

Figure 9. $\mathrm{SEM}$ images of $\mathrm{CaCO}_{3}$ particles before and after exposure to $26 \mathrm{ppbv}$ gaseous $\mathrm{HNO}_{3}$ at $\sim 41 \% \mathrm{RH}$. (a) Before exposure; (b) exposure for $1 \mathrm{~h}$; (c) exposure for $2 \mathrm{~h}$; (d) exposure for $4 \mathrm{~h}$. Reprint with permission by Krueger et al. (2003). Copyright 2003 John Wiley \& Sons, Inc.

and this was caused by the formation of $\mathrm{Ca}\left(\mathrm{NO}_{3}\right)_{2}$ which had very low DRH (Al-Abadleh et al., 2003; Kelly and Wexler, 2005). A following study (Krueger et al., 2004) examined heterogeneous reactions of $\mathrm{HNO}_{3}$ with mineral dust samples collected from four different regions, using SEM/EDX. It was suggested that calcite and dolomite particles exhibited large reactivity towards $\mathrm{HNO}_{3}$ and could be transformed to aqueous droplets, while no morphological change was observed for gypsum, aluminum silicate clay and quartz particles after exposure to $\mathrm{HNO}_{3}$ (Krueger et al., 2004).

The new laboratory discovery by Krueger et al. (2003) has been supported by a number of field measurements ( $\mathrm{Li}$ et al., 2015; Tang et al., 2016a), in some of which SEM was also utilized. For example, Laskin et al. (2005) provided the first evidence demonstrating that in the ambient air solid nonspherical $\mathrm{CaCO}_{3}$ particles could be transformed to aqueous droplets which contained $\mathrm{Ca}\left(\mathrm{NO}_{3}\right)_{2}$ formed in heterogeneous reaction with nitrogen oxides. ESEM was also applied to examine mineral dust particles collected in Beijing (Matsuki et al., 2005) and southwestern Japan (Shi et al., 2008), and both studies found that some Ca-containing particles existed in aqueous state even at RH as low as $15 \%$ because heterogeneous reactions with nitrogen oxides converted $\mathrm{CaCO}_{3}$ to $\mathrm{Ca}\left(\mathrm{NO}_{3}\right)_{2}$. Similarly, it was shown by SEM/EDX measurements (Tobo et al., 2010, 2012) that Ca-containing mineral dust particles in remote marine troposphere were transformed to aqueous droplets, because $\mathrm{CaCl}_{2}$ was formed in heterogeneous reaction of $\mathrm{CaCO}_{3}$ with $\mathrm{HCl}$. 


\section{TEM}

Compared to SEM, transmission electron microscopy (TEM) has better spatial resolution and can resolve features down to $1 \mathrm{~nm}$ or even smaller. TEM and AFM (atomic force microscopy) were employed by Buseck and colleagues (Posfai et al., 1998) to examine ambient particles collected on TEM grids under vacuum and ambient conditions. It was found that particle volumes were up to 4 times larger under ambient conditions compared to vacuum conditions. Several years later Buseck and co-workers (Wise et al., 2005) developed an environmental transmission electron microscope (ETEM) which enabled individual particles to be characterized under environmental conditions. The performance of this instrument was validated by measuring DRH and ERH of $\mathrm{NaBr}$, $\mathrm{CsCl}, \mathrm{NaCl},\left(\mathrm{NH}_{4}\right)_{2} \mathrm{SO}_{4}$ and $\mathrm{KBr}$ particles in the size range of $0.1-1 \mu \mathrm{m}$, and good agreement was found between their measured values and those reported by previous work for all of the five compounds investigated (Wise et al., 2005).

The ETEM technique was further employed to investigate hygroscopic properties of a wide range of atmospheric particles, including $\mathrm{NaCl}$-containing particles (Semeniuk et al., 2007b; Wise et al., 2007), biomass-burning particles (Semeniuk et al., 2007a) and potassium salts (Freney et al., 2009). The DRH of $\mathrm{NaCl}$ particles internally mixed with insoluble materials was determined to be $\sim 76 \%$ (equal to that for pure $\mathrm{NaCl}$ ), while internal mixing with other soluble compounds (e.g., $\mathrm{NaNO}_{3}$ ) would reduce the DRH (Wise et al., 2007). DRH and ERH were reported to be $85 \%$ and $56 \%$ for $\mathrm{KCl}$ and 96 and $60 \%$ for $\mathrm{K}_{2} \mathrm{SO}_{4}$, while $\mathrm{KNO}_{3}$ displayed continuous hygroscopic growth (Freney et al., 2009); in addition, deliquescence and efflorescence of internally mixed $\mathrm{KCl} / \mathrm{KNO}_{3}$ and $\mathrm{KCl} / \mathrm{K}_{2} \mathrm{SO}_{4}$ were also examined (Freney et al., 2009). In another study (Adachi et al., 2011), aerosol particles, mainly sulfate internally mixed with weakly hygroscopic organic materials, were collected at Mexico City, and their hygroscopic properties were investigated using ETEM. It was found that only the sulfate part was deliquesced at elevated $\mathrm{RH}$, while all the particles containing deliquesced sulfate did not necessarily became spherical. It was further suggested that the actual light scattering ability was $50 \%$ larger than that estimated by Mie theory, which assumes particle sphericity (Adachi et al., 2011).

Recently cryogenic TEM has been deployed to explore morphology, hygroscopic properties and chemical composition of atmospheric particles (Veghte et al., 2014; Patterson et al., 2016). For example, it was observed that most nascent sea spray aerosol particles were homogeneous aqueous droplets, and upon exposure to low RH they would be quickly reorganized and undergo phase separation (Patterson et al., 2016).

\subsubsection{Atomic force microscopy}

Atomic force microscopy (AFM) is a widely used technique in surface chemistry and surface science. Compared to other microscopic techniques (e.g., optical microscopy, FTIR microscopy, TEM and SEM), AFM has several unique advantages. It does not require a vacuum condition and thus can be operated under environmental conditions; in addition, it has a high spatial resolution down to the nanometer level and offers 3-D imaging (Morris et al., 2016).

In the past 2 decades, AFM has been gradually utilized in atmospheric chemistry to observe 3-D morphology of aerosol particles, and its application in atmospheric chemistry started with observation of surfaces of single crystals with atmospheric relevance. For example, AFM was employed to study the (100) cleavage surface of $\mathrm{NaCl}$ during exposure to water vapor (Dai et al., 1997). A uniform layer of water was formed on the surface, and surface steps started to evolve slowly at $\sim 35 \% \mathrm{RH}$; when RH increased to $\sim 73 \%$ (approximately the DRH of $\mathrm{NaCl}$ ), the step structure disappeared abruptly due to deliquescence of the surface (Dai et al., 1997). This pioneering work demonstrated that AFM had the potential to be used to determine the DRH of hygroscopic salts, in addition to providing rich information on surface structure change during exposure to water vapor. AFM was later used to observe the $\mathrm{MgO}(100)$ and $\mathrm{CaCO}_{3}(1014)$ surface during exposure to water vapor and gaseous nitric acid (Krueger et al., 2005). Instabilities of oscillations in AFM images were observed, indicating that deliquescence of nitrate salts, which were formed in heterogeneous reaction with nitric acid, occurred at elevated RH (Krueger et al., 2005).

To our knowledge, AFM was successfully used in 1995 to characterize aerosol particles collected using a low-pressure impactor (Friedbacher et al., 1995). Three years later, Posfai et al. (1998) used AFM to examine individual particles collected above the North Atlantic Ocean at different RH. The particle volume was observed to be 4 times larger under ambient conditions (measured by AFM) compared to that in the vacuum (measured by TEM) (Posfai et al., 1998). Another study (Wittmaack and Strigl, 2005) used AFM to measure height-to-diameter ratios of ambient particles and concluded that some particles may exist in the supersaturated metastable state at around 50\% RH. Non-contact environmental AFM was used to examine uptake of water vapor by $\mathrm{NaCl}$ nanoparticles at RH below DRH (Bruzewicz et al., 2011). $\mathrm{NaCl}$ nanoparticles started to adsorb water at RH well below its DRH (75\%), and a liquid-like surface layer with a thickness of 2-5 nm was formed at $70 \% \mathrm{RH}$, suggesting that deliquescence of $\mathrm{NaCl}$ nanoparticles was much more complicated than an abrupt first-order phase transition.

Very recently, Tivanski and co-workers (Ghorai et al., 2014; Laskina et al., 2015b; Morris et al., 2015, 2016) developed an AFM-based method to investigate hygroscopicity of particles deposited on substrates and systematically evaluated its performance by measuring hygroscopic growth factors of $\mathrm{NaCl}$, malonic acid and a binary mixture of $\mathrm{NaCl}$ with malonic or nonanoic acid. It was found that hygroscopic growth factors derived from 3-D volume-equivalent diameters always agreed well with H-TDMA results; however, hy- 
A

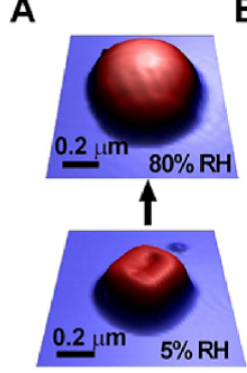

B

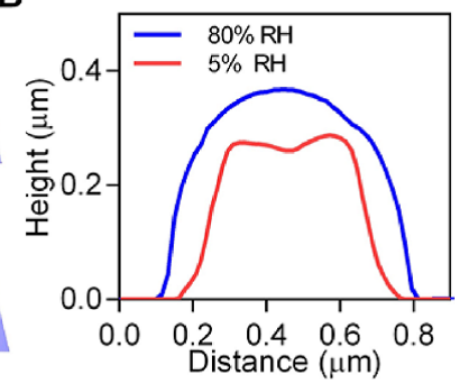

C

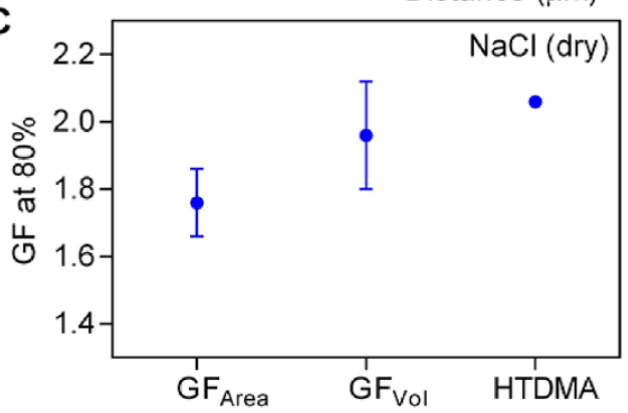

Figure 10. AFM measurements of hygroscopicity of $\mathrm{NaCl}$ particles. (a) 3-D AFM images of a $\mathrm{NaCl}$ particle at $5 \% \mathrm{RH}$ and $80 \% \mathrm{RH}$; (b) cross section of the particles at $5 \%$ (red) and $80 \%$ (blue) $\mathrm{RH}$; (c) comparison of hygroscopic growth factors derived from changes in mobility diameter (measured using H-TDMA), area-equivalent diameter (measured using AFM) and volume-equivalent diameter (measured using AFM). Reprint with permission by Morris et al. (2016). Copyright 2016 American Chemical Society.

groscopic growth factors derived from 2-D area-equivalent diameters showed significant deviation from H-TDMA results for some types of particles (Morris et al., 2016). An example is displayed in Fig. 10, suggesting that at $80 \%$ RH, the hygroscopic growth factor of $\mathrm{NaCl}$ particles derived from the volume-equivalent diameter was equal to that determined using H-TDMA, significantly larger than that derived from the area-equivalent diameter. Such deviation was caused by anisotropic growth of particles (Morris et al., 2016), and the extent of the deviation depended on the particle composition and their hydrate state at the time when they were collected on the substrate.

In addition to hygroscopicity measurement, AFM was used in several studies to characterize morphology, structure and other physicochemical properties of atmospheric particles (Lehmpuhl et al., 1999; Freedman et al., 2010; Laskina et al., 2015a). For example, AFM measurements found that organic and soot particles would shrink after interactions with $\mathrm{O}_{3}$, while inorganic particles remained unchanged (Lehmpuhl et al., 1999). Freedman et al. (2010) employed AFM coupled to Raman microscopy to characterize atmospheric particles under ambient conditions and observed core-shell structure for some organic particles. A recent study (Laskina et al., 2015a) characterized particles collected on substrates using AFM, Raman microscopy and SEM and suggested that microscopy techniques operated under ambient conditions would offer the most relevant and robust information on particle size and morphology. Conventional AFM offers no chemical information; however, it can be (and has already been) coupled to spectroscopic techniques (such as FTIR) (Dazzi et al., 2012; Ault and Axson, 2017; Dazzi and Prater, 2017), enabling detailed physical and chemical properties to be provided with high spatial resolution. Very recently, the peak force infrared microscopy, a type of scanning probe microscopy, was developed to investigate IR absorption and mechanical properties of ambient aerosol particles (Wang et al., 2017b), and a spatial resolution of $10 \mathrm{~nm}$ could be achieved.

\subsubsection{X-ray microscopy}

Scanning transmission X-ray microscopy (STXM) is a novel technique which can provide spatial distribution of physical, chemical and morphological information of individual particles (de Smit et al., 2008) and has been recently employed to investigate atmospheric particles (Ault and Axson, 2017). For example, Ghorai and Tivanski (2010) developed a STXM-based method to study hygroscopic growth of individual submicrometer particles and proposed a method to quantify the mass of water associated with individual particles at a given RH. DRH and ERH values of $\mathrm{NaCl}, \mathrm{NaBr}$, and $\mathrm{NaNO}_{3}$, determined using STXM (Ghorai and Tivanski, 2010), agreed very well with previous results, and mass hygroscopic growth factors were also reported for these particles. In a following study (Ghorai et al., 2011), STXM was used to investigate hygroscopic growth of individual malonic acid; in addition to measured mass hygroscopic growth factors, near-edge X-ray absorption fine structure spectroscopy (NEXAFS) acquired using STXM suggested that keto-enol tautomerism occurred for deliquesced malonic acid particles (Ghorai et al., 2011). The keto-enol equilibrium constants were found to vary with $\mathrm{RH}$, with enol formation favored at high RH (Ghorai et al., 2011).

Hygroscopic growth of submicrometer $\left(\mathrm{NH}_{4}\right)_{2} \mathrm{SO}_{4}$, measured using STXM/NEXAFS (Zelenay et al., 2011a), agreed well with previous studies; furthermore, analysis of STXM images and NEXAFS spectra suggested that phase separation occurred for internally mixed $\left(\mathrm{NH}_{4}\right)_{2} \mathrm{SO}_{4}$-adipic acid particles, and adipic acid was partially enclosed by $\left(\mathrm{NH}_{4}\right)_{2} \mathrm{SO}_{4}$ at high RH (Zelenay et al., 2011a). An environmental chamber was constructed to be directly coupled to a STXM instrument (Kelly et al., 2013), and this setup was utilized to explore hygroscopic properties of $\mathrm{NaCl}, \mathrm{NaBr}, \mathrm{KCl},\left(\mathrm{NH}_{4}\right)_{2} \mathrm{SO}_{4}$, levoglucosan and fructose (Piens et al., 2016). Measured mass hygroscopic growth factors were compared with those predicted by a thermodynamic model (AIOMFAC) (Zuend et al., 2011), and good agreement between measurement and prediction was found for all the compounds investigated (Piens et al., 2016). In another study, Zelenay et al. (2011b) utilized STXM/NEXAFS to investigate hygroscopic properties 
of submicrometer tannic acid and Suwannee River Fulvic acid used as proxies for humic-like substances found in atmospheric aerosol. Both compounds exhibited continuous water uptake, and at $90 \% \mathrm{RH}$ around one water molecule was associated with each oxygen atom contained by tannic acid, while approximately two water molecules were associated with each oxygen atom contained by Suwannee River Fulvic acid (Zelenay et al., 2011b).

STXM/NEXAFS has already been applied to explore hygroscopicity of ambient particles. For example, Pöhlker et al. (2014) collected aerosol particles from the Amazonian forest during periods with anthropogenic impacts and then analyzed these particles using STXM-NEXAFS at different RH. Substantial changes in particle microstructure were observed upon dehydration, very likely caused by efflorescence and crystallization of sulfate salts (Pöhlker et al., 2014). Piens et al. (2016) employed STXM-NEXAFS to examine hygroscopicity of atmospheric particles collected from the Department of Energy's Atmospheric Radiation Monitoring site in the Southern Great Plains. As shown in Fig. 11, compared to particles with medium and low hygroscopicity, particles with high hygroscopicity always contained larger fractions of $\mathrm{Na}$ and $\mathrm{Cl}$ (Piens et al., 2016).

\subsubsection{Discussion}

Hygroscopicity measurements using microscopic techniques typically rely on changes in particle diameter measured microscopically. Therefore, it would be non-trivial for these techniques to quantify hygroscopic growth factors for nonspherical particles. In addition, these techniques may not be sensitive enough to investigate water adsorption. Since single particles deposited on supporting substances are usually examined, these techniques can be employed to investigate supersaturated samples if proper supporting substances are used. They have also been widely used to explore hygroscopic properties of ambient aerosol particles which were collected on proper substances. As discussed in Sect. 3.4, microscopic techniques can be and have widely been coupled to spectroscopic tools, and if so chemical information could be simultaneously provided.

\subsection{Spectroscopic techniques}

Interaction with water vapor would lead to changes in the composition and chemical environment of particles under examination, and these changes can be monitored using spectroscopic techniques to understand hygroscopic properties of atmospherically relevant particles.

\subsubsection{Fourier transform infrared spectroscopy}

Fourier transform infrared spectroscopy (FTIR), a vibrational absorption spectroscopy, has been widely employed in laboratory (Goodman et al., 2000; Eliason et al., 2003; Asad et al., 2004; Hung et al., 2005; Najera et al., 2009; Li et al., 2010; Tan et al., 2016; Tang et al., 2016b) and field work (Maria et al., 2002; Russell et al., 2011; Takahama et al., 2013, 2016, 2019; Kuzmiakova et al., 2016) to characterize the chemical composition of aerosol particles. It can also be used in aerosol hygroscopicity studies. When water is adsorbed or absorbed by particles, change in IR absorption of particles under investigation due to water uptake can be recorded as a function of $\mathrm{RH}$, and therefore hygroscopic properties of these particles can be characterized. One advantage of FTIR is that it can be coupled with a range of accessories to form different experimental configurations, including transmission FTIR (Cziczo et al., 1997; Braban et al., 2001; Goodman et al., 2001; Zhao et al., 2006; Song and Boily, 2013; Leng et al., 2015; Zawadowicz et al., 2015), attenuated total reflection-FTIR (ATR-FTIR) (Schuttlefield et al., 2007a; Navea et al., 2010; Hatch et al., 2011; Zeng et al., 2014; Q. N. Zhang et al., 2014; Yeşilbaş and Boily, 2016; Navea et al., 2017; Gao et al., 2018), diffuse reflectance infrared Fourier transform spectroscopy (DRIFTS) (Gustafsson et al., 2005; Ma et al., 2010a; Joshi et al., 2017; Ibrahim et al., 2018) and micro-FTIR, for which FTIR is coupled with a microscope (Liu et al., 2008a; Liu and Laskin, 2009). Particles under investigation are typically deposited on proper substrates, though aerosol particles can also be studied using transmission FTIR (Cziczo et al., 1997; Cziczo and Abbatt, 2000; Zhao et al., 2006; Zawadowicz et al., 2015). FTIR has been used in a large number of studies to investigate hygroscopic properties of atmospherically relevant particles, and herein we only introduce and highlight a few representative examples.

Micro-FTIR was employed to investigate hygroscopic properties of $\mathrm{CH}_{3} \mathrm{SO}_{3} \mathrm{Na}$ particles (Liu and Laskin, 2009) and $\mathrm{NH}_{4} \mathrm{NO}_{3}$ (Wu et al., 2007). Figure 12a shows IR spectra of $\mathrm{CH}_{3} \mathrm{SO}_{3} \mathrm{Na}$ particles during humidification, and no significant change in IR spectra was observed when RH was increased from $0 \%$ to $70 \%$; however, when $\mathrm{RH}$ was increased to $71 \%$, IR absorption attributed to the $v\left(\mathrm{H}_{2} \mathrm{O}\right.$ ) band (at $\sim$ $3400 \mathrm{~cm}^{-1}$ ) became very evident and its intensity increased with further increase in $\mathrm{RH}$, indicating that the deliquescence of $\mathrm{CH}_{3} \mathrm{SO}_{3} \mathrm{Na}$ particles occurred at $71 \% \mathrm{RH}$. In addition, at $<71 \% \mathrm{RH}$ two groups of narrow and structured bands, typically observed for crystalline samples, were observed for $\mathrm{CH}_{3} \mathrm{SO}_{3} \mathrm{Na}$ particles. The first one, centered at $\sim 1197$ and $1209 \mathrm{~cm}^{-1}$, was attributed to asymmetrical stretching of $v_{8}\left(-\mathrm{SO}_{3}^{-}\right)$, and the other one, centered at $1062 \mathrm{~cm}^{-1}$, was attributed to symmetrical stretching of $v_{3}\left(-\mathrm{SO}_{3}^{-}\right)$. When $\mathrm{RH}$ was increased to $71 \%$, both bands were significantly broadened and shifted to lower wavelengths, further confirming that the DRH of $\mathrm{CH}_{3} \mathrm{SO}_{3} \mathrm{Na}$ particles was $\sim 71 \%$. IR spectra of $\mathrm{CH}_{3} \mathrm{SO}_{3} \mathrm{Na}$ particles during dehumidification are displayed in Fig. 12b. Complete disappearance of IR absorption at $\sim 3400 \mathrm{~cm}^{-1}$ and significant change in the shape and position of IR peaks of $v_{8}\left(-\mathrm{SO}_{3}^{-}\right)$and $v_{3}\left(-\mathrm{SO}_{3}^{-}\right)$were observed when $\mathrm{RH}$ was decreased from $49 \%$ to $48 \%$, suggesting that the $\mathrm{ERH}$ of $\mathrm{CH}_{3} \mathrm{SO}_{3} \mathrm{Na}$ was around $48 \%$. 


\begin{tabular}{|c|c|c|c|c|c|c|c|}
\hline $\begin{array}{c}\text { Particle } \\
\#\end{array}$ & Hygroscopicity & $\begin{array}{c}g_{m} \\
(80 \% R H)\end{array}$ & $\begin{array}{c}\text { Kequiv } \\
(80 \% \text { RH) }\end{array}$ & $\begin{array}{l}\text { Inorganic Atomic } \\
\text { Fractions }\end{array}$ & $4 \% \mathrm{RH}$ & $90 \%$ RH & Mixing State \\
\hline 1 & High & 2.73 & 0.71 & $\square$ & $\mathbf{D}$ & & OCIN \\
\hline 2 & High & 2.57 & 0.64 & & & & OCIN \\
\hline 3 & High & 2.01 & 0.41 & $\square$ & & & OCECIN \\
\hline 4 & High & 1.93 & 0.38 & 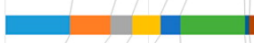 & & & OCIN \\
\hline 5 & Medium & 1.73 & 0.30 & 口 & & & OCIN \\
\hline 6 & Medium & 1.45 & 0.18 & & 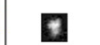 & & OCECIN \\
\hline 7 & Medium & 1.34 & 0.14 & & a & & OCIN \\
\hline 8 & Medium & 1.23 & 0.09 & & $\mathbf{D}$ & & OCECIN \\
\hline 9 & Medium & 1.15 & 0.06 & & $\theta$ & & OCECIN \\
\hline 10 & Medium & 1.11 & 0.05 & & 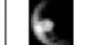 & & OCECIN \\
\hline 11 & Low & 1.04 & 0.02 & $\square$ & $\mathbf{0}$ & $\mathbf{e}$ & OCECIN \\
\hline 12 & Low & 1.01 & 0.00 & & ex & 78 & OCIN \\
\hline 13 & Low & 1.00 & 0.00 & $\square$ & $\mathbf{a}$ & $\boldsymbol{0}$ & OCEC \\
\hline 14 & Low & 1.00 & 0.00 & 1 & $=$ & $\mathbf{z}$ & OCECIN \\
\hline 15 & Low & 1.00 & 0.00 & & v & $\mathbf{q}$ & OCECIN \\
\hline
\end{tabular}

Figure 11. Hygroscopicity, mass growth factors at $80 \% \mathrm{RH}\left(g_{\mathrm{m}}\right)$, single hygroscopicity parameters $\left(\kappa_{\text {eqiv }}\right)$, inorganic atomic fractions, STXM images (acquired at $4 \% \mathrm{RH}$ and $90 \% \mathrm{RH}$ ) and mixing state for the 15 aerosol particles examined. Reprint with permission by Piens et al. (2016). Copyright 2016 American Chemical Society.

FTIR spectra can also be used to investigate hygroscopic growth quantitatively if IR absorbance can be calibrated. In the work by Liu and Laskin (2009), the absorbance ratio of $v\left(\mathrm{H}_{2} \mathrm{O}\right)\left(\right.$ at $\left.\sim 3400 \mathrm{~cm}^{-1}\right)$ to $v_{8}\left(-\mathrm{SO}_{3}^{-}\right)\left(\right.$at $\left.\sim 1192 \mathrm{~cm}^{-1}\right)$ was calibrated and then used to calculate water-to-solute ratios (WSR, defined as mole ratios of $\mathrm{H}_{2} \mathrm{O}$ to $\mathrm{CH}_{3} \mathrm{SO}_{3}^{-}$) of aqueous $\mathrm{CH}_{3} \mathrm{SO}_{3} \mathrm{Na}$ particles. As shown in Fig. 12c, WSR values determined using FTIR (Liu and Laskin, 2009) agreed well with those reported in a previous study (Peng and Chan, 2001b) using the electrodynamic balance (EDB). In another study (Liu et al., 2008a), DRH, ERH and WSR measured using micro-FTIR were found to agree well with those reported in the literature for $\mathrm{NaCl}, \mathrm{NaNO}_{3}$ and $\left(\mathrm{NH}_{4}\right)_{2} \mathrm{SO}_{4}$ particles. ATR-FTIR can be used in a similar way to micro-FTIR to investigate phase transitions and WSR of atmospherically relevant particles and has been applied to a number of com- pounds, including $\mathrm{NaCl}$ (Schuttlefield et al., 2007a; Zeng et al., 2014), $\mathrm{NaNO}_{3}$ (Tong et al., 2010b; Q. N. Zhang et al., 2014), $\mathrm{Na}_{2} \mathrm{SO}_{4}$ (Tong et al., 2010b), $\mathrm{NH}_{4} \mathrm{NO}_{3}$ (Schuttlefield et al., 2007a), $\left(\mathrm{NH}_{4}\right)_{2} \mathrm{SO}_{4}$ (Schuttlefield et al., 2007a), $\mathrm{CH}_{3} \mathrm{SO}_{3} \mathrm{Na}$ (Zeng et al., 2014), sodium formate (Gao et al., 2018), and sodium acetate (Gao et al., 2018).

In addition, ATR-FTIR (Schuttlefield et al., 2007a, b; Hatch et al., 2011; Navea et al., 2017), DRIFTS (Ma et al., 2010a; Joshi et al., 2017; Ibrahim et al., 2018) and transmission FTIR (Goodman et al., 2001) have been employed to investigate water adsorption by insoluble particles, such as mineral dust. Figure 13 displays IR spectra of adsorbed water on $\mathrm{SiO}_{2}$ at different $\mathrm{RH}$, as measured using DRIFTS at $30^{\circ} \mathrm{C}$. As shown in Fig. 13, two intensive peaks appeared in IR spectra at elevated RH (Ma et al., 2010a), one at 2600$3800 \mathrm{~cm}^{-1}$ attributed to the $\mathrm{O}-\mathrm{H}$ stretching mode and the 

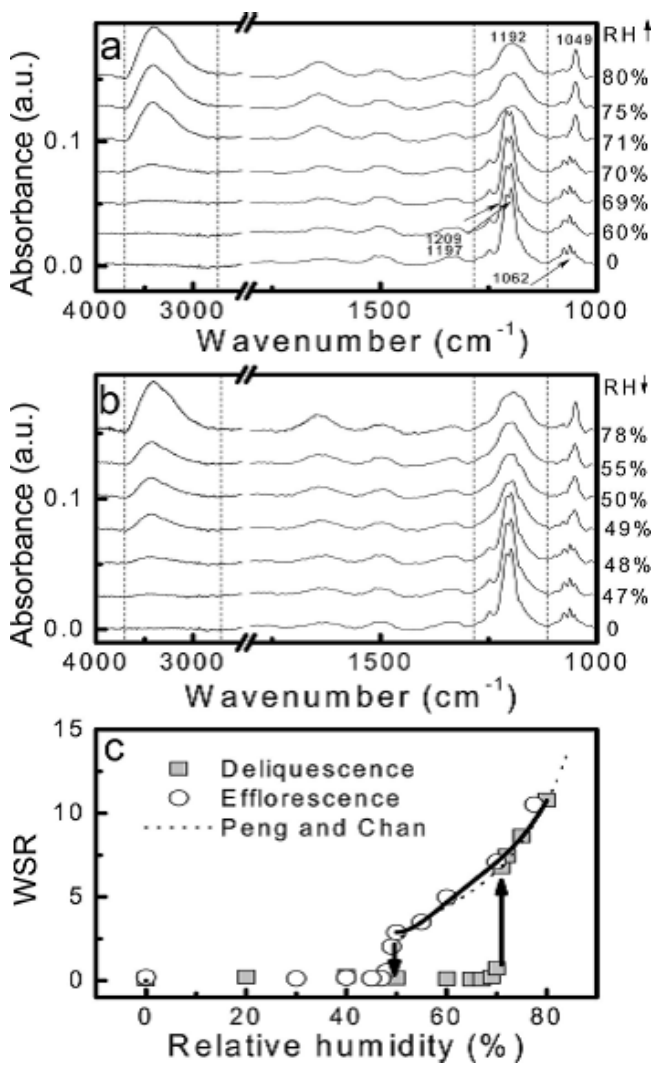

Figure 12. (a) FTIR spectra of $\mathrm{CH}_{3} \mathrm{SO}_{3} \mathrm{Na}$ particles during humidification. (b) FTIR spectra of $\mathrm{CH}_{3} \mathrm{SO}_{3} \mathrm{Na}$ particles during dehumidification. (c) Water-to-solute ratios (WSR) of $\mathrm{CH}_{3} \mathrm{SO}_{3} \mathrm{Na}$ particles as a function of RH: comparison between WSR measured by Liu and Laskin (2009) using micro-FTIR to those determined by Peng and Chan (2001b) using electrodynamic balance. Reprinted with permission by Liu et al. (2009). Copyright 2009 American Chemical Society.

other one at $\sim 1630-1650 \mathrm{~cm}^{-1}$ attributed to the bending mode of $\mathrm{H}-\mathrm{O}-\mathrm{H}$. Both peaks can be used to quantify the amount of adsorbed water, though surface $\mathrm{OH}$ groups may also contribute to the IR absorbance at $\sim 3400 \mathrm{~cm}^{-1}$ (Goodman et al., 2001; Tang et al., 2016a). The intensity of the third peak at $2100-2200 \mathrm{~cm}^{-1}$, attributed to the association mode of $\mathrm{H}-\mathrm{O}-\mathrm{H}$, was much smaller (Ma et al., 2010a). It is possible but non-trivial to convert IR absorbance to the amount of adsorbed water, and the procedure used can be found elsewhere (Goodman et al., 2001; Ma et al., 2010a; Joshi et al., 2017; Ibrahim et al., 2018). It was found that the threeparameter BET equation (Joyner et al., 1945) could well describe water adsorption as a function of $\mathrm{RH}$ on mineral oxides (such as $\mathrm{SiO}_{2}, \mathrm{TiO}_{2}, \mathrm{Al}_{2} \mathrm{O}_{3}$, and $\mathrm{MgO}$ ) (Goodman et al., 2001; Ma et al., 2010a; Joshi et al., 2017), authentic mineral dust from different sources (Joshi et al., 2017; Ibrahim et al., 2018) and Icelandic volcanic ash (Joshi et al., 2017). Another study (Hatch et al., 2011) suggested that, compared to the two-parameter BET equation, the Freundlich adsorp-

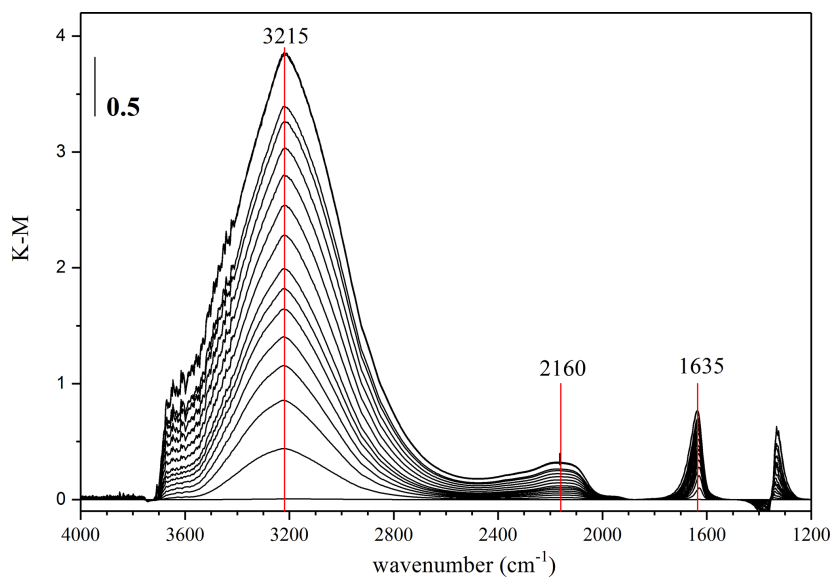

Figure 13. IR spectra of adsorbed water on $\mathrm{SiO}_{2}$ at $30^{\circ} \mathrm{C}$, as measured using DRIFTS at different RH. Reprint (with modification) with permission by Ma et al. (2010a). Copyright 2011 Elsevier.

tion isotherm could better approximate the amount of water adsorbed by kaolinite, illite, and montmorillonite at different $\mathrm{RH}$.

\subsubsection{Raman spectroscopy}

Raman spectroscopy is complementary to infrared spectroscopy. Bands which are weak in infrared spectroscopy can be strong in Raman spectroscopy, and vice versa. Compared to infrared spectroscopy, Raman spectroscopy is much less sensitive to $\mathrm{H}_{2} \mathrm{O}$, despite the symmetric stretching vibration of $\mathrm{H}_{2} \mathrm{O}$ being Raman active, and this characteristic limits application in Raman spectroscopy in exploring particles with low hygroscopicity. Meanwhile, Raman spectroscopy is very sensitive to crystalline structures, making it very useful for investigating particle-phase transition. For example, Raman spectroscopy was employed to probe phase transformation of levitated $\left(\mathrm{NH}_{4}\right)_{2} \mathrm{SO}_{4}, \mathrm{Na}_{2} \mathrm{SO}_{4}, \mathrm{LiClO}_{4}, \mathrm{Sr}\left(\mathrm{NO}_{3}\right)_{2}, \mathrm{KHSO}_{4}$, $\mathrm{RbHSO}_{4}$ and $\mathrm{NH}_{4} \mathrm{HSO}_{4}$ microparticles (Tang et al., 1995), and the occurrence of metastable solid states was observed under ambient conditions for $\mathrm{Na}_{2} \mathrm{SO}_{4}, \mathrm{LiClO}_{4}, \mathrm{Sr}\left(\mathrm{NO}_{3}\right)_{2}$ and bisulfates. Raman spectroscopy was also used to investigate hygroscopic properties of supersaturated droplets (Zhang and Chan, 2000; Zhang and Chan, 2002b), such as $\left(\mathrm{NH}_{4}\right)_{2} \mathrm{SO}_{4}$ and $\mathrm{MgSO}_{4}$.

For regular spherical droplets, their Raman spectra may overlap with strong morphology-dependent resonances (Zhang and Chan, 2002b). Nevertheless, if individual droplets were deposited on proper substrates, Raman spectra with high quality (i.e., high signal-to-noise ratios) could be obtained using confocal micro-Raman spectroscopy (Wang et al., 2005; Li et al., 2006). For example, micro-Raman spectrometry was successfully used to investigate hygroscopic properties of $\left(\mathrm{NH}_{4}\right)_{2} \mathrm{SO}_{4}, \mathrm{Ca}\left(\mathrm{NO}_{3}\right)_{2}$ and $\mathrm{NO}_{2}$-aged $\mathrm{Ca}\left(\mathrm{NO}_{3}\right)_{2}$ particles deposited on fluorinated ethylene propylene slides (Liu et al., 2008c; Zhao, 2010). Herein we use 


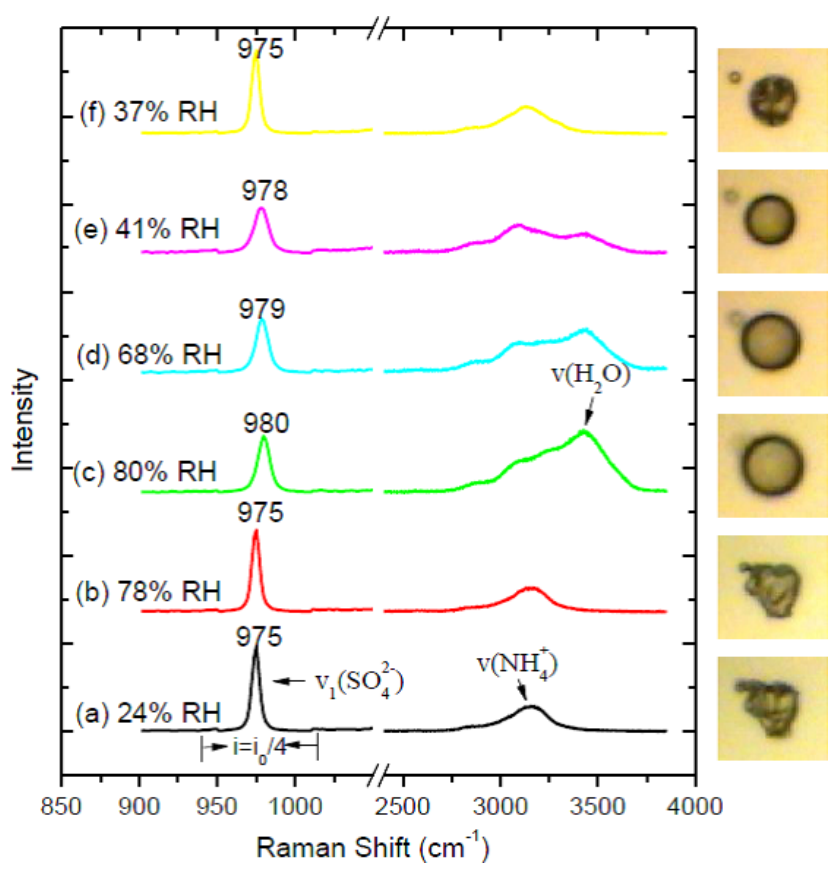

Figure 14. Raman spectra and microscopic images of an $\left(\mathrm{NH}_{4}\right)_{2} \mathrm{SO}_{4}$ particle during humidification (a-c) and dehumidification (c-f). Reprint with permission by Liu (2008). Copyright 2008 Peking University.

$\left(\mathrm{NH}_{4}\right)_{2} \mathrm{SO}_{4}$ as an example to illustrate how Raman spectroscopy can be used to determine hygroscopic properties of atmospherically relevant particles. Figure 14 shows Raman spectra and microscopic images of an $\left(\mathrm{NH}_{4}\right)_{2} \mathrm{SO}_{4}$ particle at different $\mathrm{RH}$ during humidification and dehumidification processes (Liu, 2008). When RH was increased to $80 \%$ during humidification, the Raman peak centered at $\sim 3450 \mathrm{~cm}^{-1}$, attributed to the stretching vibration of $\mathrm{H}_{2} \mathrm{O}$, started to become evident, whereas during dehumidification this peak disappeared when RH was decreased to $37 \%$. This suggested that deliquescence and efflorescence of $\left(\mathrm{NH}_{4}\right)_{2} \mathrm{SO}_{4}$ took place at 80 and $37 \% \mathrm{RH}$, respectively.

As discussed in previous work (Ling and Chan, 2007; Liu et al., 2008c; Zhao, 2010), the occurrence of deliquescence and efflorescence of $\left(\mathrm{NH}_{4}\right)_{2} \mathrm{SO}_{4}$ could also be identified from the change in position and full width at half maxima (FWHM) of the Raman peak at $970-980 \mathrm{~cm}^{-1}$ (due to symmetrical stretching of sulfate, $v_{1}-\mathrm{SO}_{4}^{2-}$ ). As shown in Fig. 14, during humidification $v_{1}-\mathrm{SO}_{4}^{2-}$ was shifted from 975 to $980 \mathrm{~cm}^{-1}$ when RH was increased to $80 \%$, and meanwhile its FWHM increased from 6 to $9 \mathrm{~cm}^{-1}$, implying the occurrence of deliquescence. For comparison, during dehumidification when $\mathrm{RH}$ was decreased to $37 \%, v_{1}-\mathrm{SO}_{4}^{2-}$ was shifted from 978 to $975 \mathrm{~cm}^{-1}$ and the corresponding FWHM decreased from $\sim 10$ to $6 \mathrm{~cm}^{-1}$, suggesting that efflorescence took place at $\sim 37 \% \mathrm{RH}$. Phase transitions could be further inferred from microscopic images (Liu et al., 2008c;
Zhao, 2010). Figure 14 shows that the particle under investigation became spherical when it was deliquesced (at $80 \% \mathrm{RH}$ ) and became irregular when efflorescence occurred (at $\sim 37 \% \mathrm{RH}$ ).

The peak intensity ratio of the stretching vibration of $\mathrm{H}_{2} \mathrm{O}$ to symmetrical stretching of sulfate is proportional to the molar ratio of $\mathrm{H}_{2} \mathrm{O}$ to sulfate in the solution and could be used to quantify the water-to-solute ratios (WSR) in aqueous $\left(\mathrm{NH}_{4}\right)_{2} \mathrm{SO}_{4}$ droplets if properly calibrated (Liu et al., 2008c). WSR values determined using Raman spectroscopy (Liu et al., 2008c) were found to agree well with those reported in the literature as a function of $\mathrm{RH}$ for $\left(\mathrm{NH}_{4}\right)_{2} \mathrm{SO}_{4}$ and $\mathrm{Ca}\left(\mathrm{NO}_{3}\right)_{2}$ during humidification and dehumidification processes (Stokes and Robinson, 1948; Tang and Munkelwitz, 1994; Clegg et al., 1998; Kelly and Wexler, 2005). In addition, Liu et al. (2008c) employed micro-Raman spectroscopy to study heterogeneous reaction of $\mathrm{CaCO}_{3}$ with $\mathrm{NO}_{2}$ and revealed that solid $\mathrm{CaCO}_{3}$ particles were converted to aqueous droplets after heterogeneous reaction with $\mathrm{NO}_{2}$, due to the formation of $\mathrm{Ca}\left(\mathrm{NO}_{3}\right)_{2}$.

Raman spectroscopy has been employed in a number of studies to investigate hygroscopic properties of organic aerosols and mixed particles (Ling and Chan, 2007, 2008; Yeung et al., 2009, 2010; Yeung and Chan, 2010; Ma and He, 2012; Q. Ma et al., 2013; Q. X. Ma et al., 2013). During humidification-dehumidification processes, oxalic acid was converted to oxalate when mixed with $\mathrm{NaCl}(\mathrm{Q}$. X. Ma et al., 2013) or $\mathrm{Ca}\left(\mathrm{NO}_{3}\right)_{2}$ (Ma and $\mathrm{He}, 2012$ ), and such conversion would lead to significant change in the hygroscopic properties of mixed particles. When a hygroscopic sulfate, such as $\left(\mathrm{NH}_{4}\right)_{2} \mathrm{SO}_{4}$ or $\left.\mathrm{Na}_{2} \mathrm{SO}_{4}\right)$, was mixed with a hygroscopic calcium salt, such as $\mathrm{Ca}\left(\mathrm{NO}_{3}\right)_{2}$ or $\mathrm{CaCl}_{2}$, gypsum, the hygroscopicity of which was very limited, would be formed by humidification. Raman spectroscopy was also used to explore hygroscopic properties of $\mathrm{NH}_{4} \mathrm{NO}_{3} /\left(\mathrm{NH}_{4}\right)_{2} \mathrm{SO}_{4}$ mixed particles (Ling and Chan, 2007), and the formation of double salts, including $3\left(\mathrm{NH}_{4} \mathrm{NO}_{3}\right) \cdot\left(\mathrm{NH}_{4}\right)_{2} \mathrm{SO}_{4}$ and $2\left(\mathrm{NH}_{4} \mathrm{NO}_{3}\right) \cdot\left(\mathrm{NH}_{4}\right)_{2} \mathrm{SO}_{4}$, was observed for the first time during crystallization. The effects of malonic, glutaric and succinic acids on the hygroscopic properties of $\left(\mathrm{NH}_{4}\right)_{2} \mathrm{SO}_{4}$ particles were explored using Raman spectroscopy (Ling and Chan, 2008). Partial crystallization of $\left(\mathrm{NH}_{4}\right)_{2} \mathrm{SO}_{4} /$ malonic acid droplets took place at $16 \% \mathrm{RH}$, while $\left(\mathrm{NH}_{4}\right)_{2} \mathrm{SO}_{4} /$ glutaric acid and $\left(\mathrm{NH}_{4}\right)_{2} \mathrm{SO}_{4}$-succinic acid particles became completely effloresced at $\sim 30 \% \mathrm{RH}$. In addition, partial deliquescence with solid inclusions was observed at $10 \% \mathrm{RH}-79 \% \mathrm{RH}$ for $\left(\mathrm{NH}_{4}\right)_{2} \mathrm{SO}_{4} /$ malonic acid, $70 \%-80 \%$ for $\left(\mathrm{NH}_{4}\right)_{2} \mathrm{SO}_{4}$ /glutaric acid, and $80 \% \mathrm{RH}-$ $90 \% \mathrm{RH}$ for $\left(\mathrm{NH}_{4}\right)_{2} \mathrm{SO}_{4} /$ succinic acid particles.

\subsubsection{Fluorescence spectroscopy}

Water molecules in aqueous solutions can exist in two states, i.e., solvated water which interacts directly with ions and free water which interacts with other water molecules. Chan and 
co-workers (Choi et al., 2004; Choi and Chan, 2005) developed a method to explore the state of water molecules in single droplets levitated in an EDB. Pyranine, a water-soluble dye, was added into the droplets. When excited by radiation at $\sim 345 \mathrm{~nm}$, Pyranine would emit fluorescence, and the spectra peaked at $\sim 440 \mathrm{~nm}$ (attributed to the presence of solvated water) and $\sim 510 \mathrm{~nm}$ (attributed to the presence of free water). The amounts of solvated and free water can be derived by combining mass hygroscopic growth factors (determined using the EDB) and the ratio of fluorescence intensity at $440 \mathrm{~nm}$ to that at $510 \mathrm{~nm}$ (Choi et al., 2004). It was found that for $\mathrm{NaCl}, \mathrm{Na}_{2} \mathrm{SO}_{4}$ and $\left(\mathrm{NH}_{4}\right)_{2} \mathrm{SO}_{4}$, efflorescence of supersaturated droplets occurred when the amount of solvated water was equal to that of free water (Choi et al., 2004; Choi and Chan, 2005). Imaging analysis further revealed that solvated water and free water were homogeneously distributed in the droplets for some types of droplets, e.g., $\mathrm{MgSO}_{4}$, but heterogeneously distributed for other types of droplets, such as $\mathrm{NaCl}$ and $\mathrm{Na}_{2} \mathrm{SO}_{4}$ (Choi and Chan, 2005).

In another study (Montgomery et al., 2015), fluorescence microscopy was used to monitor structural change in particle aggregates with $\mathrm{RH}$. In this work $\mathrm{NaCl}$ particle aggregates were collected on wire meshes and then coated with Rhodamine which would generate fluorescence. Particle aggregates collapsed and became more compact when RH was increased from $0 \%$ to $52 \%$ (Montgomery et al., 2015), lower than the DRH of $\mathrm{NaCl}(\sim 75 \%)$. Hosny et al. (2013) developed fluorescence lifetime imaging microscopy (FLIM) to determine the viscosity of individual particles by measuring the viscosity-dependent fluorescence lifetime of fluorescent molecular rotors. The viscosity of a particle is of interest because it is closely related to the phase state of the particle and largely determines diffusion in the particle (Koop et al., 2011; Reid et al., 2018). FLIM was used to investigate the viscosity of ozonated oleic acid particles and secondary organic particles formed by myrcene ozonolysis, and their viscosity was observed to increase largely with decreasing RH and increasing extent in oxidative aging (Hosny et al., 2016).

\subsubsection{Other surface characterization techniques}

In addition to the spectroscopic and microscopic methods discussed in Sect. 3.3 and 3.4, there are a number of other surface characterization techniques which can be used to explore water adsorption on surfaces, e.g., sum frequency generation spectroscopy (Ma et al., 2004; Liu et al., 2005; Jubb et al., 2012; Ault et al., 2013), atmospheric pressure X-ray photoelectron spectroscopy (Ketteler et al., 2007; Salmeron and Schlogl, 2008; Yamamoto et al., 2010a), or scanning tunneling microscopy (Wendt et al., 2006; He et al., 2009). These techniques, which are able to provide fundamental and mechanistic insights into water-surface interactions, have mainly been applied to surfaces of single crystals, and their usefulness for particles with direct atmospheric relevance is yet to be demonstrated. As a result, these techniques are not further discussed here, and readers are referred to the aforementioned literature and references therein for more details.

\subsubsection{Discussion}

Infrared and Raman spectroscopy can be used to quantify particle water content for unsaturated and supersaturated samples, with no restriction imposed by particle shape or morphology. Infrared spectroscopy is very sensitive to adsorbed water and has been widely used to investigate water adsorption (Tang et al., 2016a), as discussed in Sect. 3.3.1. In contrast, Raman spectroscopy is not sensitive enough to detect adsorbed water; nevertheless, recent work (Gen and Chan, 2017) showed that electrospray surface-enhanced Raman spectroscopy was able to detect surface-adsorbed water. One important advantage for infrared and Raman spectroscopy is that simultaneous measurement of chemical composition can be provided; therefore, they have been coupled to other techniques (such as optical microscope or electrodynamic balance) to further understand hygroscopic properties of atmospherically relevant particles, as discussed in Sects. 3.3, 3.4, 4.1 and 4.2. Infrared and Raman spectroscopy have been widely employed to characterize ambient aerosol particles collected on proper substrates, and therefore they can be used to explore hygroscopic properties of ambient particles in an offline manner.

\subsection{Measurement of electrical properties}

Deliquescence of ionic solids would lead to a significant increase in electrical conductivity and, vice versa, efflorescence of electrolyte solutions to ionic solids would cause a large decrease in electrical conductivity. Therefore, relative changes in electrical conductivity/impedance can be used to identify the occurrence of deliquescence and efflorescence (Yang et al., 2006; He et al., 2008; Schindelholz et al., 2014b, c). For example, in one study (Schindelholz et al., 2014c), micrometer-sized particles were deposited on an interdigitated microelectrode sensor housed in an environmental chamber, and the electrical impedance was detected online while RH in the chamber was varied. The measured DRH and ERH using this method were found to agree well with literature values for several compounds, e.g., $\mathrm{NaCl}$, $\mathrm{NaBr}$ and $\mathrm{KCl}$ (Schindelholz et al., 2014c). In another study (He et al., 2008), the electrical conductivity and capacitance of a single droplet were measured as different $\mathrm{RH}$ to investigate hygroscopic properties of $\mathrm{NaClO}_{4}$ particles. Overall, this method has not been widely applied to study atmospherically relevant particles and thus is not further discussed herein.

\section{Levitated single particles}

Single-particle levitation techniques can be broadly classified into three groups (Krieger et al., 2012), including electro- 
dynamic balance, optical levitation and acoustic levitation. These techniques have been widely used to investigate chemical and physical transformation of atmospherically relevant particles (Lee et al., 2008; Krieger et al., 2012). Herein we introduce the basic principles of each technique and illustrate how they can help understand aerosol hygroscopicity by discussing representative studies.

\subsection{Electrodynamic balance}

The electrodynamic balance (EDB) technique has been widely used in the last several decades, and diameters of particles which can be levitated by EDB are typically in the range of 1-100 $\mu \mathrm{m}$ (Davis, 1997; Davis, 2011). The principle, configuration and operation of EDB have been extensively documented elsewhere (Reid and Sayer, 2003; Lee et al., 2008; Davis, 2011; Krieger et al., 2012) and hence are not described in detail here. In brief, a particle can be levitated and trapped at the null point of the EBD chamber when the $\mathrm{AC}$ and DC electric fields surrounding the particle are properly adjusted. The schematic diagram of a low-temperature EDB (Tong et al., 2015) is shown in Fig. 15. The main body of the EDB was an octagonal aluminum chamber with an optical window on each side. Two cold nitrogen flows, which were first passed through copper tubes immersed in a liquid nitrogen dewar, were fed into the chamber to cool the EDB. Temperature at the null point where a particle was trapped was further regulated using a PTC heater, and temperature and RH inside the chamber were monitored online. A continuous-wave laser at $532 \mathrm{~nm}$ was used to illuminate the trapped particle, and the scattered light was measured at an angle of $21^{\circ}$ to determine the particle size.

In the absence of other forces, the gravitational force of the particle trapped in the EDB is equal to the balancing electrostatic force, given by Eq. (2) (Pope et al., 2010a; Davis, 2011):

$m g=n q C \frac{V_{\mathrm{DC}}}{z}$,

where $m$ is the particle mass, $g$ is the gravitational constant, $n$ is the number of elementary charges present on the particle, $q$ is the elementary charge, $z$ is the distance between the two electrodes, $C$ is a constant dependent on the geometrical configuration of the $\mathrm{EDB}$, and $V_{\mathrm{DC}}$ is the $\mathrm{DC}$ voltage required to levitate the particle. Equation (2) suggests that as long as the charge present on the trapped particle remains constant, the mass of the particle is proportional to the DC voltage required to balance its gravitational force. Therefore, the relative mass change in the particle due to any physical or chemical processing can be quantified by measurement of the DC voltage. Haddrell et al. (2012) discussed conditions when the assumption of constant charge may fail and proposed experimental strategies to minimize its occurrence.

In hygroscopicity studies, the relative mass change in the trapped particle (typically relative to that under dry condi-

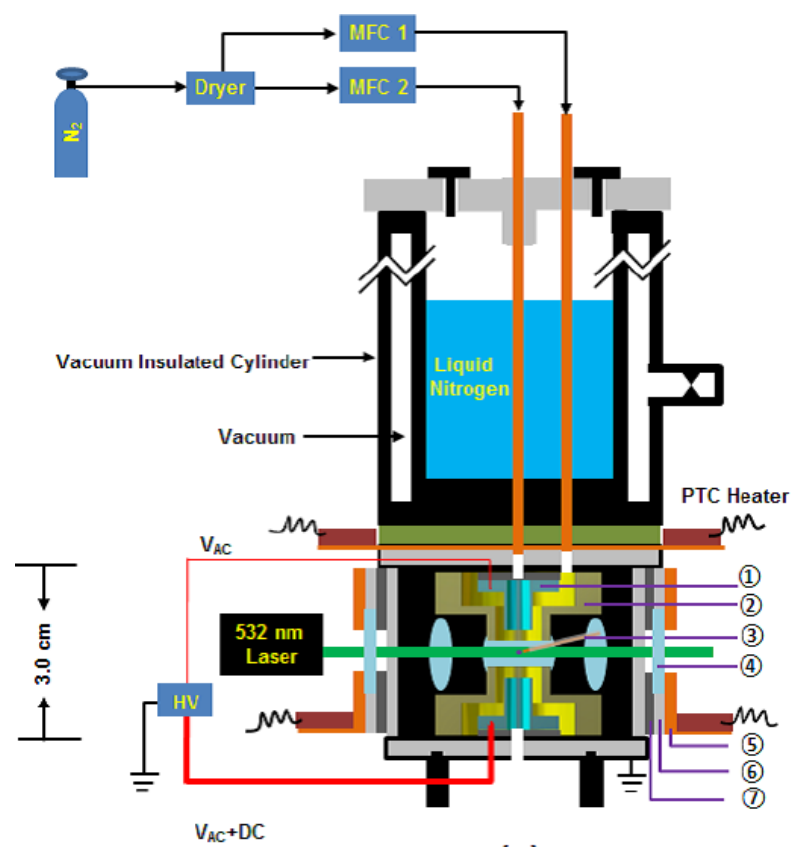

(a)

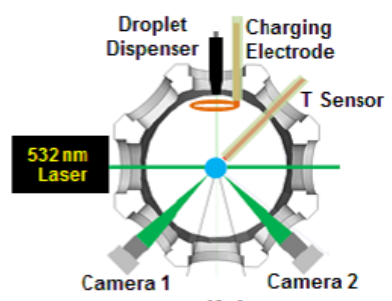

(b)

Figure 15. Schematic diagram of a cold electrodynamic balance. (a) Side view of this setup: (1) inner electrode; (2) outer electrode; (3) temperature and RH sensors; (4) glass optical window; (5) heating jacket; (6) optical window holder; (7) rubber insulator. (b) Top view of this setup: droplets were generated using a droplet dispenser and charged using a charging electrode, and one of them may be trapped at the null point. A $532 \mathrm{~nm}$ laser was used to illuminate the trapped particle, and two cameras were used to observe the particle and record the scattered light. Reprint with permission by Tong et al. (2015).

tion) during humidification and dehumidification can be determined to obtain mass hygroscopic growth factors (Peng et al., 2001; Pope et al., 2010a; Haddrell et al., 2014; Steimer et al., 2015). For example, EDB has been used to measure DRH, ERH and mass hygroscopic growth factors for a number of inorganic (Tang and Munkelwitz, 1994; Tang and Fung, 1997; Tang et al., 1997; Zhang and Chan, 2002a; Zhang and Chan, 2003; Hargreaves et al., 2010b), organic (Peng and Chan, 2001a; Peng et al., 2001; Choi and Chan, 2002b; Pope et al., 2010a; Steimer et al., 2015) and mixed inorganic/organic particles (Choi and Chan, 2002a; Zardini et al., 2008; Pope et al., 2010a) of atmospheric relevance. In addition, water uptake by different types of pollen was 


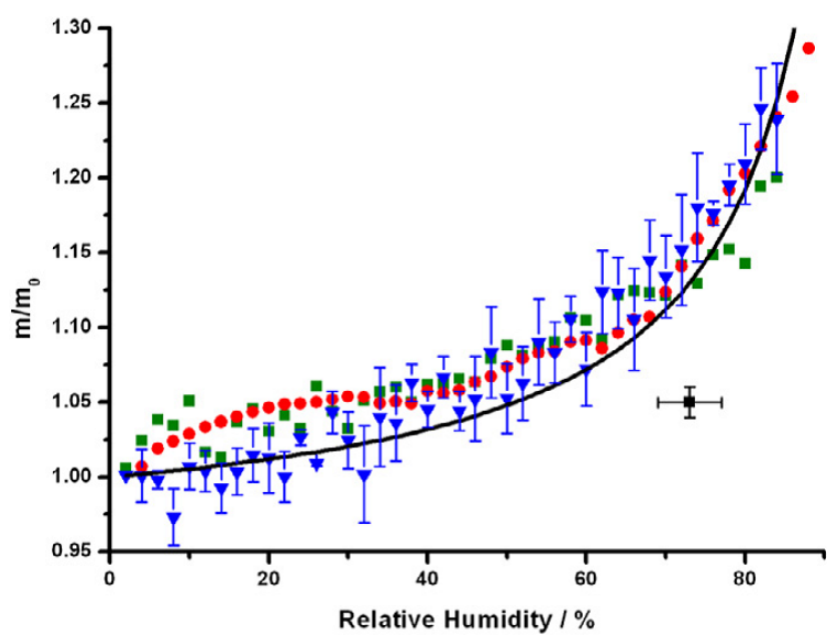

Figure 16. Mass hygroscopic growth factors (defined as the ratio of the particle mass at a given RH to the dry particle mass) of Salix caprea (red circle), Betula occidentalis (blue triangle), and Narcissus sp. (green square). For clarity only the error bars $( \pm 1 \sigma)$ are shown for Betula occidentalis, and the mass hygroscopic growth factors have similar uncertainties for the other two pollen species. The black square represents water uptake reported by Diehl et al. (2001), and the black curve represents the fitted mass hygroscopic growth curve using the $\kappa$-Kohler theory. Reprint with permission by Pope (2010). Copyright 2010 IOP Publishing Ltd.

measured as a function of RH using an EDB (Pope, 2010; Griffiths et al., 2012). As displayed in Fig. 16, pollen grains were found to be moderately hygroscopic, and the mass of water taken up at $90 \% \mathrm{RH}$ was around $30 \%$ of the dry mass (Pope, 2010). It was further found that hygroscopic growth of pollen species could be described by the $\kappa$-Kohler theory, with $\kappa$ values falling in the range of $0.05-0.1$ (Pope, 2010). In another two studies (Haddrell et al., 2013, 2014), EDB was utilized to explore hygroscopic growth of several pharmaceutically relevant formulations, and the results can help better understand where medical aerosol particles would deposit in our inhalation system.

Light scattering techniques can used to measure optical properties of single particles levitated in an EDB. For example, Tang and co-workers (Tang and Munkelwitz, 1994; Tang, 1997; Tang and Fung, 1997; Tang et al., 1997) measured the intensity of elastically scattered light from a levitated particle which was illuminated by a He-Ne laser beam, and managed to retrieve its diameter and refractive index as a function of RH using Mie theory. Since the relative mass change was also determined at the same time, change in particle density with RH could also be determined (Tang and Munkelwitz, 1994; Tang et al., 1997). In addition, spectroscopic techniques have been frequently coupled to EDB in order that chemical information could be simultaneously provided. For example, Chan and colleagues (Zhang and Chan, 2002a; Zhang and Chan, 2003; Lee et al., 2008) directed a laser beam with a wavelength of $514.5 \mathrm{~nm}$ to the trapped particle in the EDB and measured the resulting Raman signals with a CCD detector. This configuration enabled change in particle composition and hygroscopicity due to heterogeneous reactions to be monitored online in a simultaneous manner (Lee and Chan, 2007; Lee et al., 2008). Experimental work in which EDB was coupled to fluorescence spectroscopy has also been reported (Choi et al., 2004; Choi and Chan, 2005).

In addition to hygroscopicity research, EDB have also been used in a number of studies (Reid and Sayer, 2003; Lee et al., 2008; Pope et al., 2010b; Davis, 2011; Krieger et al., 2012; Bilde et al., 2015b) to investigate other physicochemical properties (including vapor pressure, mass accommodation coefficients, evaporation coefficients, and gas-phase diffusion coefficients) and chemical reactions of atmospheric particles.

\subsection{Optical levitation}

Trapping and manipulation of atoms, molecules, nanostructures and particles have been widely used in a number of scientific fields (Ashkin, 2000; McGloin, 2006; Mitchem and Reid, 2008; Krieger et al., 2012; Lehmuskero et al., 2015; Spesyvtseva and Dholakia, 2016; Gong et al., 2018). The effects of radiation pressure on microscopic particles were first demonstrated in 1970 (Ashkin, 1970). After that, levitation of solid particles and liquid droplets in air using a vertically propagating weakly focused laser beam was achieved (Ashkin and Dziedzic, 1971; Ashkin and Dziedzic, 1975). Applications of optical levitation to particles of atmospheric relevance have been previously reviewed (Mitchem and Reid, 2008; Wills et al., 2009; Krieger et al., 2012), and very recently general applications related to trapping single particles in air have also been summarized (Gong et al., 2018).

Interaction of an incident laser beam with a particle consists of two forces: (i) a scattering force that results from the transfer of momentum to the dielectric particle from backscattered photons, and (ii) a gradient force that depends on the gradient of the electromagnetic field associated with the optical beam. The first type of force exerts a push on the particle, while the second type exerts a pull (Krieger et al., 2012). Utilization of either of these two forces as the primary force to trap particles leads to two types of optical levitation techniques, i.e., optical levitation trap and optical tweezers. In an optical levitation trap, the laser beam is mildly focused and the particle adopts a stable position within the divergent beam above the focus, where the downward gravitational force is exactly balanced by the upward scattering force (Wills et al., 2009). Droplets of $20-100 \mu \mathrm{m}$ in diameter can be trapped with active compensating adjustment of light intensity with respect to changes in droplet size (Krieger et al., 2012); nevertheless, optical levitation traps are intrinsically delicate and unstable (Wills et al., 2009). Optical tweezers effectively create a strong intensity gradient in 


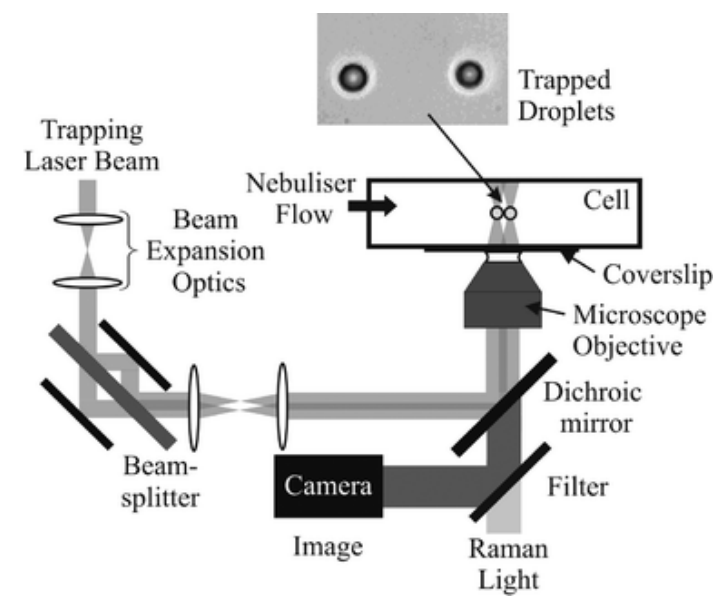

Figure 17. Schematic diagram of the dual trap configuration of the optical tweezers. Reprint with permission by Butler et al. (2008). Copyright 2008 Royal Society of Chemistry.

three dimensions, by amplifying the gradient force using a microscope objective lens to tightly focus the trapping laser beam. The gradient force leads to strong transverse and axial restoring forces that are many orders of magnitude larger than the gravitational force of the particle (Wills et al., 2009), restoring the particle to the region with the highest light intensity (Krieger et al., 2012). Therefore, particles can be captured and held tightly against the scattering and gravitational forces, allowing true 3-D confinement of particles with diameters of 1-10 $\mu \mathrm{m}$ (Krieger et al., 2012).

Different laser beams have been used as incident light sources. In optical levitation traps, mildly focused Gaussian beams (Ashkin and Dziedzic, 1975), counter-propagating Gaussian beams (Ashkin, 2000) and a Gaussian beam plus a Bessel beam (Davis et al., 2015a) can be used to trap single particles. In optical tweezers, particles can be trapped with a single laser beam (Magome et al., 2003; Mitchem et al., 2006a) or in a dual-trap configuration with two (or split) laser beams (Fallman and Axner, 1997; Buajarern et al., 2006; Butler et al., 2008), and counter-propagating Bessel beams have also been used (Lu et al., 2014). Figure 17 shows a typical experimental setup for a dual-trap configuration of optical tweezers in which droplets were generated using a nebulizer and then introduced into the trapping cell (Butler et al., 2008). A laser beam at $532 \mathrm{~nm}$ was used as the trapping light and focused by an oil immersion objective to create a working distance of $\sim 130 \mu \mathrm{m}$. A beam splitter was then used to create two parallel trapping beams that could be translated independently over distances of $>50 \mu \mathrm{m}$, allowing individual manipulation or probing of two separate particles in close range.

When a single particle is optically trapped, it can be characterized by a number of techniques. Direct imaging is the most straightforward one, and bright field imaging can be used to determine particle size with an accuracy of $\pm 0.2 \mu \mathrm{m}$

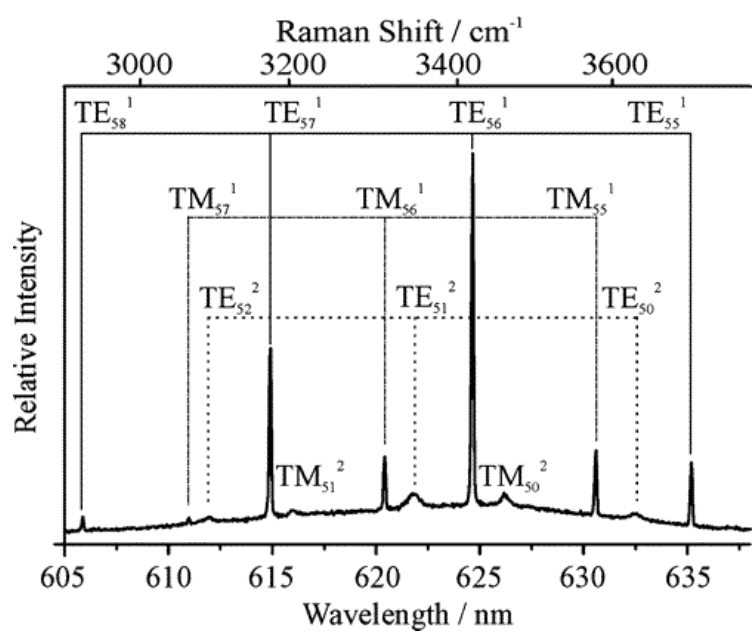

Figure 18. An example of Raman scattering from a trapped water droplet, illuminated at $514.5 \mathrm{~nm}$. Stimulated Raman scattering is observed at wavelengths commensurate with whispering gallery modes. The resonant modes can be assigned by comparison with Mie scattering calculations, and the droplet radius can then be derived. Reprint with permission by Mitchem et al. (2006a). Copyright 2006 American Chemical Society.

(Burnham and McGloin, 2009). However, this method suffers from low accuracy in size measurement due to the dependence of the axial position on laser power (Knox et al., 2007). Spectroscopy, especially Raman spectroscopy, is more accurate in particle size measurement (Wills et al., 2009) and can also offer compositional information (Reid et al., 2007). Known as cavity-enhanced Raman spectroscopy, spectra recorded from optically trapped particles comprise of spontaneous and stimulated Raman scattering (Mitchem et al., 2006a; Wills et al., 2009). Spontaneous Raman scattering can be used to investigate changes in $\mathrm{OH}$ stretching vibrations $\left(2900-3700 \mathrm{~cm}^{-1}\right)$ of particulate water during hygroscopic growth as well as hydrogen bonding environments within the particle. On the other hand, stimulated Raman scattering can be strongly amplified (by a factor of >10) (Mitchem et al., 2006a), but it occurs only at distinct wavelengths that are commensurate with whispering gallery modes (WGMs). This stimulated Raman scattering under WGMs, as shown in Fig. 18, is also commonly referred to as morphology-dependent resonances or cavity resonances (Mitchem et al., 2006a). Using the stimulated Raman spectra, one can achieve a sizing accuracy of $\pm 2 \mathrm{~nm}$ that is only limited by spectral dispersion of the spectrograph (Mitchem et al., 2006a; Mitchem and Reid, 2008). Other techniques have also been coupled with optical levitation, including elastic (Mie) scattering (Ward et al., 2008) and light absorption (Knox and Reid, 2008).

There are a number of studies in which optical levitation techniques were employed to investigate hygroscopic properties of atmospheric particles. Based on an early design (Hop- 
kins et al., 2004), Mitchem et al. (2006a) investigated hygroscopic growth of a $\mathrm{NaCl}$ particle trapped by optical tweezers for $\mathrm{RH}>80 \%$ by characterizing spontaneous and stimulated Raman scattering. Changes in the $\mathrm{OH}$ stretching band of the particle were observed as RH increased, and size measurement was achieved with an accuracy of a few nanometers and a time resolution of $1 \mathrm{~s}$. The measured equilibrium sizes agreed well with these predicted using the Köhler theory, and the largest uncertainties came from the error in RH measurement with a capacitive sensor ( $\pm 2 \%$ for $\mathrm{RH}$ below $90 \%$ ) (Mitchem et al., 2006a). The change in the $\mathrm{OH}$ stretching band was also used to probe the formation and destruction of hydrogen bonding in a trapped $\mathrm{NaCl}$ particle at different $\mathrm{RH}$ (Treuel et al., 2010).

A dual-trap configuration of optical tweezers, in which two particles could be levitated simultaneously (as shown in Fig. 17), was employed to investigate hygroscopic properties of individual particles (Butler et al., 2008). In this setup, the first particle with well-known hygroscopicity (in this case, $\mathrm{NaCl})$ served as an accurate $\mathrm{RH}$ probe $( \pm 0.09 \%$ even for $\mathrm{RH}>90 \%)$, while the second particle ( $\mathrm{NaCl} /$ glutaric acid, for example) was interrogated for its hygroscopic properties as an "unknown" particle. Excellent agreement between experimental measurement and prediction using the Köhler theory was achieved (Butler et al., 2008). Hygroscopic properties of inorganic/organic mixed particles, including $\mathrm{NaCl} /$ glutartic acid and $\left(\mathrm{NH}_{4}\right)_{2} \mathrm{SO}_{4} /$ glutartic acid mixtures with different mass ratios, were further studied using this comparative approach (Hanford et al., 2008). Measured equilibrium sizes of those inorganic/organic mixed particles were found to agree well with theoretical predictions, demonstrating the robustness of this approach for hygroscopicity study at the high RH (>97\%).

Using the dual-trap configuration, hygroscopic properties of $\mathrm{NaCl}$ and $\left(\mathrm{NH}_{4}\right)_{2} \mathrm{SO}_{4}$ were measured at low $\mathrm{RH}$ (down to $80 \%$ ) (Walker et al., 2010). The usage of $\mathrm{NaCl}$ as a reference particle could reduce the errors associated with the measured equilibrium wet size of $\left(\mathrm{NH}_{4}\right)_{2} \mathrm{SO}_{4}$ to $<0.2 \%$; for comparison, the errors could be as large as $\pm 5 \%$ when a capacitance $\mathrm{RH}$ probe was used. The difference between the measured and modeled growth factors was found to be in the range of $0.1 \%-0.3 \%$ for $\left(\mathrm{NH}_{4}\right)_{2} \mathrm{SO}_{4}$ in the medium $\mathrm{RH}$ region (84\% RH-96\% RH) (Walker et al., 2010). In a following study (Hargreaves et al., 2010a), the dual-trap configuration was utilized to investigate hygroscopic properties of $\mathrm{NaCl}$ at $45 \% \mathrm{RH}-75 \% \mathrm{RH}$, and growth factors of $\mathrm{NaCl}$ measured by this (Hargreaves et al., 2010a) and previous studies (Butler et al., 2008; Hanford et al., 2008) were found to be in excellent agreement with those predicted (Clegg and Wexler, 2011) for $\mathrm{RH}$ in the range of $45 \%-99 \%$.

Optical levitation can also be used to explore phase transitions and surface hydration. For example, liquid- to solid-phase transitions were observed for the $\left(\mathrm{NH}_{4}\right)_{2} \mathrm{SO}_{4} /$ glycerol $/ \mathrm{H}_{2} \mathrm{O}$ system via morphologydependent resonances and Raman spectroscopy (Trunk et al., 1997), and Raman spectroscopy revealed the presence of adsorbed water on the surface of optically levitated mineral oxide particles at different RH (Rkiouak et al., 2014). In addition, optical tweezers were utilized to investigate efflorescence and deliquescence of a number of inorganic salts (Davis et al., 2015a). Compared to deliquescence, efflorescence usually occurs for a lower RH (Martin, 2000). Immersion of solid particles (e.g., mineral dust) in aqueous droplets would cause efflorescence to take place at higher $\mathrm{RH}$, as observed in previous work (Han et al., 2002; Pant et al., 2006). Recently optical levitation was employed to explore efflorescence of supersaturated aqueous droplets induced by collision with solid particles (Davis et al., 2015a, b). It was found that upon collision with several different types of solid particles, including $\mathrm{NaCl}, \mathrm{KCl},\left(\mathrm{NH}_{4}\right)_{2} \mathrm{SO}_{4}$, and $\mathrm{Na}_{2} \mathrm{SO}_{4}$, aqueous $\mathrm{NH}_{4} \mathrm{NO}_{3},\left(\mathrm{NH}_{4}\right)_{2} \mathrm{SO}_{4}$ and $\mathrm{NaCl}$ droplets would effloresce at $\mathrm{RH}$ significantly higher than those for homogeneous efflorescence (Davis et al., 2015b).

Kinetics of water uptake by aerosol particles can also be studied using optical levitation techniques. For example, hygroscopic properties of $\mathrm{NaCl}$ particles coated with oleic acid was examined using optical tweezers (Dennis-Smither et al., 2012). It was observed that efflorescence and deliquescence behavior of the $\mathrm{NaCl}$ particle and the timescales to reach reequilibrium were not affected by the presence of oleic acid; furthermore, heterogeneous oxidation by $\mathrm{O}_{3}$ was found to increase the hygroscopicity of oleic acid in the $\mathrm{NaCl}$-oleic acid mixed particle (Dennis-Smither et al., 2012). In another study (Tong et al., 2011), optical tweezers were employed to explore the timescales for mass transfer of water in glassy aerosol particles. It was found that the halftime for re-equilibration after $\mathrm{RH}$ change could increase from tens and hundreds of seconds (RH above glass transition) to $>1000 \mathrm{~s}$ (RH below glass transition) for sucrose-water, raffinose-water and sucrose-NaCl-water systems.

Particle viscosity determines diffusion coefficients of water molecules in the particles, affecting water uptake kinetics (Reid et al., 2018). A novel microrheological method, which employed holographic aerosol optical tweezers, has been developed to measure particle viscosity in the range of $10^{-3}$ to $10^{9} \mathrm{~Pa} \mathrm{~S}$ (Power et al., 2013). In brief, coalescence between two airborne particles, with volumes smaller than $500 \mathrm{fL}$, was initiated using the optical tweezers, and the time required by the coalesced particle to relax to a sphere was measured to infer particle viscosity. More details of this method can be found elsewhere (Power et al., 2013; Song et al., 2016).

In addition, optical levitation techniques have also been employed to investigate a myriad of heterogeneous processes, including evaporation of volatile/semi-volatile species, mixing of inorganic/organic particles and heterogeneous reactions (Mitchem et al., 2006b; Buajarern et al., 2007; Tang et al., 2014; Jones et al., 2015; Gorkowski et al., 2016; Cai and Zhang, 2017). Optical tweezers have recently become commercially available, and commercial instruments have been used to investigate physicochemical 
properties and processes of atmospherically relevant particles (Davies and Wilson, 2016; Haddrell et al., 2017).

\subsection{Acoustic levitation}

Inside a typical acoustic levitator, a high-frequency sound wave, generated using a piezoelectric oscillator (also called a radiator), is reflected by a concave reflector. Standing waves can be generated in the space between the radiator and the reflector if the radiator and the reflector are properly positioned. Droplets with diameters ranging from tens of micrometers to a few millimeters can then be trapped in the vertical position near one of these existing wave nodes. A detailed description of this technique can be found elsewhere (Kavouras and Krammer, 2003; Ettner et al., 2004; Mason et al., 2008). The size of the levitated particle can be characterized using a camera, and spectroscopic techniques, such as FTIR and Raman spectroscopy, can be coupled to the acoustic levitator so that chemical information can be simultaneously provided (Brotton and Kaiser, 2013).

Acoustic levitation has been used in a variety of research fields to investigate interactions of single solid/liquid particles with different gases (Kavouras and Krammer, 2003; Mason et al., 2008; Schenk et al., 2012), including water vapor. For example, Schenk et al. (2012) used an acoustic levitator to measure hygroscopicity of imidazolium-based ionic liquids, and low temperature acoustic levitation was developed to study homogeneous and heterogeneous freezing of aqueous droplets (Ettner et al., 2004; Diehl et al., 2009, 2014). Particles which can be acoustically levitated are typically $>20 \mu \mathrm{m}$ (Mason et al., 2008; Krieger et al., 2012), while most of atmospheric aerosol particles are significantly smaller (Seinfeld and Pandis, 2016). Therefore, compared to the other two levitation techniques (i.e., EDB and optical levitation), acoustic levitation is much less widely utilized in atmospheric chemistry (Krieger et al., 2012).

\subsection{Discussion}

Both EDB and optical levitation can measure liquid water content for unsaturated and supersaturated samples, as particles used in these experiments are free of contact with other substances. EDB measures relative mass change to quantify aerosol liquid water content, and thus there is no constrain on particle shape, whereas for optical levitation, particle diameter change is usually measured optically, and particles under investigation need to be spherical. Both techniques may not be sensitive enough to study water adsorption. To our knowledge, they have not been used to investigate hygroscopic properties of ambient aerosol particles, though in principle they both have the capacity. One reason is that particles that can be explored using these techniques are usually 1 order of magnitude larger than those typically found in the troposphere. Another reason could be that only one particle can be examined in each experiment, while there are numerous aerosol particles in the ambient air. One unique advantage of these two techniques is that size, chemical composition and optical properties of levitated particles can be obtained in an online and noninvasive manner, making them very valuable to explore aerosol properties and processes at the fundamental level (Lee et al., 2008; Krieger et al., 2012).

\section{Aerosol particles}

In this section techniques that can be employed to investigate hygroscopic properties of airborne aerosol particles and can also be deployed for field measurements are reviewed. We discuss in Sect. 5.1 humidity-tandem differential mobility analyzers which measure mobility diameter change in aerosol particles upon humidity change. Hygroscopic growth would further lead to change in aerosol optical properties, which can be measured to infer aerosol hygroscopicity, as reviewed in Sect. 5.2. In Sect. 5.3 we discuss in brief a few techniques developed to explore hygroscopic properties of black carbon aerosol in specific.

\subsection{Humidity-tandem differential mobility analyzer (H-TDMA)}

\subsubsection{Basic H-TDMA}

The tandem differential mobility analyzer (TDMA) was pioneered in 1978 and called the aerosol mobility chromatograph at that time (Liu et al., 1978). The terminology "TDMA" was first introduced in 1986 in a study (Rader and McMurry, 1986) which showed that size change as small as $1 \%$ could be readily measured. In addition to size change due to humidification (humidity-TDMA), TDMAs can also be used to measure particle size change due to other processing such as heating (Bilde et al., 2015a). H-TDMA is probably the most widely used technique for aerosol hygroscopicity measurement in both laboratory (Gibson et al., 2006; Herich et al., 2009; Koehler et al., 2009; Wex et al., 2009; Good et al., 2010b; Wu et al., 2011; Hu et al., 2014; Lei et al., 2014; Gomez-Hernandez et al., 2016; Jing et al., 2016; Zieger et al., 2017) and field studies (McMurry and Stolzenburg, 1989; Swietlicki et al., 2008; Ye et al., 2011, 2013; X. Wang et al., 2014; Yeung et al., 2014b; Atkinson et al., 2015; Cheung et al., 2015; Wu et al., 2016; Sorooshian et al., 2017). There are a number of H-TDMAs developed and used by individual research groups, and all the instruments follow the same principle. Recently these instruments have also become commercially available, e.g., from Brechtel Manufacturing Inc. (Lopez-Yglesias et al., 2014) and MSP Corporation (Sarangi et al., 2019). Swietlicki et al. (2008) provided a good description of the operation principle, and discussed potential error sources for H-TDMA measurements; Duplissy et al. (2009) analyzed the result from an intercomparison of six different H-TDMAs and recommended guidelines for design, calibra- 


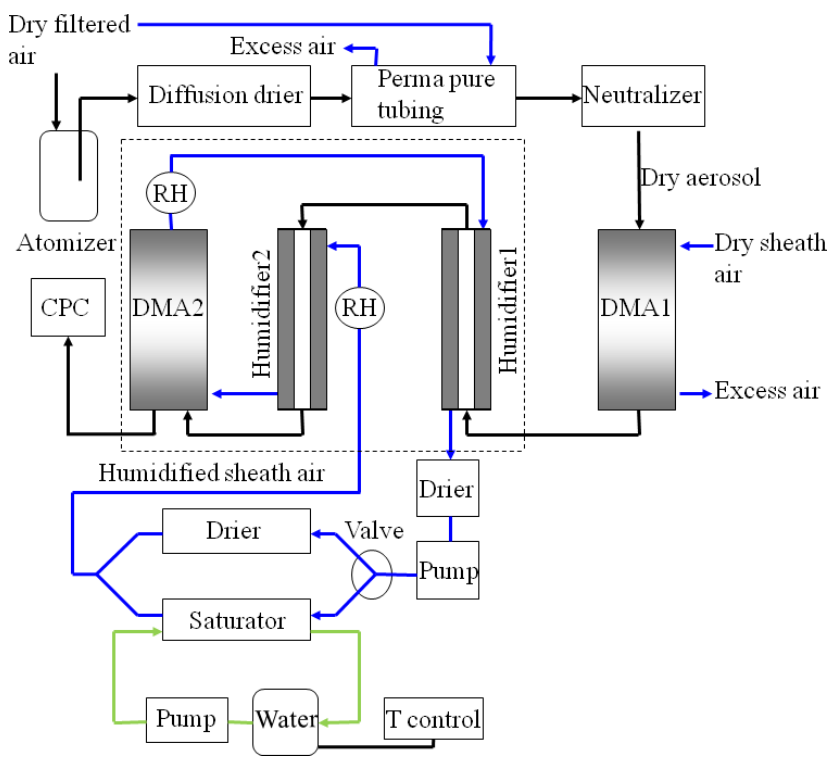

Figure 19. Schematic diagram of a typical H-TDMA instrument. Reprint with permission by Jing et al. (2016).

tion, operation and data analysis for H-TDMAs. Below we describe in brief how a typical H-TDMA works.

As illustrated in Fig. 19, polydisperse ambient or laboratory-generated aerosol particles were sampled through an aerosol dryer to reduce the $\mathrm{RH}$ to $<15 \%$, and the dry aerosol flow was passed through a neutralizer and then the first DMA (DMA1) to generate quasi-monodisperse aerosol particles. After that, the aerosol flow was delivered through a humidification section to be humidified to a given $\mathrm{RH}$, and aerosol particles exiting the humidification section were monitored using the second DMA (DMA2) coupled with a condensation particle counter (CPC) to provide number size distributions. The growth factor (GF) is defined as the ratio of aerosol mobility diameter at a given $\mathrm{RH}$ to that at dry condition. The raw H-TDMA data should be inverted to retrieve the actual growth factor probability density function (Rader and McMurry, 1986; Gysel et al., 2009; Good et al., 2010a), and currently the inversion algorithm developed by Gysel et al. (2009) is widely used. One major uncertainty for H-TDMA measurements stems from the accuracy of RH in the second DMA, and considerable efforts are needed to minimize the RH and temperature fluctuation (Swietlicki et al., 2008; Duplissy et al., 2009; Massling et al., 2011; LopezYglesias et al., 2014). The residence time in the humidification section should exceed $10 \mathrm{~s}$ for aerosol particles to reach the equilibrium under a given $\mathrm{RH}$, while it should not be more than $40 \mathrm{~s}$ due to potential evaporation of semi-volatile species (Chan and Chan, 2005; Duplissy et al., 2009). In addition, it is important to check the H-TDMA performance via comparing the measured GF with theoretical values for reference aerosol particles, such as $\left(\mathrm{NH}_{4}\right)_{2} \mathrm{SO}_{4}$ and $\mathrm{NaCl}$ (Swietlicki et al., 2008; Duplissy et al., 2009).

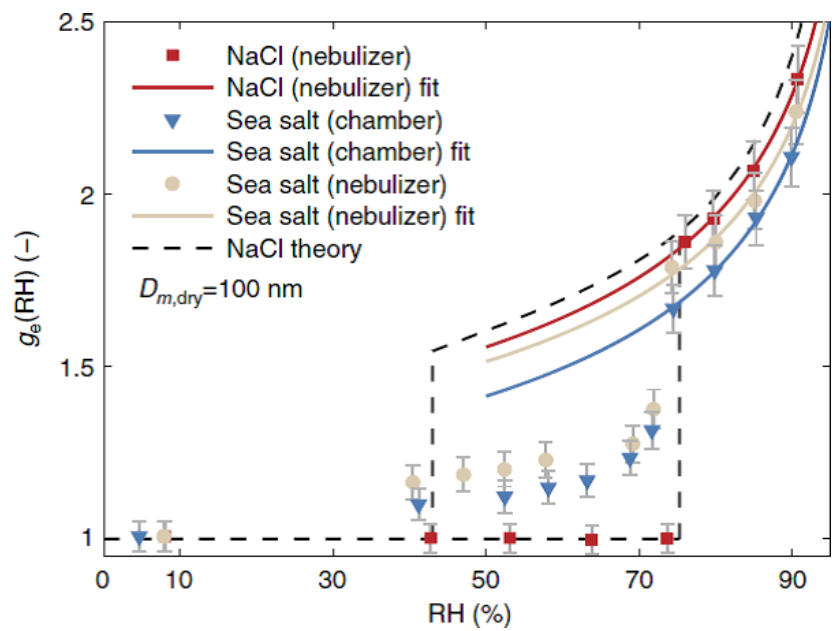

Figure 20. Measured hygroscopic growth factors of $\mathrm{NaCl}$ and synthetic sea salt aerosol particles as different $\mathrm{RH}$. $\mathrm{NaCl}$ aerosol particles were generated using a nebulizer, and both a nebulizer and a sea spray chamber were used to generate sea salt aerosol particles. Reprint with permission by Zieger et al. (2017).

In typical laboratory studies (Herich et al., 2009; Koehler et al., 2009; Jing et al., 2016; Zieger et al., 2017), aerosol size is measured at different $\mathrm{RH}$ using the H-TDMA to get the RH-dependent GF. Humidograms, in which GF are plotted as a function of $\mathrm{RH}$, are shown in Fig. 20 for $\mathrm{NaCl}$ and synthetic sea salt aerosol particles, suggesting that at a given $\mathrm{RH}$, GF of sea salt aerosol is $8 \%-15 \%$ smaller than $\mathrm{NaCl}$ aerosol (Zieger et al., 2017). Since both $\mathrm{NaCl}$ and synthetic sea salt aerosol particles are non-spherical under dry conditions, growth factors were reported after shape factor correction. The difference in $\mathrm{GF}$ between $\mathrm{NaCl}$ and synthetic sea salt aerosols was attributed to the presence of hydrates (such as the hydrates of $\mathrm{MgCl}_{2}$ and $\mathrm{CaCl}_{2}$ ) with lower hygroscopicity (when compared to $\mathrm{NaCl}$ ) in synthetic sea salt (Zieger et al., 2017).

H-TDMA has been widely used to investigate hygroscopic growth of secondary organic aerosol (Prenni et al., 2007; Duplissy et al., 2008; Wex et al., 2009; Good et al., 2010b; Massoli et al., 2010; Duplissy et al., 2011; Alfarra et al., 2013; Zhao et al., 2016), which significantly contributed to submicrometer aerosol particles over the globe (Zhang et al., 2007). Using an aerosol flow tube, Massoli et al. (2010) generated secondary organic aerosols (SOA) via $\mathrm{OH}$ oxidation of $\alpha$-pinene, 1,3,5-trimethylbenzenen (TMB), m-xylene and a $50: 50$ mixture of $\alpha$-pinene and $\mathrm{m}$-xylene and measured their hygroscopic growth at $90 \% \mathrm{RH}$ using a H-TDMA. As shown in Fig. 21, measured GF at $90 \%$ RH ranged from 1.05 (nonhygroscopic) to 1.35 (moderately hygroscopic) for SOA systems examined, increasing linearly with $\mathrm{O}: \mathrm{C}$ ratios determined using an Aerodyne High Resolution Time-of-Flight Mass Spectrometer (Massoli et al., 2010). In addition, for most SOA systems studied, single hygroscopicity parameters 


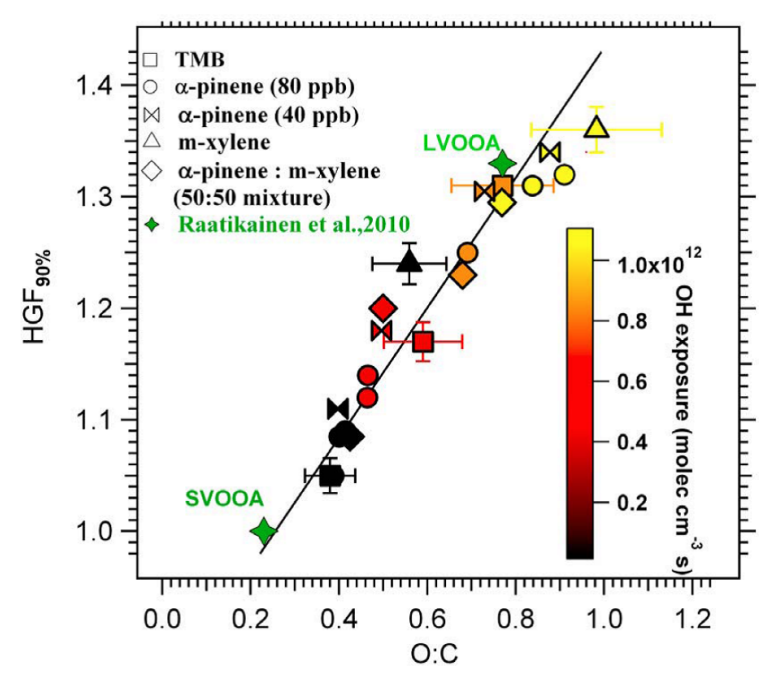

Figure 21. Growth factors of SOA measured using a H-TDMA at $90 \% \mathrm{RH}$ as a function of $\mathrm{O}: \mathrm{C}$ ratios. Reprint with permission by Massoli et al. (2010). Copyright 2010 American Geophysical Union.

$(\kappa)$ derived from H-TDMA measurements were smaller than these derived from CCN activity measurements (Massoli et al., 2010). Gaps between hygroscopic growth and cloud activation have also been observed in a number of other studies for SOA (Prenni et al., 2007; Juranyi et al., 2009; Petters et al., 2009; Wex et al., 2009; Good et al., 2010b; Whitehead et al., 2014; Zhao et al., 2016). One major reason for such gaps is that SOA usually contain substantial amount of slightly soluble materials, which only undergo partial dissolution under water-subsaturated conditions but can be dissolved to a significantly larger extent under water supersaturated conditions (when more water is available). Further discussion on reconciliation between hygroscopic growth and cloud activation can be found elsewhere (Petters et al., 2009; Wex et al., 2009). In another study (Y. J. Li et al., 2014), H-TDMA was used to explore hygroscopic properties of SOA formed via $\mathrm{OH}$ oxidation and direct photolysis of methoxylphenol (a model compound for biomass-burning aerosol) in the aqueous phase. For SOA generated from aqueous-phase $\mathrm{OH}$ oxidation, GF at $90 \% \mathrm{RH}$ was observed to increase linearly with the $\mathrm{O}: \mathrm{C}$ ratio, but the slope was around 3 times smaller than that reported by Massoli et al. (2010).

Since RH scanning is time-consuming, in most ambient applications H-TDMA measurements are usually carried out at a fixed RH (mostly $90 \%$ and $85 \%$ to a less extent) for one or a few dry particle diameters (Swietlicki et al., 2008; Kreidenweis and Asa-Awuku, 2014; Cheung et al., 2015). Usually at least one diameter in the center of Aitken mode $(\sim 50 \mathrm{~nm})$ and one size in the center of the accumulation mode $(\sim 150 \mathrm{~nm})$ are selected (Swietlicki et al., 2008$)$. The second DMA is typically scanned over a diameter range to cover a corresponding GF range between 0.9 and 2.0 (some- times up to 2.5 ) at $90 \%$ RH (Swietlicki et al., 2008). However, there have been a few studies which measured GF of size-selected ambient aerosols as a function of RH (Santarpia et al., 2004; Cheung et al., 2015). For example, Cheung et al. (2015) measured the GF of ambient aerosol particles (100 and $200 \mathrm{~nm})$ as a function of RH (10\%-93\%) in Hong Kong using a H-TDMA and found that the derived $\kappa$ values at (or above) $90 \% \mathrm{RH}$ were significantly larger than those derived at $40 \%$ RH. Each set of such measurements took $\sim 3 \mathrm{~h}$, limiting its application to periods with large fluctuation in aerosol composition (Cheung et al., 2015).

To further understand hygroscopic properties of ambient aerosol particles, aerosol hygroscopicity closure studies have been widely carried out (Swietlicki et al., 1999; Dick et al., 2000; Gysel et al., 2007; Cerully et al., 2011; Wu et al., 2013, 2016; Schurman et al., 2017; Hong et al., 2018). In such studies, hygroscopic growth measurements using H-TDMA are concurrently performed with aerosol chemical composition measurements, and measured growth factors can then be compared to these calculated based measured chemical composition. Aerosol chemical compositions were usually measured offline in the early stage (Swietlicki et al., 1999; Dick et al., 2000) and have been increasingly determined online with high time resolution using aerosol mass spectrometry (Gysel et al., 2007; Wu et al., 2013) and single-particle mass spectrometry (X. M. Wang et al., 2014; K. Li et al., 2018). For example, Wu et al. (2013) used a H-TDMA to measure aerosol hygroscopic growth at $90 \% \mathrm{RH}$ and an Aerodyne High Resolution Time-of-Flight Mass Spectrometer (HR-ToF-AMS) to measure size-resolved aerosol chemical composition at a middle-level mountain area in central Germany. Single hygroscopicity parameters, $\kappa_{\mathrm{htdma}}$, derived from growth factors measured using H-TDMA, were compared to those derived from aerosol composition $\left(\kappa_{\text {chem }}\right)$, assuming ideal mixing. If the average compositions of submicron particles were used to calculate $\kappa_{\text {chem }}$, reasonably good agreement between $\kappa_{\text {htdma }}$ and $\kappa_{\text {chem }}$ was found for $250 \mathrm{~nm}$ particles while no correlation was observed for $100 \mathrm{~nm}$ particles (Wu et al., 2013). If size-resolved aerosol compositions were used to calculate $\kappa_{\text {chem }}$, as shown in Fig. 22, good closure between $\kappa_{\text {chem }}$ and $\kappa_{\mathrm{htdma}}$ were found for all four particle sizes. Figure 22 also reveals that $\kappa_{\text {chem }}$ were significantly larger than $\kappa_{\text {htdma }}$, indicating that ideal mixing assumption may overestimate aerosol hygroscopic growth (Wu et al., 2013). Simultaneous H-TDMA and HR-ToF-AMS measurements were also carried out at a coastal suburban site in Hong Kong (Yeung et al., 2014a). Approximations for growth factors of organic aerosols, using the fraction of $\mathrm{m} / \mathrm{z} 44$, the oxygen-to-carbon ratio and PMF-resolved organic factors from HR-ToF-AMS measurements, did not yield better closure results, likely because of the overall dominance of sulfate during the whole measurement period.

H-TDMA measurements in Shanghai at wintertime showed that aerosol particles ( $250 \mathrm{~nm}$ in dry diameter) could be classified into two modes according to their hygroscopic- 

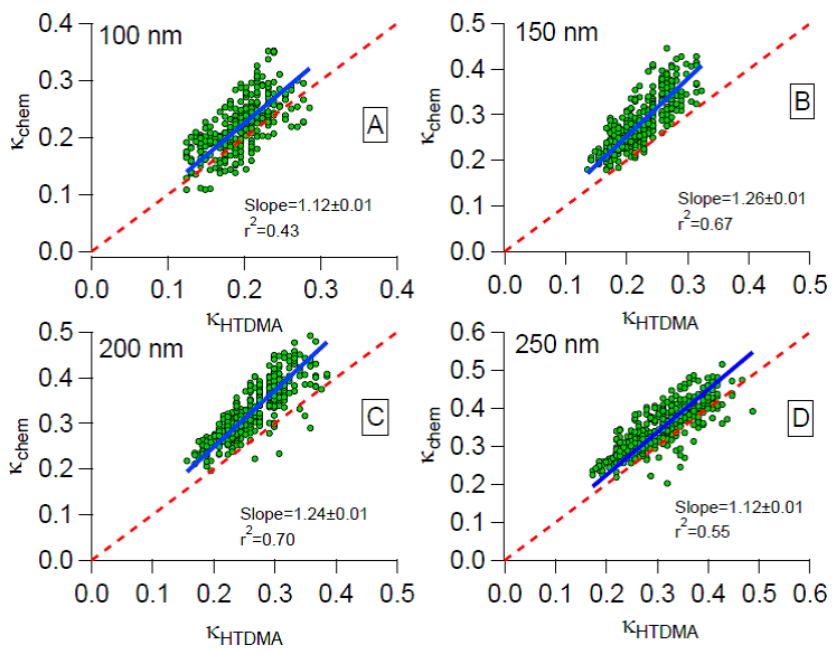

Figure 22. Comparison between $\kappa_{\text {chem }}$ (calculated using sizeresolved aerosol compositions) and $\kappa_{\text {htdma }}$ (derived from H-TDMA measurements) for aerosol particles with dry diameters of (a) 100, (b) 150 , (c) 200 and (d) $250 \mathrm{~nm}$. Reprint with permission by Wu et al. (2013).

ity (X. Wang et al., 2014). The first mode had growth factors of $\sim 1.05$ at $85 \% \mathrm{RH}$, mainly containing fresh elemental carbon and minerals, as revealed by measurements using a single-particle mass spectrometer (aerosol time-of-flight mass spectrometer). In contrast, the second mode had growth factors of $\sim 1.46$ at $85 \% \mathrm{RH}$ and were enriched with elemental carbon and organic carbon particles internally mixed with secondary inorganic materials.

\subsubsection{H-TDMAs with extended performance}

While most H-TDMAs only work at around room temperature, Weingartner et al. (2002) designed a H-TDMA which could measure hygroscopic growth of aerosol particle below $0{ }^{\circ} \mathrm{C}$ (temperature: -20 to $30^{\circ} \mathrm{C}$; $\mathrm{RH}: 10 \%-90 \%$ ). Measured hygroscopic growth factors showed good agreement with theoretical calculations for $\left(\mathrm{NH}_{4}\right)_{2} \mathrm{SO}_{4}, \mathrm{NaCl}$ and $\mathrm{NaNO}_{3}$ at both 20 and $-10^{\circ} \mathrm{C}$ (Gysel et al., 2002). This instrument was subsequently deployed at a high-alpine site ( $3580 \mathrm{~m}$ above sea level) to investigate hygroscopic properties of ambient aerosol particles at $-10^{\circ} \mathrm{C}$ (Weingartner et al., 2002), and the average GF at $85 \% \mathrm{RH}$ were measured to be $1.44,1.49$ and 1.53 for aerosol particles with dry diameters of 50,100 and $250 \mathrm{~nm}$.

$\mathrm{RH}$ in the troposphere frequently exceeds $90 \%$, and it is desirable to investigate hygroscopic growth of aerosol particles at $>90 \%$ RH. Hennig et al. (2005) developed a highhumidity TDMA which could be operated at $98 \% \mathrm{RH}$, and the absolute accuracy of RH at $98 \%$ was $\pm 1.2 \%$. It was found that within the uncertainties, the measured GF in the RH range of $84 \%-98 \%$ agreed well with theoretical values (Hennig et al., 2005). The Leipzig Aerosol Cloud In- teraction Simulator (LACIS), a laminar flow tube designed to study cloud formation and growth, could be operated at stable RH ranging from almost $0 \%$ up to $99.1 \%$ (Stratmann et al., 2004), and aerosol particles and/or droplets exiting the flow tube were detected using an optical particle sizer especially developed for this instrument. LACIS was employed to study hygroscopic growth of $\left(\mathrm{NH}_{4}\right)_{2} \mathrm{SO}_{4}$ and $\mathrm{NaCl}$ aerosol particles at $85.8 \% \mathrm{RH}-99.1 \% \mathrm{RH}$ (Wex et al., 2005). At $99 \%$ RH, measured GF values agreed well with these predicted assuming solution ideality for $\mathrm{NaCl}$, whereas for $\left(\mathrm{NH}_{4}\right)_{2} \mathrm{SO}_{4}$, solution ideality assumption would overestimate GF values by up to $20 \%$ (Wex et al., 2005). In a following study (Niedermeier et al., 2008), LACIS was used to investigate hygroscopic growth of sea salt aerosol up to $99.1 \% \mathrm{RH}$.

Long duration is required by the second DMA to measure size distributions of humidified aerosol particles, and therefore the H-TDMA technique is usually quite slow. It typically takes $\sim 30 \mathrm{~min}$ for a traditional H-TDMA to determine GF values at a given $\mathrm{RH}$ for five different dry diameters (Cerully et al., 2011; Pinterich et al., 2017b). Instruments with fast duty cycles are of great interest and have been developed and deployed (Sorooshian et al., 2008; Pinterich et al., 2017a, b). For example, after replacing the second DMA (used in the traditional H-TDMA) with a water-based fast integrated mobility spectrometer which could provide $1 \mathrm{~Hz}$ size distribution measurements (Pinterich et al., 2017a), the improved instrument, called the humidity-controlled fast integrated mobility spectrometer (HFIMS), only took $\sim 3 \mathrm{~min}$ to measure GF of particles with five different dry diameters at a given RH (Pinterich et al., 2017b).

Since the upper size limit is $<1000 \mathrm{~nm}$ for a typical DMA and GF values at $90 \% \mathrm{RH}$ can be $>2$ for atmospheric particles, most H-TDMAs can only be used for particles with dry diameters smaller than $500 \mathrm{~nm}$ (McFiggans et al., 2006; Swietlicki et al., 2008). Several instruments, which could measure hygroscopic growth of aerosol particles larger than $500 \mathrm{~nm}$ in dry diameter, have been developed (Kreisberg et al., 2001; Hegg et al., 2007; Massling et al., 2007; Snider and Petters, 2008; Kaaden et al., 2009; Kim et al., 2014). One obvious approach to overcome the DMA sizing limit is to use optical particle counters for particle sizing, as adopted by some previous studies (Kreisberg et al., 2001; Hegg et al., 2007; Snider and Petters, 2008). Another approach is to use aerodynamic particle sizers (APS) for particle sizing (Massling et al., 2007; Kaaden et al., 2009; Schladitz et al., 2011; Kim and Park, 2012). For example, a H-DMAAPS was developed to explore hygroscopic growth of large aerosol particles (Massling et al., 2007; Kaaden et al., 2009). As shown in Fig. 23, the dry aerosol flow was first delivered through a custom-built high-aerosol flow-DMA (HAFDMA) which could select particles with dry mobility diameters over $1000 \mathrm{~nm}$, and the dry aerosol flow exiting the DMA was split into two identical flows; the first flow was directly sampled by the first APS to measure the aerodynamic size 


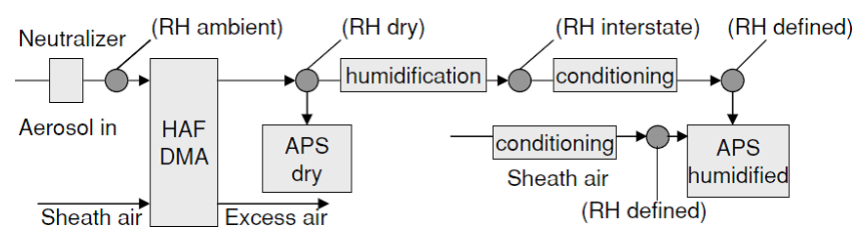

Figure 23. Schematic diagram of a H-DMA-APS apparatus. Reprint with permission by Kaaden et al. (2009). Copyright 2009 Blackwell Munksgaard.

distribution under dry conditions, and the second flow was first delivered through a humidifier to be humidified to a given RH (e.g., $90 \%$ ) and then sampled into the second APS so that the aerodynamic size distribution of the humidified aerosol was measured.

The utilization of H-TDMAs to measure aerosol hygroscopic growth factors assumes particle sphericity. Some particles in the atmosphere, such as mineral dust and soot, are known to be non-spherical, and therefore GF measured using H-TDMA may not correctly reflect the amount of aerosol liquid water (Weingartner et al., 1997; Rissler et al., 2005; Vlasenko et al., 2005; Koehler et al., 2009; Tritscher et al., 2011). Very recently, an instrument, called differential mobility analyzer-humidified centrifugal particles mass analyzer (DMA-HCPMA), was developed to measure mass change in submicron aerosol particles at different RH (10\%-95\%) (Vlasenko et al., 2017). In this setup, a dry aerosol flow was delivered through a DMA to produce quasi-monodisperse particles and then through an aerosol humidifier to be humidified to a give RH; after that, the aerosol flow was delivered through a centrifugal particle mass analyzer (which would classify aerosol particles according to their mass-tocharge ratios) (Olfert and Collings, 2005; Rissler et al., 2014; Kuwata, 2015) and then a CPC so that aerosol particle mass could be determined as a function of RH (Vlasenko et al., 2017). The measured mass growth factors were found to agree well with theoretical values for $\left(\mathrm{NH}_{4}\right)_{2} \mathrm{SO}_{4}$ and $\mathrm{NaCl}$, and this newly developed DMA-HCPMA setup was successfully deployed to explore hygroscopic properties of ambient aerosol particles (Vlasenko et al., 2017). It can be expected that DMA-HCPMA would significantly improve our knowledge of hygroscopicity of non-spherical aerosol particles.

\subsection{Optical properties}

Optical properties of aerosol particles depend on their size and refractive indices, both strongly affected by their hygroscopic properties. Measurements of aerosol optical properties as a function of $\mathrm{RH}$, indispensable for elucidating the impacts of aerosol particles on visibility and radiative balance, can be used to infer aerosol hygroscopicity. Several techniques have been developed and deployed, as discussed in this section.

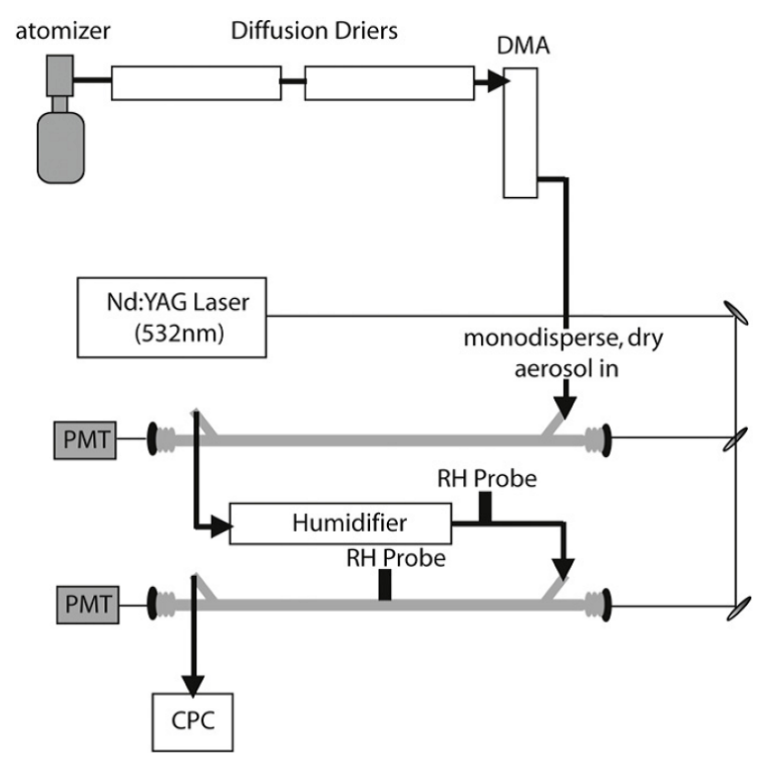

Figure 24. Schematic diagram of the apparatus used by Tolbert and co-workers to measure the dependence of aerosol light extinction on RH. Reprint with permission by Beaver et al. (2008). Copyright 2008 IOP Publishing Ltd.

\subsubsection{Extinction}

Cavity ring-down spectroscopy (CRDS), a highly sensitive method for optical extinction measurement, has been extensively employed for gas and aerosol detection (Brown, 2003; Baynard et al., 2006, 2007; Langridge et al., 2011; Sobanski et al., 2016; Peng et al., 2018). For a typical CRDS setup, a laser beam pulse is coupled into a high-finesse optical cavity (which has one high-reflectivity mirror on each end) from one end of the cavity, and the decay of the intensity of the light transmitted from the other end is monitored. The change in decay lifetimes of transmitted light intensity can be related to the extinction coefficient, $\alpha_{\text {ext }}$, using Eq. (3) (Baynard et al., 2007; Langridge et al., 2011):

$\alpha_{\mathrm{ext}}=\frac{R_{L}}{c}\left(\frac{1}{\tau}-\frac{1}{\tau_{0}}\right)$,

where $R_{L}$ is the ratio of the distance between the two mirrors to the length of the cavity filled with aerosol particles, $c$ is the speed of light $\left(\mathrm{m} \mathrm{s}^{-1}\right)$, and $\tau$ and $\tau_{0}$ are the measured decay lifetimes of light intensity with and without aerosol particles present in the cavity. If aerosol particles delivered into the cavity are monodisperse, the extinction coefficient of each individual particle, $\sigma_{\text {ext }}$, can be calculated using Eq. (4) (Freedman et al., 2009):

$\sigma_{\mathrm{ext}}=\frac{\sigma_{\mathrm{ext}}}{N_{p}}$,

where $N_{p}$ is the aerosol number concentration $\left(\mathrm{cm}^{-3}\right)$.

A CRD spectrometer was employed by Tolbert and coworkers to investigate the effects of RH on aerosol optical 
extinction at $532 \mathrm{~nm}$, and its schematic diagram is depicted in Fig. 24 (Beaver et al., 2008). The aerosol flow generated using an atomizer was delivered through diffusion dryers to reduce its $\mathrm{RH}$ to $<10 \%$ and passed through a DMA to produce quasi-monodisperse aerosol particles. The aerosol flow was then delivered into the first cavity to measure the aerosol optical extinction at $532 \mathrm{~nm}$ under dry conditions; after that, the aerosol flow entered a humidifier to be humidified to a given $\mathrm{RH}$ and was then delivered into the second cavity to measure the aerosol optical extinction under the humidified condition. In the final, the aerosol flow was sampled by a $\mathrm{CPC}$ to measure the number concentration. For $\left(\mathrm{NH}_{4}\right)_{2} \mathrm{SO}_{4}$ aerosol particles in the size range of $200-700 \mathrm{~nm}$, the measured optical growth factors at $80 \% \mathrm{RH}$, defined as the ratio of the extinction coefficient at $80 \% \mathrm{RH}$ to that under dry conditions, were found to be in good agreement with those calculated from diameter-based growth factors using Mie theory (Garland et al., 2007).

CRDS was used to examine the effect of RH on aerosol optical extinction for phthalic acid, pyromellitic acid and 4hydroxybenzoic acid aerosol particles in the size range of 150-500 nm (Beaver et al., 2008). The optical growth factors were found to be smaller for the three organic compounds examined, compared to $\left(\mathrm{NH}_{4}\right)_{2} \mathrm{SO}_{4}$. For example, for aerosol particles with a dry diameter of $335 \mathrm{~nm}$, optical growth factors at $80 \% \mathrm{RH}$ were measured to be 1.3 and 1.1 for phthalic and pyromellitic acid (Beaver et al., 2008), compared to 3.0 for $\left(\mathrm{NH}_{4}\right)_{2} \mathrm{SO}_{4}$. Optical extinction coefficients of 4-hydroxybenzoic acid particles at $80 \% \mathrm{RH}$ were smaller than those under dry conditions (Beaver et al., 2008), implying that morphological and structural change may occur for these particles during humidification. Similarly, optical growth factors of illite and kaolinite aerosol particles were found to be $<1$ at 50 and $68 \%$ RH (Attwood and Greenslade, 2011), due to structural rearrangement of clay mineral particles after water uptake. Optical growth factors of internally mixed aerosol particles, which contained $\left(\mathrm{NH}_{4}\right)_{2} \mathrm{SO}_{4}$ and organic materials, were also studied (Garland et al., 2007; Robinson et al., 2013, 2014). Another study (Michel Flores et al., 2012) measured optical growth factors (at wavelengths of 355 and $532 \mathrm{~nm}$ ) at 80 and $90 \%$ RH for aerosol particles with different extents of optical absorption ranging from purely scattering (e.g., $\left.\left(\mathrm{NH}_{4}\right)_{2} \mathrm{SO}_{4}\right)$ to highly absorbing (e.g., nigrosine) and found good agreement between measured optical growth factors and those calculated using Mie theory.

CRDS has also been widely deployed to investigate optical extinction of ambient aerosol particles at different $\mathrm{RH}$ (X. L. Zhang et al., 2014; Atkinson et al., 2015; Brock et al., 2016a). For example, an eight-channel CRD spectrometer was developed by NOAA Earth System Research Laboratory (Langridge et al., 2011). This instrument could measure aerosol optical growth factors at three wavelengths (405, 532 and $662 \mathrm{~nm}$ ) simultaneously and has been successfully deployed for aircraft measurements (Langridge et al., 2011).
In addition to CRDS, broadband cavity enhanced spectroscopy (BBCEAS), also called cavity enhanced differential optical absorption spectroscopy (CE-DOAS), is an alternative high-finesse cavity-based technique with high sensitivity in optical extinction measurements (Platt et al., 2009; Washenfelder et al., 2013, 2016). Compared to CRDS, one major advantage of BBCEAS is that optical extinction can be measured as a function of wavelength. BBCEAS, as described in detail elsewhere (Platt et al., 2009; Varma et al., 2013; Washenfelder et al., 2013, 2016; Zhao et al., 2014; Wang et al., 2017a; Z. Y. Li et al., 2018), has also been widely used in gas and aerosol measurements. Zhao et al. (2014) utilized BBCEAS to measure aerosol optical extinction at $641 \mathrm{~nm}$ as a function of $\mathrm{RH}$, and for $200 \mathrm{~nm}\left(\mathrm{NH}_{4}\right)_{2} \mathrm{SO}_{4}$, the measured optical growth factors agreed well with those calculated using Mie theory. The instrument was further deployed to simultaneously measure optical extinction of ambient submicrometer aerosol at $<20 \%$ and $85 \%$ RH at Hefei Radiation Observatory. The result is displayed in Fig. 25, suggesting that the optical growth factors at $85 \% \mathrm{RH}$ varied from $\sim 1$ to $>2.5$ during the campaign (Zhao et al., 2017).

\subsubsection{Scattering}

Humidified nephelometry, which was first developed as early as in the 1960s (Pilat and Charlson, 1966; Covert et al., 1972), has been widely used to measure aerosol light scattering coefficients at different RH (Rood et al., 1985; Carrico et al., 1998; Li-Jones et al., 1998; Day et al., 2000; Malm et al., 2000a, b; Koloutsou-Vakakis et al., 2001; FierzSchmidhauser et al., 2010a; Zieger et al., 2010, 2013; Kreidenweis and Asa-Awuku, 2014; Zhang et al., 2015; Titos et al., 2016). Due to its high time resolution, this technique is very suitable for online measurement of ambient aerosols. A very recent review paper (Titos et al., 2016) summarized and discussed theories, history, measurement uncertainties and ambient applications of this technique in a comprehensive manner. As a result, herein we only introduce in brief its basic principle, representative instrumental configurations and exemplary applications.

The scattering enhancement factor, $f(\mathrm{RH})$, defined as the ratio of the aerosol scattering coefficient at a given $\mathrm{RH}$ to that at dry conditions, is typically reported by humidified nephelometry measurements (Kreidenweis and AsaAwuku, 2014; Titos et al., 2016). Figure 26 shows the schematic diagram of a humidified three-wavelength integrating nephelometer (TSI 3563) at 450, 550 and $700 \mathrm{~nm}$ (Fierz-Schmidhauser et al., 2010c). The aerosol flow was first delivered through an aerosol humidifier which could increase the $\mathrm{RH}$ to $95 \%$ and then through an aerosol dryer to reduce the $\mathrm{RH}$ to below $40 \%$. After that, the aerosol flow was sampled into the nephelometer to measure aerosol scattering coefficients at three different wavelengths. The flow exiting the nephelometer was pulled through a mass flow controller (to control the sample flow rate) by a pump. The performance 


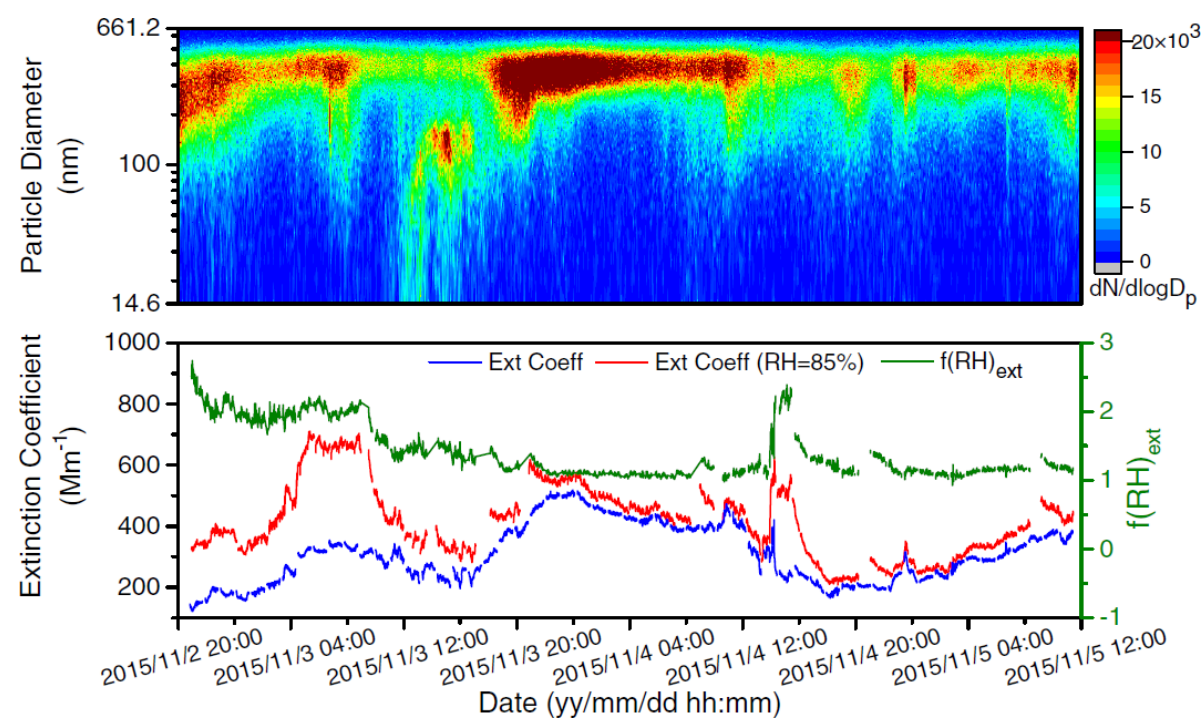

Figure 25. Aerosol properties measured at Hefei Radiation Observatory. Upper panel: aerosol number size distribution of submicrometer particles; lower panel: extinction coefficient of submicrometer particles under dry conditions (blue curve, left $y$ axis) and at $85 \%$ RH (red curve, left $y$ axis) and optical growth factors at $85 \%$ RH (green curve, right $y$ axis). Reprint with permission by Zhao et al. (2017). Copyright 2017 Optical Society of America.

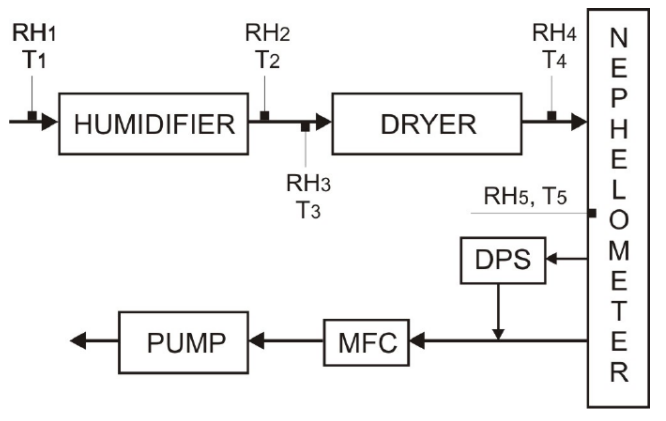

Figure 26. Schematic diagram of a humidified three-wavelength integrating nephelometer (DPS: dew point sensor; MFC: mass flow controller). Reprint with permission by Fierz-Schmidhauser et al. (2010c).

of the aerosol dryer could be adjusted to vary the RH of the flow entering the nephelometer, and thus scattering coefficients could be measured as a function of RH $(40 \%-$ $90 \%$ ); in addition, using such a configuration, light scattering properties of supersaturated aerosol particles, i.e., the hysteresis effect, could be examined (Fierz-Schmidhauser et al., 2010c). The humidified nephelometer was used to measure light scattering properties of monodisperse $\left(\mathrm{NH}_{4}\right)_{2} \mathrm{SO}_{4}$ and $\mathrm{NaCl}$ aerosol particles with dry diameters of 100,150 , 240 and $300 \mathrm{~nm}$, and the measured $f(\mathrm{RH})$ values agreed with these predicted using Mie theory (Fierz-Schmidhauser et al., 2010c). Some instruments could measure aerosol light scattering at different $\mathrm{RH}$ in a simultaneous manner, via using two or more nephelometers in parallel (Carrico et al., 1998).
A number of previous studies have carried out field measurements of $f(\mathrm{RH})$ at various locations over the globe (Zieger et al., 2013; Kreidenweis and Asa-Awuku, 2014; Titos et al., 2016). As summarized by Titos et al. (2016), $f(\mathrm{RH})$ values (for $80 \% \mathrm{RH}-85 \% \mathrm{RH}$ ) were larger for marine sites (ranging from 1.5 to 3.5), when compared with most continental sites; furthermore, $f(\mathrm{RH})$ values were found to be in the range of 1.1-2.1 for dust particles, and larger $f(\mathrm{RH})$ values observed for dust may be caused by the co-presence of sea salt aerosol. A field study (Li-Jones et al., 1998) carried out on Barbados (West Indies) found that $f(\mathrm{RH})$ values (for $\mathrm{RH}$ in the range of $67 \%-83 \%$ ) were very small (1.0-1.1) for mineral dust transported from North Africa, indicating that large variation in ambient RH may not lead to significant change in optical properties of mineral dust aerosol.

Since aerosol light scattering coefficients depend on particle size and refractive index in a complex manner even for spherical particles, it is not straightforward to link $f(\mathrm{RH})$ with the aerosol liquid water content (Kreidenweis and AsaAwuku, 2014). A number of studies (Malm and Day, 2001; Fierz-Schmidhauser et al., 2010b; Zieger et al., 2010; Chen et al., 2014; Kreidenweis and Asa-Awuku, 2014; Kuang et al., 2017, 2018) have discussed how measured $f(\mathrm{RH})$ values could be used to derive single hygroscopicity parameters $(\kappa)$ (Petters and Kreidenweis, 2007) and aerosol liquid water contents. In addition, it should be emphasized that humiditydependent aerosol scattering coefficients (as well as aerosol extinction and absorption coefficients) themselves are important parameters to assess the impacts of aerosols on visibility and direct radiative forcing. 


\subsubsection{Absorption}

Photoacoustic spectroscopy has been developed and deployed to measure aerosol optical absorption in a direct manner (Arnott et al., 2003; Lack et al., 2009; Lewis et al., 2009; Moosmuller et al., 2009; Gyawali et al., 2012; Langridge et al., 2013; Lack et al., 2014). In brief, the aerosol flow is continuously sampled into a cell which serves as an acoustic resonator section and illuminated by a modulated laser beam. The laser radiation absorbed by aerosol particles is transferred to the surrounding air as heat, leading to the generation of an acoustic wave which is amplified in the resonator and detected using a microphone (Moosmuller et al., 2009; Gyawali et al., 2012). The signal intensity measured by the microphone is proportional to optical absorption and can be used to derive aerosol optical absorption coefficients after proper calibration (Moosmuller et al., 2009; Gyawali et al., 2012). In principle, hygroscopic growth of aerosol particles at elevated RH would lead to increase in particle size and thus enhancement in aerosol optical absorption due to the lensing effect (Lewis et al., 2009). Nevertheless, several studies suggested that photoacoustic spectroscopy measurements at high RH are likely to significantly underestimate the actual aerosol optical absorption (Arnott et al., 2003; Lewis et al., 2009; Langridge et al., 2013). For example, Langridge et al. (2013) used photoacoustic spectroscopy at $532 \mathrm{~nm}$ to measure optical absorption of several types of aerosol particles with various hygroscopicity, morphology and refractive indices and found that the measured absorption exhibited strong low biases at high RH. The underestimation of optical absorption is due to that acoustic signals are affected by evaporation of aerosol liquid water when aerosol particles absorb radiation and get heated. As a result, Langridge et al. (2013) concluded that photoacoustic spectroscopy was not a suitable technique to measure aerosol optical absorption at elevated RH. Similarly, other techniques used for direct measurement of aerosol optical absorption, such as the filter-based method and photothermal interferometry, did not perform well at elevated RH either (Schmid et al., 2006; Sedlacek and Lee, 2007).

An indirect method has been developed (Khalizov et al., 2009; Xue et al., 2009; Brem et al., 2012; Chen et al., 2015) to explore the effect of RH on aerosol optical absorption, which was calculated as the difference between aerosol light extinction and scattering. In the setup developed by Brem et al. (2012), aerosol light extinction and scattering at three wavelengths $(467,530$ and $660 \mathrm{~nm})$ were measured at different RH using an optical extinction cell and a nephelometer. As RH was increased from 38 to $95 \%$, light absorption of nigrosine aerosol was enhanced by a factor of $\sim 1.24$ for all three wavelengths (Brem et al., 2012). In some other work (Khalizov et al., 2009; Xue et al., 2009; Chen et al., 2015), CRDS, instead of the optical extinction cell, was used to measure the aerosol optical extinction.

\subsection{Other aerosol-based techniques}

Black carbon (BC) aerosol is of great concern due to its impacts on human health and climate (Bond et al., 2013). The hygroscopicity of $\mathrm{BC}$, varying with atmospheric aging processes, largely determines its dry and wet deposition rates and thus lifetimes (Schwarz et al., 2010; Q. Q. Wang et al., 2014) and also affects its optical absorption through lensing effects (Redemann et al., 2001). Therefore, it is important to understand hygroscopic properties of $\mathrm{BC}$ aerosol in the troposphere; however, techniques discussed in Sect. 5.1-5.2 are not specific to BC-containing particles. Since typical BC mass fractions in submicrometer particles are only a few percentages, in general these techniques cannot provide specific information on ambient BC aerosol hygroscopicity.

Single-particle soot photometers (SP2), as described in a number of studies (Gao et al., 2007; Slowik et al., 2007; Schwarz et al., 2008; Moteki and Kondo, 2010), have been widely employed to measure the mass and mixing state of individual BC particles in the troposphere. In brief, when an aerosol particle which contains a detectable amount of refractory BC enters a SP2, it is heated by a laser beam (1064 nm) to the incandescence temperature, leading to the emission of thermal radiation. The intensity of the thermal radiation, proportional to the mass of refractory $\mathrm{BC}$, is monitored to quantify the amount of $\mathrm{BC}$ contained by individual particles. In addition, measurement of the light scattered by the particle during its initial interaction with the laser beam can be used to derive the optical diameter. Therefore, a SP2 measures both the mass of non-refractory $\mathrm{BC}$ and the optical diameter of each individual particle. In the last several years a few SP2-based instruments have been developed to measure hygroscopic properties of $\mathrm{BC}$ aerosol in specific (McMeeking et al., 2011; Liu et al., 2013a; Schwarz et al., 2015; Ohata et al., 2016), as introduced below.

A SP2 was coupled to a H-TDMA to measure hygroscopic properties of BC aerosol (McMeeking et al., 2011), and the experimental diagram is displayed in Fig. 27. The aerosol flow was dried to $<20 \% \mathrm{RH}$ and then passed through the first DMA to produce quasi-monodisperse aerosol with a specific size; after that, the aerosol flow was humidified to a specific $\mathrm{RH}$ and then passed through the second DMA. The aerosol flow exiting the second DMA was then split into two flows, sampled by a CPC and a SP2, respectively. The usage of SP2 enabled identification of $\mathrm{BC}$ aerosol particles, and mobility diameter changes in aerosol particles identified to be $\mathrm{BC}$ could be used to calculate hygroscopic growth factors specific to $\mathrm{BC}$ aerosol; alternatively, hygroscopic properties of $\mathrm{BC}$ aerosol could be obtained from the change in optical diameter measured by the SP2 (McMeeking et al., 2011). The H-TDMA-SP2 apparatus was deployed to investigate hygroscopic properties of BC aerosol in June-July 2011 at the Weybourne Atmospheric Observatory near the North Norfolk coastline. During this campaign two types of $\mathrm{BC}$ aerosol with distinctive hygroscopicity were observed (Liu et al., 
2013a). Hygroscopic growth factors at $90 \% \mathrm{RH}$ were measured to be $\sim 1.05$ for the first type $\mathrm{BC}$ aerosol and ranged from $\sim 1.25$ to $\sim 1.6$ for the second type, depending on the composition of soluble materials associated with BC particles (Liu et al., 2013a).

Schwarz et al. (2015) developed a humidified-dual SP2 setup (HD-SP2) to measure hygroscopic properties of BC aerosol. In this setup, one sample flow was dried, and optical diameters of each BC-containing particle were measured under dry conditions using the first SP2; the other sample flow was first humidified to a given RH (e.g., 90\%), and optical diameters of individual BC-containing particles were determined using the second SP2. Optical diameters of BC particles measured under dry and humidified conditions could then be used to determine hygroscopic properties specific to BC-containing particles. The HD-SP2 was deployed on the NASA DC-8 aircraft in the summer of 2013 to investigate hygroscopic properties of BC aerosol in North American wildfire plumes (Perring et al., 2017). An average $\kappa$ value of 0.04 was found for the sampled BC aerosol and was increased by $\sim 0.06$ after $40 \mathrm{~h}$ aging in the atmosphere (Perring et al., 2017).

In another study (Ohata et al., 2016), an aerosol particle mass analyzer (APM) was coupled to a humidified SP2 to investigate hygroscopic properties of $\mathrm{BC}$ aerosol. The experimental scheme employed can be summarized as below (Ohata et al., 2016): (i) the sample flow, dried to < $10 \% \mathrm{RH}$, was delivered through an APM to select particles with a given mass-to-charge ratio (with identical mass if multiple charged particles were excluded in data analysis); (ii) the aerosol flow exiting the APM was humidified to a given $\mathrm{RH}$ and sampled into a SP2 to measure optical diameters of BC-containing particles under humidified conditions. Since dry diameters of BC-containing particles could be calculated from the mass of particles selected using the APM, hygroscopic growth factors of $\mathrm{BC}$ aerosol could be consequently determined (Ohata et al., 2016).

\subsection{Discussion}

All the techniques covered in Sect. 5 can be (and have been) used in laboratory and field measurements. Since airborne particles are examined, aerosol water contents can be quantified for unsaturated and supersaturated samples using these techniques. Because these techniques rely on measurements of particle diameters to investigate hygroscopic properties, it can be non-trivial to determine aerosol liquid water content for nonspherical aerosol particles. In addition, they may not be sensitive enough to study water adsorption. Although in general these techniques do not measure chemical compositions themselves, a number of offline and online instruments, including advanced mass spectroscopic tools (e.g., aerosol mass spectrometers and single-particle mass spectrometers), are available to provide chemical information in parallel, sig- nificantly deepening our knowledge of hygroscopic properties of complex aerosols.

\section{Summary and final remarks}

Hygroscopicity is one of the most important physiochemical properties of atmospheric aerosols, largely determining their environmental and climatic impacts. In addition to atmospheric science, it is also of great concern in many other scientific and technical fields, such as surface science, heterogeneous catalysis, geochemistry/astrochemistry, and pharmaceutical and food science. A myriad of experimental techniques have been developed and employed to explore hygroscopic properties of aerosol particles for $\mathrm{RH}<100 \%$. In this paper we have reviewed experimental techniques for investigating aerosol hygroscopicity in a comprehensive manner.

Table 1 summarizes key features of major techniques for aerosol hygroscopicity studies so that one can get a quick overview of these techniques and understand roughly the advantages and disadvantages of each technique. Several techniques discussed in Sects. 2-5, such as Knudsen cell reactors, Beta-gauge and TEOM, are not included in Table 1, because up to now application of these techniques to investigate hygroscopic properties of atmospherically relevant particles is still very limited, or because they are only applicable to certain types of atmospheric particles. It is difficult to compare a number of techniques in a table, and our opinions are arguable; in addition, technical advances may change the picture. For example, conventional H-TDMA can only be used for aerosol particles less than $500 \mathrm{~nm}$, and as discussed in Sect. 5.1.2, recent development in long DMA makes it possible to explore hygroscopic properties of larger aerosol particles. In total, 19 techniques are included in Table 1, and several key features are summarized and compared, including the following.

1. Working principle: we briefly explain why and/or how each technique can be used to investigate aerosol hygroscopicity.

2. Sample status: the sample under investigation is a bulk solution, a sample deposited on proper substrates, levitated particles or aerosol particles.

3. Size range: the approximate size range of particles that can be explored using each technique. If the sample is a bulk solution or particles deposited on a substrate, the particle size range is practically not limited. Therefore, size range is only relevant for techniques which examine single particles (either deposited on proper substrates or levitated) and aerosol particles. We note that and Axson (2017) provided a nice summary of typical size ranges of aerosol particles for a number of techniques used for aerosol characterization. 


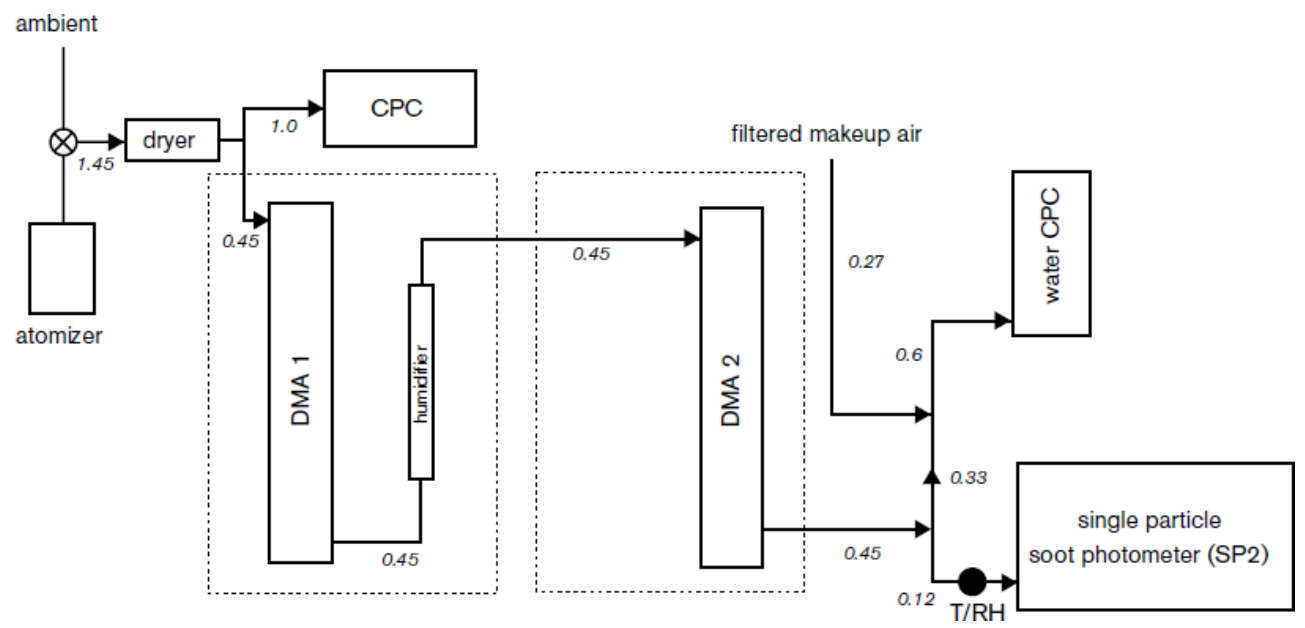

Figure 27. Schematic diagram of the H-TDMA-SP2 apparatus. Flow rates shown in this figure are in the unit of L/min. Reprint with permission by McMeeking et al. (2011).

4. Supersaturated samples: whether a technique can be used to investigate hygroscopic properties of supersaturated droplets (when RH is below DRH).

5. Nonspherical particles: whether a technique can be used to measure hygroscopic growth factors of nonspherical particles, i.e., whether the measurement of growth factors requires the assumption of particle sphericity.

6. Water adsorption: whether a technique is sensitive enough to investigate water adsorption down to a few monolayers.

7. Ambient application: whether a technique has been used to explore hygroscopic properties of ambient aerosol particles. Furthermore, is the measurement online or offline?

Future directions are outlined and discussed below in order to improve existing techniques and to develop new techniques for a better understanding of aerosol hygroscopicity.

1. The majority of instruments covered in this paper are not applicable to ambient aerosol particles. Future directions should focus on the development of aerosol hygroscopicity techniques that are field deployable, robust, and automatic. Especially up to now most ambient measurements conducted were ground-based, and therefore instruments which have high time resolution to be deployed on aircrafts (Langridge et al., 2011; Pinterich et al., 2017b; Wang et al., 2019) are highly needed.

2. The maximum RH that many techniques/instruments can currently reach is usually around $90 \%$, and recent studies have revealed the importance of hygroscopic growth measurements at RH very close to $100 \%$ (Wex et al., 2009). Therefore, efforts should be made to improve these instruments so that they can be employed to investigate hygroscopic properties at very high $\mathrm{RH}$ (e.g., up to $99 \% \mathrm{RH}$ ). Furthermore, currently RH measurements typically have an absolute uncertainty of $1 \%$ or larger, and uncertainties in RH measurement would affect hygroscopic growth factors reported at a given $\mathrm{RH}$, especially for high RH at which growth factors are more sensitive to RH; therefore, advancement in RH measurements (Liang et al., 2018) will contribute to the improvement in aerosol hygroscopicity measurement techniques.

3. Temperatures in the troposphere range from $\sim 200$ to $>300 \mathrm{~K}$, and temperature has been found to have a profound effect on particle phase state and thus liquid water content. Nevertheless, most techniques available currently, especially those which investigate hygroscopic properties of aerosol particles, can only be operated at around room temperature. Further instrumental development, which would enable hygroscopic growth measurements at lower temperatures, is warranted.

4. Most techniques are operated under ambient pressure, while many processes involved aerosol particles are often carried out at pressures substantially lower than atmospheric pressure (Zhao et al., 2009; Schilling and Winterer, 2014; Rosenberger et al., 2018). As a result, new techniques that allow direct measurements of hygroscopic properties at lower pressure are needed for better characterization of aerosol hygroscopicity under conditions with reduced pressure. Such instruments would also be very valuable for characterizing aerosol particles at high altitudes where the pressure is significantly lower than the ground level. 
Table 1. Summary and comparison of key features of major techniques for aerosol hygroscopicity measurements. Please refer to Sect. 6 for further information.

\begin{tabular}{|c|c|c|c|c|}
\hline & isopiestic method & nonisopiestic method & physisorption analyzer & katharometer \\
\hline (1) working principle & measure water vapor & measure water vapor & measure water vapor change & measure water vapor change \\
\hline & pressure of a solution & pressure of a solution & when exposure to particles & when exposure to particles \\
\hline (2) sample status & bulk solution & bulk solution & particles deposited on substrates & particles deposited on substrates \\
\hline (3) size range & not applicable & not applicable & not applicable & not applicable \\
\hline (4) supersaturated samples & No & No & No & Yes \\
\hline (5) nonspherical particles & Yes & Yes & Yes & Yes \\
\hline (6) water adsorption & No & No & Yes & No \\
\hline \multirow[t]{2}{*}{ (7) ambient application } & No & No & Yes (offline) & Yes (offline) \\
\hline & analytical balance & thermogravimetric analysis & QCM & optical microscopy \\
\hline (1) working principle & $\begin{array}{l}\text { measure sample mass } \\
\text { at different } \mathrm{RH}\end{array}$ & $\begin{array}{l}\text { measure sample mass } \\
\text { at different } \mathrm{RH}\end{array}$ & $\begin{array}{l}\text { measure sample mass } \\
\text { at different } \mathrm{RH}\end{array}$ & $\begin{array}{l}\text { monitor particle morphology } \\
\text { at different RH }\end{array}$ \\
\hline (2) sample status & $\begin{array}{l}\text { particles deposited } \\
\text { on substrates }\end{array}$ & $\begin{array}{l}\text { particles deposited } \\
\text { on substrates }\end{array}$ & $\begin{array}{l}\text { particles deposited } \\
\text { on substrates }\end{array}$ & $\begin{array}{l}\text { particles deposited } \\
\text { on substrates }\end{array}$ \\
\hline (3) size range & not applicable & not applicable & not applicable & $>1 \mu \mathrm{m}$ \\
\hline (4) supersaturated samples & No & No & No & Yes \\
\hline (5) nonspherical particles & Yes & Yes & Yes & No \\
\hline (6) water adsorption & No & Yes & Yes & No \\
\hline \multirow[t]{2}{*}{ (7) ambient application } & Yes (offline) & Yes (offline) & Yes (offline) & Yes (offline) \\
\hline & electron microscopy & AFM & X-ray microscopy & FTIR spectroscopy \\
\hline (1) working principle & $\begin{array}{l}\text { monitor particle morphology } \\
\text { at different RH }\end{array}$ & $\begin{array}{l}\text { monitor particle morphology } \\
\text { at different RH }\end{array}$ & $\begin{array}{l}\text { monitor particle morphology } \\
\text { at different RH }\end{array}$ & $\begin{array}{l}\text { monitor IR spectra of the } \\
\text { sample at different } \mathrm{RH}\end{array}$ \\
\hline (2) sample status & $\begin{array}{l}\text { particles deposited } \\
\text { on substrates }\end{array}$ & $\begin{array}{l}\text { particles deposited } \\
\text { on substrates }\end{array}$ & $\begin{array}{l}\text { particles deposited } \\
\text { on substrates }\end{array}$ & $\begin{array}{l}\text { particles deposited } \\
\text { on substrates }\end{array}$ \\
\hline (3) size range & $>10 \mathrm{~nm}$ & $>10 \mathrm{~nm}$ & $>200 \mathrm{~nm}$ & not applicable \\
\hline (4) supersaturated samples & Yes & Yes & Yes & Yes \\
\hline (5) nonspherical particles & No & No & No & Yes \\
\hline (6) water adsorption & No & No & No & Yes \\
\hline \multirow[t]{2}{*}{ (7)ambient application } & Yes (offline) & Yes (offline) & Yes (offline) & Yes (offline) \\
\hline & Raman spectroscopy & EDB & optical levitation & acoustic levitation \\
\hline (1) working principle & $\begin{array}{l}\text { monitor Raman spectra of } \\
\text { the sample at different } \mathrm{RH}\end{array}$ & $\begin{array}{l}\text { measure the mass of levitated particles } \\
\text { as different RH }\end{array}$ & $\begin{array}{l}\text { measure diameters of levitated } \\
\text { particles as different } \mathrm{RH}\end{array}$ & $\begin{array}{l}\text { measure diameters of levitated } \\
\text { particles as different } \mathrm{RH}\end{array}$ \\
\hline (2) sample status & particles deposited on substrates & levitated particles & levitated particles & levitated particles \\
\hline (3) size range & not applicable & a few to tens $\mu \mathrm{m}$ & one to tens $\mu \mathrm{m}$ & $>20 \mu \mathrm{m}$ \\
\hline (4) supersaturated samples & Yes & Yes & Yes & Yes \\
\hline (5) nonspherical particles & Yes & Yes & No & No \\
\hline (6) water adsorption & No & No & No & No \\
\hline \multirow[t]{2}{*}{ (7) ambient application } & Yes (offline) & No & No & No \\
\hline & H-TDMA & light extinction & light scattering & \\
\hline (1) working principle & $\begin{array}{l}\text { measure aerosol diameters } \\
\text { at different } \mathrm{RH}\end{array}$ & $\begin{array}{l}\text { measure aerosol light extinction } \\
\text { at different RH }\end{array}$ & $\begin{array}{l}\text { measure aerosol light scattering } \\
\text { properties at different RH }\end{array}$ & \\
\hline (2) sample status & aerosol particles & aerosol particles & aerosol particles & \\
\hline (3) size range & $<1 \mu \mathrm{m}$ & a few nm to a few $\mu \mathrm{m}$ & a few nm to a few $\mu \mathrm{m}$ & \\
\hline (4) RH lower than DRH & Yes & Yes & Yes & \\
\hline (5) nonspherical particles & No & No & No & \\
\hline (6) water adsorption & No & No & No & \\
\hline (7) ambient application & Yes (online) & Yes (online) & Yes (online) & \\
\hline
\end{tabular}

5. Aerosol hygroscopicity is a property that depends on chemical compositions and its measurements can be affected by phase state and viscosity of the particles. Application of multiple techniques to examine the same type of atmospherically relevant particles will deepen our understanding of aerosol hygroscopicity. In addition, simultaneous measurements of chemical composition and other physicochemical properties (e.g., particle phase state and viscosity) of aerosol particles of different hygroscopicity can be very valuable.

6. As shown in this review paper, many instruments employed to probe aerosol hygroscopicity are custom built; furthermore, even for the same type of instruments, op- erational protocols may vary at different groups. Instrumental comparisons, proven to be a good approach to validate instrumental performance and identify potential issues, have been carried out for H-TDMAs (Duplissy et al., 2009; Massling et al., 2011), and similar intercomparison should be performed for other techniques and instruments. Furthermore, standardized procedures for calibration, operation, data analysis and quality assurance, if can be formulated, would help increase data quality for aerosol hygroscopicity measurements.

Data availability. This is a review paper, and all the data used come from the literature cited. 
Author contributions. MT and CKC conceived and coordinated this paper; MT, Chak KC, YJL, HS, QM and ZW wrote the paper with contribution from all the other coauthors.

Competing interests. The authors declare that they have no conflict of interest.

Acknowledgements. This is contribution no. IS-2748 from GIGCAS.

Financial support. This research has been supported by the National Natural Science Foundation of China (grant nos. 91644106, 91744204, 4167517, 41875142, and 91844301), the Chinese Academy of Sciences international collaborative project (grant no. 132744KYSB20160036), the Guangdong Foundation for Program of Science and Technology Research (grant no. 2017B030314057), and the State Key Laboratory of Organic Geochemistry (grant no. SKLOG2016-A05). Mingjin Tang would like to thank the CAS Pioneer Hundred Talents program for providing a starting grant.

Review statement. This paper was edited by Paola Formenti and reviewed by Defeng Zhao and one anonymous referee.

\section{References}

Adachi, K., Freney, E. J., and Buseck, P. R.: Shapes of internally mixed hygroscopic aerosol particles after deliquescence, and their effect on light scattering, Geophys. Res. Lett., 38, L13804, doi:13810.11029/12011g1047540, 2011.

Adams, J. R. and Merz, A. R.: Hygroscopicity of Fertilizer Materials and Mixtures, Ind. Eng. Chem., 21, 305-307, 1929.

Ahlneck, C. and Zografi, G.: The molecular basis of moisture effects on the physical and chemical stability of drugs in the solid state, Int. J. Pharm., 62, 87-95, 1990.

Ahn, K.-H., Kim, S.-M., Jung, H.-J., Lee, M.-J., Eom, H.-J., Maskey, S., and Ro, C.-U.: Combined Use of Optical and Electron Microscopic Techniques for the Measurement of Hygroscopic Property, Chemical Composition, and Morphology of Individual Aerosol Particles, Anal. Chem., 82, 7999-8009, 2010.

Al-Abadleh, H. A. and Grassian, V. H.: Heterogeneous Reaction of $\mathrm{NO}_{2}$ on Hexane Soot: A Knudsen Cell and FT-IR Study, J. Phys. Chem. A, 104, 11926-11933, 2000.

Al-Abadleh, H. A., Krueger, B. J., Ross, J. L., and Grassian, V. H.: Phase transitions in calcium nitrate thin films, Chem. Commun., 2796-2797, 2003.

Alfarra, M. R., Good, N., Wyche, K. P., Hamilton, J. F., Monks, P. S., Lewis, A. C., and McFiggans, G.: Water uptake is independent of the inferred composition of secondary aerosols derived from multiple biogenic VOCs, Atmos. Chem. Phys., 13, 1176911789, https://doi.org/10.5194/acp-13-11769-2013, 2013.

Allan, M. and Mauer, L. J.: Comparison of methods for determining the deliquescence points of single crystalline ingredients and blends, Food Chem., 195, 29-38, 2016.
Amdur, S.: Determination of solute properties by vapor pressure measurements of the solvent in dilute solutions, J. Chem. Phys., 61, 3445-3449, 1974.

Apelblat, A.: The vapor pressures of water over saturated solutions of barium chloride, magnesium nitrate, calcium nitrate, potassium carbonate, and zinc sulfate at temperatures from $283 \mathrm{~K}$ to 323 K, J. Chem. Thermodyn., 24, 619-626, 1992.

Arenas, K. J. L., Schill, S. R., Malla, A., and Hudson, P. K.: Deliquescence Phase Transition Measurements by Quartz Crystal Microbalance Frequency Shifts, J. Phys. Chem. A, 116, 76587667, 2012.

Arnott, W. P., Moosmuller, H., Sheridan, P. J., Ogren, J. A., Raspet, R., Slaton, W. V., Hand, J. L., Kreidenweis, S. M., and Collett, J. L.: Photoacoustic and filter-based ambient aerosol light absorption measurements: Instrument comparisons and the role of relative humidity, J. Geophys. Res.-Atmos., 108, 4034, https://doi.org/10.1029/2002JD002165, 2003.

Asad, A., Mmereki, B. T., and Donaldson, D. J.: Enhanced uptake of water by oxidatively processed oleic acid, Atmos. Chem. Phys., 4, 2083-2089, https://doi.org/10.5194/acp-4-2083-2004, 2004.

Ashkin, A.: Acceleration and trapping of particles by radiation pressure, Phys. Rev. Lett., 24, 156-159, 1970.

Ashkin, A.: History of optical trapping and manipulation of smallneutral particle, atoms, and molecules, IEEE J. Sel. Top. Quant., 6, 841-856, 2000.

Ashkin, A. and Dziedzic, J. M.: Optical levitation by radiation pressure, Appl. Phys. Lett., 19, 283-285, 1971.

Ashkin, A. and Dziedzic, J. M.: Optical levitation of liquid droplets by radiation pressure, Science, 187, 1073-1075, 1975.

Atkins, P. W.: Physical Chemistry (Sixith Edition), Oxford University Press, Oxford, UK, 1998.

Atkinson, D. B., Radney, J. G., Lum, J., Kolesar, K. R., Cziczo, D. J., Pekour, M. S., Zhang, Q., Setyan, A., Zelenyuk, A., and Cappa, C. D.: Aerosol optical hygroscopicity measurements during the 2010 CARES campaign, Atmos. Chem. Phys., 15, 40454061, https://doi.org/10.5194/acp-15-4045-2015, 2015.

Attwood, A. R. and Greenslade, M. E.: Optical Properties and Associated Hygroscopicity of Clay Aerosols, Aerosol Sci. Technol., 45, 1350-1359, 2011.

Ault, A. P. and Axson, J. L.: Atmospheric Aerosol Chemistry: Spectroscopic and Microscopic Advances, Anal. Chem., 89, 430-452, 2017.

Ault, A. P., Zhao, D. F., Ebben, C. J., Tauber, M. J., Geiger, F. M., Prather, K. A., and Grassian, V. H.: Raman microspectroscopy and vibrational sum frequency generation spectroscopy as probes of the bulk and surface compositions of size-resolved sea spray aerosol particles, Phys. Chem. Chem. Phys., 15, 6206-6214, 2013.

Baynard, T., Garland, R. M., Ravishankara, A. R., Tolbert, M. A., and Lovejoy, E. R.: Key factors influencing the relative humidity dependence of aerosol light scattering, Geophys. Res. Lett., 33, L06813, https://doi.org/10.1029/2005GL024898, 2006.

Baynard, T., Lovejoy, E. R., Pettersson, A., Brown, S. S., Lack, D., Osthoff, H., Massoli, P., Ciciora, S., Dube, W. P., and Ravishankara, A. R.: Design and application of a pulsed cavity ringdown aerosol extinction spectrometer for field measurements, Aerosol Sci. Technol., 41, 447-462, 2007.

Beaver, M. R., Garland, R. M., Hasenkopf, C. A., Baynard, T., Ravishankara, A. R., and Tolbert, M. A.: A laboratory investigation 
of the relative humidity dependence of light extinction by organic compounds from lignin combustion, Environ. Res. Lett., 3, 045003, https://doi.org/10.1088/1748-9326/3/4/045003, 2008.

Bechtold, M. F. and Newton, R. F.: The vapor pressures of salt solutions, J. Am. Chem. Soc., 62, 1390-1393, 1940.

Bedoya-Velásquez, A. E., Navas-Guzmán, F., Granados-Muñoz, M. J., Titos, G., Román, R., Casquero-Vera, J. A., Ortiz-Amezcua, P., Benavent-Oltra, J. A., de Arruda Moreira, G., MontillaRosero, E., Hoyos, C. D., Artiñano, B., Coz, E., Olmo-Reyes, F. J., Alados-Arboledas, L., and Guerrero-Rascado, J. L.: Hygroscopic growth study in the framework of EARLINET during the SLOPE I campaign: synergy of remote sensing and in situ instrumentation, Atmos. Chem. Phys., 18, 7001-7017, https://doi.org/10.5194/acp-18-7001-2018, 2018.

Bertram, A. K., Martin, S. T., Hanna, S. J., Smith, M. L., Bodsworth, A., Chen, Q., Kuwata, M., Liu, A., You, Y., and Zorn, S. R.: Predicting the relative humidities of liquid-liquid phase separation, efflorescence, and deliquescence of mixed particles of ammonium sulfate, organic material, and water using the organic-to-sulfate mass ratio of the particle and the oxygen-tocarbon elemental ratio of the organic component, Atmos. Chem. Phys., 11, 10995-11006, https://doi.org/10.5194/acp-11-109952011, 2011.

Bertram, T. H. and Thornton, J. A.: Toward a general parameterization of $\mathrm{N}_{2} \mathrm{O}_{5}$ reactivity on aqueous particles: the competing effects of particle liquid water, nitrate and chloride, Atmos. Chem. Phys., 9, 8351-8363, https://doi.org/10.5194/acp-9-8351-2009, 2009.

Beyer, K. D., Schroeder, J. R., and Kissinger, J. A.: TemperatureDependent Deliquescence Relative Humidities and Water Activities Using Humidity Controlled Thermogravimetric Analysis with Application to Malonic Acid, J. Phys. Chem. A, 118, 24882497, 2014.

Bilde, M., Barsanti, K., Booth, M., Cappa, C. D., Donahue, N. M., Emanuelsson, E. U., McFiggans, G., Krieger, U. K., Marcolli, C., Topping, D., Ziemann, P., Barley, M., Clegg, S., Dennis-Smither, B., Hallquist, M., Hallquist, Å. M., Khlystov, A., Kulmala, M., Mogensen, D., Percival, C. J., Pope, F., Reid, J. P., Ribeiro da Silva, M. A. V., Rosenoern, T., Salo, K., Soonsin, V. P., Yli-Juuti, T., Prisle, N. L., Pagels, J., Rarey, J., Zardini, A. A., and Riipinen, I.: Saturation Vapor Pressures and Transition Enthalpies of Low-Volatility Organic Molecules of Atmospheric Relevance: From Dicarboxylic Acids to Complex Mixtures, Chem. Rev., 115, 4115-4156, 2015a.

Bilde, M., Barsanti, K., Booth, M., Cappa, C. D., Donahue, N. M., Emanuelsson, E. U., McFiggans, G., Krieger, U. K., Marcolli, C., Topping, D., Ziemann, P., Barley, M., Clegg, S., Dennis-Smither, B., Hallquist, M., Hallquist, Å. M., Khlystov, A., Kulmala, M., Mogensen, D., Percival, C. J., Pope, F., Reid, J. P., Ribeiro da Silva, M. A. V., Rosenoern, T., Salo, K., Soonsin, V. P., Yli-Juuti, T., Prisle, N. L., Pagels, J., Rarey, J., Zardini, A. A., and Riipinen, I.: Saturation Vapor Pressures and Transition Enthalpies of Low-Volatility Organic Molecules of Atmospheric Relevance: From Dicarboxylic Acids to Complex Mixtures, Chem. Rev., 115, 4115-4156, 2015b.

Bond, T. C., Doherty, S. J., Fahey, D. W., Forster, P. M., Berntsen, T., DeAngelo, B. J., Flanner, M. G., Ghan, S., Karcher, B., Koch, D., Kinne, S., Kondo, Y., Quinn, P. K., Sarofim, M. C., Schultz, M. G., Schulz, M., Venkataraman, C., Zhang, H., Zhang, S., Bel- louin, N., Guttikunda, S. K., Hopke, P. K., Jacobson, M. Z., Kaiser, J. W., Klimont, Z., Lohmann, U., Schwarz, J. P., Shindell, D., Storelvmo, T., Warren, S. G., and Zender, C. S.: Bounding the role of black carbon in the climate system: A scientific assessment, J. Geophys. Res.-Atmos., 118, 5380-5552, 2013.

Braban, C. F., Abbatt, J. P. D., and Cziczo, D. J.: Deliquescence of ammonium sulfate particles at sub-eutectic temperatures, Geophys. Res. Lett., 28, 3879-3882, 2001.

Brem, B. T., Gonzalez, F. C. M., Meyers, S. R., Bond, T. C., and Rood, M. J.: Laboratory-Measured Optical Properties of Inorganic and Organic Aerosols at Relative Humidities up to $95 \%$, Aerosol Sci. Technol., 46, 178-190, 2012.

Brock, C. A., Wagner, N. L., Anderson, B. E., Attwood, A. R., Beyersdorf, A., Campuzano-Jost, P., Carlton, A. G., Day, D. A., Diskin, G. S., Gordon, T. D., Jimenez, J. L., Lack, D. A., Liao, J., Markovic, M. Z., Middlebrook, A. M., Ng, N. L., Perring, A. E., Richardson, M. S., Schwarz, J. P., Washenfelder, R. A., Welti, A., Xu, L., Ziemba, L. D., and Murphy, D. M.: Aerosol optical properties in the southeastern United States in summer - Part 1: Hygroscopic growth, Atmos. Chem. Phys., 16, 49875007, https://doi.org/10.5194/acp-16-4987-2016, 2016a.

Brock, C. A., Wagner, N. L., Anderson, B. E., Beyersdorf, A., Campuzano-Jost, P., Day, D. A., Diskin, G. S., Gordon, T. D., Jimenez, J. L., Lack, D. A., Liao, J., Markovic, M. Z., Middlebrook, A. M., Perring, A. E., Richardson, M. S., Schwarz, J. P., Welti, A., Ziemba, L. D., and Murphy, D. M.: Aerosol optical properties in the southeastern United States in summer Part 2: Sensitivity of aerosol optical depth to relative humidity and aerosol parameters, Atmos. Chem. Phys., 16, 5009-5019, https://doi.org/10.5194/acp-16-5009-2016, 2016b.

Brooks, S. D., Wise, M. E., Cushing, M., and Tolbert, M. A.: Deliquescence behavior of organic/ammonium sulfate aerosol, Geophys. Res. Lett., 29, 1917, https://doi.org/10.1029/2002GL014733, 2002.

Brotton, S. J. and Kaiser, R. I.: In Situ Raman Spectroscopic Study of Gypsum $(\mathrm{CaSO} 4 * 2 \mathrm{H} 2 \mathrm{O})$ and Epsomite $(\mathrm{MgSO} 4 * 7 \mathrm{H} 2 \mathrm{O}) \mathrm{De}-$ hydration Utilizing an Ultrasonic Levitator, J. Phys. Chem. Lett., 4, 669-673, 2013.

Brown, J. K. M. and Hovmoller, M. S.: Epidemiology - Aerial dispersal of pathogens on the global and continental scales and its impact on plant disease, Science, 297, 537-541, 2002.

Brown, S. S.: Absorption spectroscopy in high-finesse cavities for atmospheric studies, Chem. Rev., 103, 5219-5238, 2003.

Bruzewicz, D. A., Checco, A., Ocko, B. M., Lewis, E. R., McGraw, R. L., and Schwartz, S. E.: Reversible uptake of water on $\mathrm{NaCl}$ nanoparticles at relative humidity below deliquescence point observed by noncontact environmental atomic force microscopy, J. Chem. Phys., 134, 044702, https://doi.org/10.1063/1.3524195, 2011.

Buajarern, J., Mitchem, L., Ward, A. D., Nahler, N. H., McGloin, D., and Reid, J. P.: Controlling and characterizing the coagulation of liquid aerosol droplets, J. Chem. Phys., 125, 114506, https://doi.org/10.1063/1.2336772, 2006.

Buajarern, J., Mitchem, L., and Reid, J. P.: Characterizing the formation of organic layers on the surface of inorganic/aqueous aerosols by Raman spectroscopy, J. Phys. Chem. A, 111, 1185211859, 2007.

Burnham, D. R. and McGloin, D.: Radius measurements of optically trapped aerosols through Brownian motion, New J. Phys., 
11, 063022, https://doi.org/10.1088/1367-2630/11/6/063022, 2009.

Butler, J. R., Mitchem, L., Hanford, K. L., Treuel, L., and Reid, J. P.: In situ comparative measurements of the properties of aerosol droplets of different chemical composition, Faraday Discuss., 137, 351-366, 2008.

Cai, C. and Zhang, Y.: Application of optical tweezers technology in physical chemistry characterization of aerosol, Chinese Optics, 10, 641-655, 2017.

Carrico, C. M., Rood, M. J., and Ogren, J. A.: Aerosol light scattering properties at Cape Grim, Tasmania, during the First Aerosol Characterization Experiment (ACE 1), J. Geophys. Res.-Atmos., 103, 16565-16574, 1998.

Carvalho, T. C., Peters, J. I., and Williams, R. O.: Influence of particle size on regional lung deposition - What evidence is there?, Int. J. Pharm., 406, 1-10, 2011.

Cerully, K. M., Raatikainen, T., Lance, S., Tkacik, D., Tiitta, P., Petäjä, T., Ehn, M., Kulmala, M., Worsnop, D. R., Laaksonen, A., Smith, J. N., and Nenes, A.: Aerosol hygroscopicity and CCN activation kinetics in a boreal forest environment during the 2007 EUCAARI campaign, Atmos. Chem. Phys., 11, 12369-12386, https://doi.org/10.5194/acp-11-12369-2011, 2011.

Chan, C. K., Kwok, C. S., and Chow, A. H. L.: Study of hygroscopic properties of aqueous mixtures of disodium fluorescein and sodium chloride using an electrodynamic balance, Pharm. Res., 14, 1171-1175, 1997.

Chan, M. N. and Chan, C. K.: Mass transfer effects in hygroscopic measurements of aerosol particles, Atmos. Chem. Phys., 5, 2703-2712, https://doi.org/10.5194/acp-5-2703-2005, 2005.

Chen, D. B., Haugstad, G., Li, Z. J., and Suryanarayanan, R.: Water Sorption Induced Transformations in Crystalline Solid Surfaces: Characterization by Atomic Force Microscopy, J. Pharm. Sci., 99, 4032-4041, 2010.

Chen, H., Hu, D. W., Wang, L., Mellouki, A., and Chen, J. M.: Modification in light absorption cross section of laboratory-generated black carbon-brown carbon particles upon surface reaction and hydration, Atmos. Environ., 116, 253-261, 2015.

Chen, H. H., Nanayakkara, C. E., and Grassian, V. H.: Titanium Dioxide Photocatalysis in Atmospheric Chemistry, Chem. Rev., 112, 5919-5948, 2012.

Chen, J., Zhao, C. S., Ma, N., and Yan, P.: Aerosol hygroscopicity parameter derived from the light scattering enhancement factor measurements in the North China Plain, Atmos. Chem. Phys., 14, 8105-8118, https://doi.org/10.5194/acp-14-8105-2014, 2014.

Cheng, Y. F., Wiedensohler, A., Eichler, H., Heintzenberg, J., Tesche, M., Ansmann, A., Wendisch, M., Su, H., Althausen, D., Herrmann, H., Gnauk, T., Bruggemann, E., Hu, M., and Zhang, Y. H.: Relative humidity dependence of aerosol optical properties and direct radiative forcing in the surface boundary layer at Xinken in Pearl River Delta of China: An observation based numerical study, Atmos. Environ., 42, 6373-6397, 2008.

Cheng, Y. F., Su, H., Koop, T., Mikhailov, E., and Poschl, U.: Size dependence of phase transitions in aerosol nanoparticles, Nat. Commun., 6, 5923, https://doi.org/10.1038/ncomms6923, 2015.

Cheng, Y. F., Zheng, G. J., Wei, C., Mu, Q., Zheng, B., Wang, Z. B., Gao, M., Zhang, Q., He, K. B., Carmichael, G., Pöschl, U., and $\mathrm{Su}, \mathrm{H}$.: Reactive nitrogen chemistry in aerosol water as a source of sulfate during haze events in China, Sci. Adv., 2, e1601530, https://doi.org/10.1126/sciadv.1601530, 2016.
Cheung, H. H. Y., Yeung, M. C., Li, Y. J., Lee, B. P., and Chan, C. K.: Relative Humidity- Dependent HTDMA Measurements of Ambient Aerosols at the HKUST Supersite in Hong Kong, China, Aerosol Sci. Technol., 49, 643-654, 2015.

Chi, J. W., Li, W. J., Zhang, D. Z., Zhang, J. C., Lin, Y. T., Shen, X. J., Sun, J. Y., Chen, J. M., Zhang, X. Y., Zhang, Y. M., and Wang, W. X.: Sea salt aerosols as a reactive surface for inorganic and organic acidic gases in the Arctic troposphere, Atmos. Chem. Phys., 15, 11341-11353, https://doi.org/10.5194/acp-15-113412015, 2015.

Chin, M., Ginoux, P., Kinne, S., Torres, O., Holben, B. N., Duncan, B. N., Martin, R. V., Logan, J. A., Higurashi, A., and Nakajima, T.: Tropospheric aerosol optical thickness from the GOCART model and comparisons with satellite and Sun photometer measurements, J. Atmos. Sci., 59, 461-483, 2002.

Choi, M. Y. and Chan, C. K.: The effects of organic species on the hygroscopic behaviors of inorganic aerosols, Environ. Sci. Technol., 36, 2422-2428, 2002a.

Choi, M. Y. and Chan, C. K.: Continuous measurements of the water activities of aqueous droplets of water-soluble organic compounds, J. Phys. Chem. A, 106, 4566-4572, 2002b.

Choi, M. Y. and Chan, C. K.: Investigation of Efflorescence of Inorganic Aerosols Using Fluorescence Spectroscopy, J. Phys. Chem. A, 109, 1042-1048, 2005.

Choi, M. Y., Chan, C. K., and Zhang, Y.-H.: Application of Fluorescence Spectroscopy To Study the State of Water in Aerosols, J. Phys. Chem. A., 108, 1133-1138, 2004.

Chow, J. C.: Measurement methods to determine compliance with ambient air quality standards for suspended particles, J. Air Waste Manage., 45, 320-382, 1995.

Chow, J. C., Doraiswamy, P., Watson, J. G., Antony-Chen, L. W., Ho, S. S. H., and Sodeman, D. A.: Advances in integrated and continuous measurements for particle mass and chemical, composition, J. Air Waste Manage., 58, 141-163, 2008.

Clegg, S. L. and Wexler, A. S.: Densities and Apparent Molar Volumes of Atmospherically Important Electrolyte Solutions. 1. The Solutes $\mathrm{H} 2 \mathrm{SO} 4, \mathrm{HNO} 3, \mathrm{HCl}, \mathrm{Na} 2 \mathrm{SO} 4, \mathrm{NaNO} 3, \mathrm{NaCl}$, (NH4)(2)SO4, NH4NO3, and $\mathrm{NH} 4 \mathrm{Cl}$ from 0 to 50 degrees $\mathrm{C}$, Including Extrapolations to Very Low Temperature and to the Pure Liquid State, and $\mathrm{NaHSO} 4, \mathrm{NaOH}$, and $\mathrm{NH} 3$ at 25 degrees C, J. Phys. Chem. A, 115, 3393-3460, 2011.

Clegg, S. L., Brimblecombe, P., and Wexler, A. S.: Thermodynamic Model of the System $\mathrm{H}^{+}-\mathrm{NH}_{4}^{+}-\mathrm{Na}^{+}-\mathrm{SO}_{4}^{2-}-\mathrm{NO}_{3}^{-}-\mathrm{Cl}^{-}-\mathrm{H}_{2} \mathrm{O}$ at 298.15 K, J. Phys. Chem. A., 102, 2155-2171, 1998.

Courtney, W. J., Shaw, R. W., and Dzubay, T. G.: Precision and accuracy of a $\beta$ gauge for aerosol mass determinations, Environ. Sci. Technol., 16, 236-239, 1982.

Covert, D. S., Charlson, R. J., and Ahlquist, N. C.: A Study of the Relationship of Chemical Composition and Humidity to Light Scattering by Aerosols, J. Appl. Meteorol., 11, 968-976, 1972.

Cziczo, D. J. and Abbatt, J. P. D.: Deliquescence, efflorescence, and supercooling of ammonium sulfate aerosols at low temperature: Implications for cirrus cloud formation and aerosol phase in the atmosphere, J. Geophys. Res.-Atmos., 104, 13781-13790, 1999.

Cziczo, D. J. and Abbatt, J. P. D.: Infrared observations of the response of $\mathrm{NaCl}, \mathrm{MgCl} 2, \mathrm{NH} 4 \mathrm{HSO} 4$, and $\mathrm{NH} 4 \mathrm{NO} 3$ aerosols to changes in relative humidity from 298 to 238 K, J. Phys. Chem. A, 104, 2038-2047, 2000. 
Cziczo, D. J., Nowak, J. B., Hu, J. H., and Abbatt, J. P. D.: Infrared spectroscopy of model tropospheric aerosols as a function of relative humidity: Observation of deliquescence and crystallization, J. Geophys. Res.-Atmos., 102, 18843-18850, 1997.

Dai, Q., Hu, J., and Salmeron, M.: Adsorption of water on $\mathrm{NaCl}$ (100) surfaces: Role of atomic steps, J. Phys. Chem. B, 101, 1994-1998, 1997.

Darquenne, C., Fleming, J. S., Katz, I., Martin, A. R., Schroeter, J., Usmani, O. S., Venegas, J., and Schmid, O.: Bridging the Gap Between Science and Clinical Efficacy: Physiology, Imaging, and Modeling of Aerosols in the Lung, J. Aerosol Med. Pulm. D., 29, 107-126, 2016.

Davidson, N., Tong, H. J., Kalberer, M., Seville, P. C., Ward, A. D., Kuimova, M. K., and Pope, F. D.: Measurement of the Raman spectra and hygroscopicity of four pharmaceutical aerosols as they travel from pressurised metered dose inhalers (pMDI) to a model lung, Int. J. Pharm., 520, 59-69, 2017.

Davies, J. F. and Wilson, K. R.: Raman Spectroscopy of Isotopic Water Diffusion in Ultraviscous, Glassy, and Gel States in Aerosol by Use of Optical Tweezers, Anal. Chem., 88, 23612366, 2016.

Davis, E. J.: A history of single aerosol particle levitation, Aerosol Sci. Technol., 26, 212-254, 1997.

Davis, E. J.: Electrodynamic Levitation of Particles, in: Aerosol Measurement: Principles, Techniques, and Applications, edited by: Kulkarni, P., Baron, P. A., and Willeke, K., John Wiley \& Sons, Inc., Hoboken, New Jersey, 2011.

Davis, R. D., Lance, S., Gordon, J. A., and Tolbert, M. A.: Long Working-Distance Optical Trap for in Situ Analysis of ContactInduced Phase Transformations, Anal. Chem., 87, 6186-6194, 2015a.

Davis, R. D., Lance, S., Gordon, J. A., Ushijima, S. B., and Tolbert, M. A.: Contact efflorescence as a pathway for crystallization of atmospherically relevant particles, P. Natl. Acad. Sci. USA, 112, 15815-15820, 2015b.

Day, D. E., Malm, W. C., and Kreidenweis, S. M.: Aerosol light scattering measurements as a function of relative humidity, J. Air Waste Manage., 50, 710-716, 2000.

Dazzi, A. and Prater, C. B.: AFM-IR: Technology and Applications in Nanoscale Infrared Spectroscopy and Chemical Imaging, Chem. Rev., 117, 5146-5173, 2017.

Dazzi, A., Prater, C. B., Hu, Q. C., Chase, D. B., Rabolt, J. F., and Marcott, C.: AFM-IR: Combining Atomic Force Microscopy and Infrared Spectroscopy for Nanoscale Chemical Characterization, Appl. Spectrosc., 66, 1365-1384, 2012.

de Smit, E., Swart, I., Creemer, J. F., Hoveling, G. H., Gilles, M. K., Tyliszczak, T., Kooyman, P. J., Zandbergen, H. W., Morin, C., Weckhuysen, B. M., and de Groot, F. M. F.: Nanoscale chemical imaging of a working catalyst by scanning transmission X-ray microscopy, Nature, 456, 222-239, 2008.

DeMott, P. J., Möhler, O., Stetzer, O., Vali, G., Levin, Z., Petters, M. D., Murakami, M., Leisner, T., Bundke, U., Klein, H., Kanji, Z. A., Cotton, R., Jones, H., Benz, S., Brinkmann, M., Rzesanke, D., Saathoff, H., Nicolet, M., Saito, A., Nillius, B., Bingemer, H., Abbatt, J., Ardon, K., Ganor, E., Georgakopoulos, D. G., and Saunders, C.: Resurgence in Ice Nuclei Measurement Research, B. Am. Meteorol. Soc., 92, 1623-1635, 2011.

DeMott, P. J., Möhler, O., Cziczo, D. J., Hiranuma, N., Petters, M. D., Petters, S. S., Belosi, F., Bingemer, H. G., Brooks, S. D.,
Budke, C., Burkert-Kohn, M., Collier, K. N., Danielczok, A., Eppers, O., Felgitsch, L., Garimella, S., Grothe, H., Herenz, P., Hill, T. C. J., Höhler, K., Kanji, Z. A., Kiselev, A., Koop, T., Kristensen, T. B., Krüger, K., Kulkarni, G., Levin, E. J. T., Murray, B. J., Nicosia, A., O'Sullivan, D., Peckhaus, A., Polen, M. J., Price, H. C., Reicher, N., Rothenberg, D. A., Rudich, Y., Santachiara, G., Schiebel, T., Schrod, J., Seifried, T. M., Stratmann, F., Sullivan, R. C., Suski, K. J., Szakáll, M., Taylor, H. P., Ullrich, R., Vergara-Temprado, J., Wagner, R., Whale, T. F., Weber, D., Welti, A., Wilson, T. W., Wolf, M. J., and Zenker, J.: The Fifth International Workshop on Ice Nucleation phase 2 (FIN-02): laboratory intercomparison of ice nucleation measurements, Atmos. Meas. Tech., 11, 6231-6257, https://doi.org/10.5194/amt11-6231-2018, 2018.

Demou, E., Visram, H., Donaldson, D. J., and Makar, P. A.: Uptake of water by organic films: the dependence on the film oxidation state, Atmos. Environ., 37, 3529-3537, 2003.

Dennis-Smither, B. J., Hanford, K. L., Kwamena, N. O. A., Miles, R. E. H., and Reid, J. P.: Phase, Morphology, and Hygroscopicity of Mixed Oleic Acid/Sodium Chloride/Water Aerosol Particles before and after Ozonolysis, J. Phys. Chem. A, 116, 6159-6168, 2012.

Després, V. R., Huffman, J. A., Burrows, S. M., Hoose, C., Safatov, A. S., Buryak, G., Fröhlich-Nowoisky, J., Elbert, W., Andreae, M. O., Pöschl, U., and Jaenicke, R.: Primary biological aerosol particles in the atmosphere: a review, Tellus B, 64, 15598, https://doi.org/10.3402/tellusb.v64i0.15598, 2012.

Dick, W. D., Saxena, P., and McMurry, P. H.: Estimation of water uptake by organic compounds in submicron aerosols measured during the Southeastern Aerosol and Visibility Study, J. Geophys. Res.-Atmos., 105, 1471-1479, 2000.

Diehl, K., Quick, C., Matthias-Maser, S., Mitra, S. K., and Jaenicke, R.: The ice nucleating ability of pollen - Part I: Laboratory studies in deposition and condensation freezing modes, Atmos. Res., 58, 75-87, 2001.

Diehl, K., Ettner-Mahl, M., Hannemann, A., and Mitra, S. K.: Homogeneous freezing of single sulfuric and nitric acid solution drops levitated in an acoustic trap, Atmos. Res., 94, 356-361, 2009.

Diehl, K., Debertshäuser, M., Eppers, O., Schmithüsen, H., Mitra, S. K., and Borrmann, S.: Particle surface area dependence of mineral dust in immersion freezing mode: investigations with freely suspended drops in an acoustic levitator and a vertical wind tunnel, Atmos. Chem. Phys., 14, 12343-12355, https://doi.org/10.5194/acp-14-12343-2014, 2014.

Duplissy, J., Gysel, M., Alfarra, M. R., Dommen, J., Metzger, A., Prevot, A. S. H., Weingartner, E., Laaksonen, A., Raatikainen, T., Good, N., Turner, S. F., McFiggans, G., and Baltensperger, U.: Cloud forming potential of secondary organic aerosol under near atmospheric conditions, Geophys. Res. Lett., 35, L03818, https://doi.org/10.1029/2007GL031075, 2008.

Duplissy, J., Gysel, M., Sjogren, S., Meyer, N., Good, N., Kammermann, L., Michaud, V., Weigel, R., Martins dos Santos, S., Gruening, C., Villani, P., Laj, P., Sellegri, K., Metzger, A., McFiggans, G. B., Wehrle, G., Richter, R., Dommen, J., Ristovski, Z., Baltensperger, U., and Weingartner, E.: Intercomparison study of six HTDMAs: results and recommendations, Atmos. Meas. Tech., 2, 363-378, https://doi.org/10.5194/amt-2363-2009, 2009. 
Duplissy, J., DeCarlo, P. F., Dommen, J., Alfarra, M. R., Metzger, A., Barmpadimos, I., Prevot, A. S. H., Weingartner, E., Tritscher, T., Gysel, M., Aiken, A. C., Jimenez, J. L., Canagaratna, M. R., Worsnop, D. R., Collins, D. R., Tomlinson, J., and Baltensperger, U.: Relating hygroscopicity and composition of organic aerosol particulate matter, Atmos. Chem. Phys., 11, 11551165, https://doi.org/10.5194/acp-11-1155-2011, 2011.

Dybwad, G. L.: A sensitive new method for the determination of adhesive bonding between a particle and a substrate, J. Appl. Phys., 58, 2789-2790, 1985.

Ebert, M., Inerle-Hof, M., and Weinbruch, S.: Environmental scanning electron microscopy as a new technique to determine the hygroscopic behaviour of individual aerosol particles, Atmos. Environ., 36, 5909-5916, 2002.

Eichler, H., Cheng, Y. F., Birmili, W., Nowak, A., Wiedensohler, A., Bruggemann, E., Gnauk, T., Herrmann, H., Althausen, D., Ansmann, A., Engelmann, R., Tesche, M., Wendisch, M., Zhang, Y. H., Hu, M., Liu, S., and Zeng, L. M.: Hygroscopic properties and extinction of aerosol particles at ambient relative humidity in South-Eastern China, Atmos. Environ., 42, 6321-6334, 2008.

Eliason, T. L., Aloisio, S., Donaldson, D. J., Cziczo, D. J., and Vaida, V.: Processing of unsaturated organic acid films and aerosols by ozone, Atmos. Environ., 37, 2207-2219, 2003.

Eom, H.-J., Gupta, D., Li, X., Jung, H.-J., Kim, H., and Ro, C.U.: Influence of Collecting Substrates on the Characterization of Hygroscopic Properties of Inorganic Aerosol Particles, Anal. Chem., 86, 2648-2656, 2014.

Ettner, M., Mitra, S. K., and Borrmann, S.: Heterogeneous freezing of single sulfuric acid solution droplets: laboratory experiments utilizing an acoustic levitator, Atmos. Chem. Phys., 4, 1925-1932, https://doi.org/10.5194/acp-4-1925-2004, 2004.

Ewing, G. E.: Ambient thin film water on insulator surfaces, Chem. Rev., 106, 1511-1526, 2006.

Fallman, E. and Axner, O.: Design for fully steerable dual-trap optical tweezers, Appl. Optics, 36, 2107-2113, 1997.

Fan, S. M., Horowitz, L. W., Levy, H., and Moxim, W. J.: Impact of air pollution on wet deposition of mineral dust aerosols, Geophys. Res. Lett., 31, L02104, https://doi.org/10.1029/2003gl018501, 2004.

Farmer, D. K., Cappa, C. D., and Kreidenweis, S. M.: Atmospheric Processes and Their Controlling Influence on Cloud Condensation Nuclei Activity, Chem. Rev., 115, 4199-4217, 2015.

Feingold, G. and Morley, B.: Aerosol hygroscopic properties as measured by lidar and comparison with in situ measurements, J. Geophys. Res.-Atmos., 108, 4327, https://doi.org/10.1029/2002JD002842, 2003.

Fernandez, A. J., Molero, F., Becerril-Valle, M., Coz, E., Salvador, P., Artinano, B., and Pujadas, M.: Application of remote sensing techniques to study aerosol water vapour uptake in a real atmosphere, Atmos. Res., 202, 112-127, 2018.

Ferrare, R. A., Melfi, S. H., Whiteman, D. N., Evans, K. D., Poellot, M., and Kaufman, Y. J.: Raman lidar measurements of aerosol extinction and backscattering - 2. Derivation of aerosol real refractive index, single-scattering albedo, and humidification factor using Raman lidar and aircraft size distribution measurements, J. Geophys. Res.-Atmos., 103, 19673-19689, 1998.

Feth, M. P., Jurascheck, J., Spitzenberg, M., Dillenz, J., Bertele, G., and Stark, H.: New Technology for the Investigation of Water Vapor Sorption-Induced Crystallographic Form Transformations of Chemical Compounds: A Water Vapor Sorption GravimetryDispersive Raman Spectroscopy Coupling, J. Pharm. Sci., 100, 1080-1092, 2011.

Fierz-Schmidhauser, R., Zieger, P., Gysel, M., Kammermann, L., DeCarlo, P. F., Baltensperger, U., and Weingartner, E.: Measured and predicted aerosol light scattering enhancement factors at the high alpine site Jungfraujoch, Atmos. Chem. Phys., 10, 2319 2333, https://doi.org/10.5194/acp-10-2319-2010, 2010a.

Fierz-Schmidhauser, R., Zieger, P., Vaishya, A., Monahan, C., Bialek, J., O’Dowd, C. D., Jennings, S. G., Baltensperger, U., and Weingartner, E.: Light scattering enhancement factors in the marine boundary layer (Mace Head, Ireland), J. Geophys. Res.Atmos., 115, D20204, https://doi.org/10.1029/2009JD013755, 2010 b.

Fierz-Schmidhauser, R., Zieger, P., Wehrle, G., Jefferson, A., Ogren, J. A., Baltensperger, U., and Weingartner, E.: Measurement of relative humidity dependent light scattering of aerosols, Atmos. Meas. Tech., 3, 39-50, https://doi.org/10.5194/amt-3-392010, 2010c.

Finlayson-Pitts, B. J. and Pitts, J. N.: Chemistry of the Upper and Lower Atmosphere: Theory, Experiments, and Applications, Academic Press, San Diego, 2000.

Fisher, M. C., Henk, D. A., Briggs, C. J., Brownstein, J. S., Madoff, L. C., McCraw, S. L., and Gurr, S. J.: Emerging fungal threats to animal, plant and ecosystem health, Nature, 484, 186-194, 2012.

Michel Flores, J., Bar-Or, R. Z., Bluvshtein, N., Abo-Riziq, A., Kostinski, A., Borrmann, S., Koren, I., Koren, I., and Rudich, Y.: Absorbing aerosols at high relative humidity: linking hygroscopic growth to optical properties, Atmos. Chem. Phys., 12, 5511-5521, https://doi.org/10.5194/acp-12-5511-2012, 2012.

Fröhlich-Nowoisky, J., Kampf, C. J., Weber, B., Huffman, J. A., Pöhlker, C., Andreae, M. O., Lang-Yona, N., Burrows, S. M., Gunthe, S. S., Elbert, W., Su, H., Hoor, P., Thines, E., Hoffmann, T., Després, V. R., and Pöschl, U.: Bioaerosols in the Earth system: Climate, health, and ecosystem interactions, Atmos. Res., 182, 346-376, 2016.

Freedman, M. A.: Phase separation in organic aerosol, Chem. Soc. Rev., 46, 7694-7705, 2017.

Freedman, M. A., Hasenkopf, C. A., Beaver, M. R., and Tolbert, M. A.: Optical Properties of Internally Mixed Aerosol Particles Composed of Dicarboxylic Acids and Ammonium Sulfate, J. Phys. Chem. A, 113, 13584-13592, 2009.

Freedman, M. A., Baustian, K. J., Wise, M. E., and Tolbert, M. A.: Characterizing the Morphology of Organic Aerosols at Ambient Temperature and Pressure, Anal. Chem., 82, 7965-7972, 2010.

Freney, E. J., Martin, S. T., and Buseck, P. R.: Deliquescence and Efflorescence of Potassium Salts Relevant to Biomass-Burning Aerosol Particles, Aerosol Sci. Technol., 43, 799-807, 2009.

Friedbacher, G., Grasserbauer, M., Meslmani, Y., Klaus, N., and Higatsberger, M. J.: Investigation of Environmental Aerosol by Atomic Force Microscopy, Anal. Chem., 67, 1749-1754, 1995.

Gao, R. S., Schwarz, J. P., Kelly, K. K., Fahey, D. W., Watts, L. A., Thompson, T. L., Spackman, J. R., Slowik, J. G., Cross, E. S., Han, J. H., Davidovits, P., Onasch, T. B., and Worsnop, D. R.: A novel method for estimating light-scattering properties of soot aerosols using a modified single-particle soot photometer, Aerosol Sci. Technol., 41, 125-135, 2007.

Gao, X. Y., Zhang, Y. H., and Liu, Y.: Temperature-dependent hygroscopic behaviors of atmospherically relevant water-soluble 
carboxylic acid salts studied by ATR-FTIR spectroscopy, Atmos. Environ., 191, 312-319, 2018.

Garland, R. M., Ravishankara, A. R., Lovejoy, E. R., Tolbert, M. A., and Baynard, T.: Parameterization for the relative humidity dependence of light extinction: Organicammonium sulfate aerosol, J. Geophys. Res.-Atmos., 112, D19303, https://doi.org/10.1029/2006JD008179, 2007.

Gen, M. and Chan, C. K.: Electrospray surface-enhanced Raman spectroscopy (ES-SERS) for probing surface chemical compositions of atmospherically relevant particles, Atmos. Chem. Phys., 17, 14025-14037, https://doi.org/10.5194/acp-17-140252017, 2017.

Ghorai, S. and Tivanski, A. V.: Hygroscopic Behavior of Individual Submicrometer Particles Studied by X-ray Spectromicroscopy, Anal. Chem., 82, 9289-9298, 2010.

Ghorai, S., Laskin, A., and Tivanski, A. V.: Spectroscopic Evidence of Keto-Enol Tautomerism in Deliquesced Malonic Acid Particles, J. Phys. Chem. A, 115, 4373-4380, 2011.

Ghorai, S., Wang, B., Tivanski, A., and Laskin, A.: Hygroscopic Properties of Internally Mixed Particles Composed of $\mathrm{NaCl}$ and Water-Soluble Organic Acids, Environ. Sci. Technol., 48, 22342241, 2014.

Gibson, E. R., Hudson, P. K., and Grassian, V. H.: Physicochemical properties of nitrate aerosols: Implications for the atmosphere, J. Phys. Chem. A, 110, 11785-11799, 2006.

Golabiazar, R. and Sadeghi, R.: Vapor Pressure Osmometry Determination of the Osmotic and Activity Coefficients of Dilute Aqueous Solutions of Symmetrical Tetraalkyl Ammonium Halides at 308.15 K, J. Chem. Eng. Data, 59, 76-81, 2014.

Gomery, K., Humphrey, E. C., and Herring, R.: Examining Protein Crystallization Using Scanning Electron Microscopy, Microsc. Microanal., 19, 145-149, 2013.

Gomez-Hernandez, M., McKeown, M., Secrest, J., Marrero-Ortiz, W., Lavi, A., Rudich, Y., Collins, D. R., and Zhang, R. Y.: Hygroscopic Characteristics of Alkylaminium Carboxylate Aerosols, Environ. Sci. Technol., 50, 2292-2300, 2016.

Gong, Z., Pan, Y.-L., Videen, G., and Wang, C.: Optical trapping and manipulation of single particles in air: Principles, technical details, and applications, J. Quant. Spectrosc. Ra., 214, 94-119, 2018.

Good, N., Coe, H., and McFiggans, G.: Instrumentational operation and analytical methodology for the reconciliation of aerosol water uptake under sub- and supersaturated conditions, Atmos. Meas. Tech., 3, 1241-1254, https://doi.org/10.5194/amt-3-12412010, 2010a.

Good, N., Topping, D. O., Duplissy, J., Gysel, M., Meyer, N. K., Metzger, A., Turner, S. F., Baltensperger, U., Ristovski, Z., Weingartner, E., Coe, H., and McFiggans, G.: Widening the gap between measurement and modelling of secondary organic aerosol properties?, Atmos. Chem. Phys., 10, 2577-2593, https://doi.org/10.5194/acp-10-2577-2010, 2010b.

Goodman, A. L., Underwood, G. M., and Grassian, V. H.: A Laboratory Study of the Heterogeneous Reaction of Nitric Acid on Calcium Carbonate Particles, J. Geophys. Res.-Atmos., 105, 2905329064, 2000.

Goodman, A. L., Bernard, E. T., and Grassian, V. H.: Spectroscopic Study of Nitric Acid and Water Adsorption on Oxide Particles: Enhanced Nitric Acid Uptake Kinetics in the Presence of Adsorbed Water, J. Phys. Chem. A, 105, 6443-6457, 2001.
Gorkowski, K., Beydoun, H., Aboff, M., Walker, J. S., Reid, J. P., and Sullivan, R. C.: Advanced aerosol optical tweezers chamber design to facilitate phase-separation and equilibration timescale experiments on complex droplets, Aerosol Sci. Technol., 50, 1327-1341, 2016.

Gough, R. V., Chevrier, V. F., Baustian, K. J., Wise, M. E., and Tolbert, M. A.: Laboratory studies of perchlorate phase transitions: Support for metastable aqueous perchlorate solutions on Mars, Earth Planet. Sc. Lett., 312, 371-377, 2011.

Gough, R. V., Chevrier, V. F., and Tolbert, M. A.: Formation of liquid water at low temperatures via the deliquescence of calcium chloride: Implications for Antarctica and Mars, Planet. Space Sci., 131, 79-87, 2016.

Griffiths, P. T., Borlace, J. S., Gallimore, P. J., Kalberer, M., Herzog, M., and Pope, F. D.: Hygroscopic growth and cloud activation of pollen: a laboratory and modelling study, Atmos. Sci. Lett., 13, 289-295, 2012.

Gu, W., Li, Y. J., Tang, M. J., Jia, X. H., Ding, X., Bi, X. H., and Wang, X. M.: Water uptake and hygroscopicity of perchlorates and implications for the existence of liquid water in some hyperarid environments, RSC Adv., 7, 46866-46873, 2017a.

Gu, W., Li, Y., Zhu, J., Jia, X., Lin, Q., Zhang, G., Ding, X., Song, W., Bi, X., Wang, X., and Tang, M.: Investigation of water adsorption and hygroscopicity of atmospherically relevant particles using a commercial vapor sorption analyzer, Atmos. Meas. Tech., 10, 3821-3832, https://doi.org/10.5194/amt10-3821-2017, 2017b.

Guo, L., Gu, W., Peng, C., Wang, W., Li, Y. J., Zong, T., Tang, Y., Wu, Z., Lin, Q., Ge, M., Zhang, G., Hu, M., Bi, X., Wang, X., and Tang, M.: A comprehensive study of hygroscopic properties of calcium- and magnesium-containing salts: implication for hygroscopicity of mineral dust and sea salt aerosols, Atmos. Chem. Phys., 19, 2115-2133, https://doi.org/10.5194/acp19-2115-2019, 2019.

Gupta, D., Eom, H.-J., Cho, H.-R., and Ro, C.-U.: Hygroscopic behavior of $\mathrm{NaCl}-\mathrm{MgCl}_{2}$ mixture particles as nascent seaspray aerosol surrogates and observation of efflorescence during humidification, Atmos. Chem. Phys., 15, 11273-11290, https://doi.org/10.5194/acp-15-11273-2015, 2015.

Gustafsson, R. J., Orlov, A., Badger, C. L., Griffiths, P. T., Cox, R. A., and Lambert, R. M.: A comprehensive evaluation of water uptake on atmospherically relevant mineral surfaces: DRIFT spectroscopy, thermogravimetric analysis and aerosol growth measurements, Atmos. Chem. Phys., 5, 3415-3421, https://doi.org/10.5194/acp-5-3415-2005, 2005.

Gyawali, M., Arnott, W. P., Zaveri, R. A., Song, C., Moosmüller, H., Liu, L., Mishchenko, M. I., Chen, L.-W. A., Green, M. C., Watson, J. G., and Chow, J. C.: Photoacoustic optical properties at UV, VIS, and near IR wavelengths for laboratory generated and winter time ambient urban aerosols, Atmos. Chem. Phys., 12, 2587-2601, https://doi.org/10.5194/acp-12-2587-2012, 2012.

Gysel, M., Weingartner, E., and Baltensperger, U.: Hygroscopicity of Aerosol Particles at Low Temperatures. 2. Theoretical and Experimental Hygroscopic Properties of Laboratory Generated Aerosols, Environ. Sci. Technol., 36, 63-68, 2002.

Gysel, M., Crosier, J., Topping, D. O., Whitehead, J. D., Bower, K. N., Cubison, M. J., Williams, P. I., Flynn, M. J., McFiggans, G. B., and Coe, H.: Closure study between chemical composition and hygroscopic growth of aerosol particles during TORCH2, 
Atmos. Chem. Phys., 7, 6131-6144, https://doi.org/10.5194/acp7-6131-2007, 2007.

Gysel, M., McFiggans, G. B., and Coe, H.: Inversion of tandem differential mobility analyser (TDMA) measurements, J. Aerosol. Sci., 40, 134-151, 2009.

Hänel, G.: The Properties of Atmospheric Aerosol Particles as Functions of the Relative Humidity at Thermodynamic Equilibrium with the Surrounding Moist Air, in: Advances in Geophysics, edited by: Landsberg, H. E. and Mieghem, J. V., Elsevier, 73-188, 1976.

Haarig, M., Ansmann, A., Gasteiger, J., Kandler, K., Althausen, D., Baars, H., Radenz, M., and Farrell, D. A.: Dry versus wet marine particle optical properties: $\mathrm{RH}$ dependence of depolarization ratio, backscatter, and extinction from multiwavelength lidar measurements during SALTRACE, Atmos. Chem. Phys., 17, 1419914217, https://doi.org/10.5194/acp-17-14199-2017, 2017.

Haddrell, A. E., Davies, J. F., Yabushita, A., and Reid, J. P.: Accounting for Changes in Particle Charge, Dry Mass and Composition Occurring During Studies of Single Levitated Particles, J. Phys. Chem. A, 116, 9941-9953, 2012.

Haddrell, A. E., Hargreaves, G., Davies, J. F., and Reid, J. P.: Control over hygroscopic growth of saline aqueous aerosol using Pluronic polymer additives, Int. J. Pharm., 443, 183-192, 2013.

Haddrell, A. E., Davies, J. F., Miles, R. E. H., Reid, J. P., Dailey, L. A., and Murnane, D.: Dynamics of aerosol size during inhalation: Hygroscopic growth of commercial nebulizer formulations, Int. J. Pharm., 463, 50-61, 2014.

Haddrell, A. E., Miles, R. E. H., Bzdek, B. R., Reid, J. P., Hopkins, R. J., and Walker, J. S.: Coalescence Sampling and Analysis of Aerosols using Aerosol Optical Tweezers, Anal. Chem., 89, 2345-2352, 2017.

Han, J. H., Hung, H. M., and Martin, S. T.: Size effect of hematite and corundum inclusions on the efflorescence relative humidities of aqueous ammonium nitrate particles, J. Geophys. Res.-Atmos., 107, 4086, https://doi.org/10.1029/2001JD001054, 2002.

Hand, J. L. and Malm, W. C.: Review of aerosol mass scattering efficiencies from ground-based measurements since 1990, J. Geophys. Res.-Atmos., 112, D16203, https://doi.org/10.1029/2007JD008484, 2007.

Hanford, K. L., Mitchem, L., Reid, J. P., Clegg, S. L., Topping, D. O., and McFiggans, G. B.: Comparative thermodynamic studies of aqueous glutaric acid, ammonium sulfate and sodium chloride aerosol at high humidity, J. Phys. Chem. A, 112, 9413-9422, 2008.

Hargreaves, G., Kwamena, N. O. A., Zhang, Y. H., Butler, J. R., Rushworth, S., Clegg, S. L., and Reid, J. P.: Measurements of the Equilibrium Size of Supersaturated Aqueous Sodium Chloride Droplets at Low Relative Humidity Using Aerosol Optical Tweezers and an Electrodynamic Balance, J. Phys. Chem. A, 114, 1806-1815, 2010a.

Hargreaves, G., Kwamena, N. O. A., Zhang, Y. H., Butler, J. R., Rushworth, S., Clegg, S. L., and Reid, J. P.: Measurements of the Equilibrium Size of Supersaturated Aqueous Sodium Chloride Droplets at Low Relative Humidity Using Aerosol Optical Tweezers and an Electrodynamic Balance, J. Phys. Chem. A, 114, 1806-1815, 2010b.

Hatch, C. D., Gierlus, K. M., Schuttlefield, J. D., and Grassian, V. H.: Water adsorption and cloud condensation nuclei activity of calcite and calcite coated with model humic and fulvic acids, Atmos. Environ., 42, 5672-5684, 2008.

Hatch, C. D., Wiese, J. S., Crane, C. C., Harris, K. J., Kloss, H. G., and Baltrusaitis, J.: Water Adsorption on Clay Minerals As a Function of Relative Humidity: Application of BET and Freundlich Adsorption Models, Langmuir, 28, 1790-1803, 2011.

He, K. J., Cheng, H., Zhu, Y. Y., Wang, L. Y., and Zhang, Y. H.: Measurement of electric properties of the single supersaturated aerosol droplet, Chin. Sci. Bull., 53, 1773-1776, 2008.

He, Y. B., Tilocca, A., Dulub, O., Selloni, A., and Diebold, U.: Local ordering and electronic signatures of submonolayer water on anatase $\mathrm{TiO}_{2}$ (101), Nat. Mater., 8, 585-589, 2009.

Hefter, G., May, P. M., Marshall, S. L., Cornish, J., and Kron, I.: Improved apparatus and procedures for isopiestic studies at elevated temperatures, Rev. Sci. Instrum., 68, 2558-2567, 1997.

Hegg, D. A., Covert, D. S., Jonsson, H., and Covert, P. A.: An instrument for measuring size-resolved aerosol hygroscopicity at both sub- and super-micron sizes, Aerosol Sci. Technol., 41, 873-883, 2007.

Hennig, T., Massling, A., Brechtel, F. J., and Wiedensohler, A.: A Tandem DMA for highly temperature-stabilized hygroscopic particle growth measurements between $90 \%$ and $98 \%$ relative humidity, J. Aerosol Sci., 36, 1210-1223, 2005.

Hepburn, J. R. I.: 69. The vapour pressure of water over aqueous solutions of the chlorides of the alkaline-earth metals. Part I. Experimental, with a critical discussion of vapour-pressure data, J. Chem. Soc., 550-566, 1932.

Herich, H., Tritscher, T., Wiacek, A., Gysel, M., Weingartner, E., Lohmann, U., Baltensperger, U., and Cziczo, D. J.: Water uptake of clay and desert dust aerosol particles at sub- and supersaturated water vapor conditions, Phys. Chem. Chem. Phys., 11, 7804-7809, 2009.

Hickey, A. J. and Martonen, T. B.: Hehavior of hygroscopic pharmaceutical aerosols and the influence of hydrophobic addtives, Pharm. Res., 10, 1-7, 1993.

Hiranuma, N., Brooks, S. D., Auvermann, B. W., and Littleton, R.: Using environmental scanning electron microscopy to determine the hygroscopic properties of agricultural aerosols, Atmos. Environ., 42, 1983-1994, 2008.

Hiranuma, N., Augustin-Bauditz, S., Bingemer, H., Budke, C., Curtius, J., Danielczok, A., Diehl, K., Dreischmeier, K., Ebert, M., Frank, F., Hoffmann, N., Kandler, K., Kiselev, A., Koop, T., Leisner, T., Möhler, O., Nillius, B., Peckhaus, A., Rose, D., Weinbruch, S., Wex, H., Boose, Y., DeMott, P. J., Hader, J. D., Hill, T. C. J., Kanji, Z. A., Kulkarni, G., Levin, E. J. T., McCluskey, C. S., Murakami, M., Murray, B. J., Niedermeier, D., Petters, M. D., O’Sullivan, D., Saito, A., Schill, G. P., Tajiri, T., Tolbert, M. A., Welti, A., Whale, T. F., Wright, T. P., and Yamashita, K.: A comprehensive laboratory study on the immersion freezing behavior of illite NX particles: a comparison of 17 ice nucleation measurement techniques, Atmos. Chem. Phys., 15, 2489-2518, https://doi.org/10.5194/acp-15-2489-2015, 2015.

Hitzenberger, R., Berner, A., Dusek, U., and Alabashi, R.: Humidity-Dependent Growth of Size-Segregated Aerosol Samples, Aerosol Sci. Technol., 27, 116-130, 1997.

Hoffman, R. C., Laskin, A., and Finlayson-Pitts, B. J.: Sodium nitrate particles: physical and chemical properties during hydration and dehydration, and implications for aged sea salt aerosols, J. Aerosol. Sci., 35, 869-887, 2004. 
Hofmann, W.: Modelling inhaled particle deposition in the human lung-A review, J. Aerosol. Sci., 42, 693-724, 2011.

Hong, J., Xu, H., Tan, H., Yin, C., Hao, L., Li, F., Cai, M., Deng, X., Wang, N., Su, H., Cheng, Y., Wang, L., Petäjä, T., and Kerminen, V.-M.: Mixing state and particle hygroscopicity of organic-dominated aerosols over the Pearl River Delta region in China, Atmos. Chem. Phys., 18, 14079-14094, https://doi.org/10.5194/acp-18-14079-2018, 2018.

Hoose, C. and Möhler, O.: Heterogeneous ice nucleation on atmospheric aerosols: a review of results from laboratory experiments, Atmos. Chem. Phys., 12, 9817-9854, https://doi.org/10.5194/acp-12-9817-2012, 2012.

Hopkins, R. J., Mitchem, L., Ward, A. D., and Reid, J. P.: Control and characterisation of a single aerosol droplet in a single-beam gradient-force optical trap, Phys. Chem. Chem. Phys., 6, 49244927, 2004.

Hosny, N. A., Fitzgerald, C., Tong, C. L., Kalberer, M., Kuimova, M. K., and Pope, F. D.: Fluorescent lifetime imaging of atmospheric aerosols: a direct probe of aerosol viscosity, Faraday Discuss., 165, 343-356, 2013.

Hosny, N. A., Fitzgerald, C., Vysniauskas, A., Athanasiadis, A., Berkemeier, T., Uygur, N., Poschl, U., Shiraiwa, M., Kalberer, M., Pope, F. D., and Kuimova, M. K.: Direct imaging of changes in aerosol particle viscosity upon hydration and chemical aging, Chem. Sci., 7, 1357-1367, 2016.

Hu, D. W., Li, C. L., Chen, H., Chen, J. M., Ye, X. N., Li, L., Yang, X., Wang, X. M., Mellouki, A., and Hu, Z. Y.: Hygroscopicity and optical properties of alkylaminium sulfates, J. Environ. Sci., 26, 37-43, 2014.

Hung, H. M., Katrib, Y., and Martin, S. T.: Products and mechanisms of the reaction of oleic acid with ozone and nitrate radical, J. Phys. Chem. A, 109, 4517-4530, 2005.

Hung, H. M., Wang, K. C., and Chen, J. P.: Adsorption of nitrogen and water vapor by insoluble particles and the implication on cloud condensation nuclei activity, J. Aerosol. Sci., 86, 24-31, 2015.

Ibrahim, S., Romanias, M. N., Alleman, L. Y., Zeineddine, M. N., Angeli, G. K., Trikalitis, P. N., and Thevenet, F.: Water Interaction with Mineral Dust Aerosol: Particle Size and Hygroscopic Properties of Dust, ACS Earth Space Chem., 2, 376-386, 2018.

Inerle-Hof, M., Weinbruch, S., Ebert, M., and Thomassen, Y.: The hygroscopic behaviour of individual aerosol particles in nickel refineries as investigated by environmental scanning electron microscopy, J. Environ. Monitor., 9, 301-306, 2007.

IPCC: Climate Change 2013: The Physical Science Basis, Cambridge University Press, Cambridge, UK, 2013.

Jakli, G. and Vanhook, W. A.: Osmotic coefficients of aqueous solutions of $\mathrm{NaBr}, \mathrm{NaI}, \mathrm{KF}$, and $\mathrm{CaCl}_{2}$ between 0 and $90^{\circ} \mathrm{C}$, J. Chem. Eng. Dara, 17, 348-355, 1972.

Jia, X. H., Gu, W. J., Li, Y. J., Cheng, P., Tang, Y. J., Guo, L. Y., Wang, X. M., and Tang, M. J.: Phase transitions and hygroscopic growth of $\mathrm{Mg}(\mathrm{ClO} 4) 2, \mathrm{NaClO} 4$, and $\mathrm{NaClO} 4 \cdot \mathrm{H} 2 \mathrm{O}$ : implications for the stability of aqueous water in hyperarid environments on Mars and on Earth, ACS Earth Space Chem., 2, 159-167, 2018.

Jickells, T. D., An, Z. S., Andersen, K. K., Baker, A. R., Bergametti, G., Brooks, N., Cao, J. J., Boyd, P. W., Duce, R. A., Hunter, K. A., Kawahata, H., Kubilay, N., laRoche, J., Liss, P. S., Mahowald, N., Prospero, J. M., Ridgwell, A. J., Tegen, I., and Torres, R.:
Global Iron Connections between Desert Dust, Ocean Biogeochemistry, and Climate, Science, 308, 67-71, 2005.

Jing, B., Tong, S., Liu, Q., Li, K., Wang, W., Zhang, Y., and Ge, M.: Hygroscopic behavior of multicomponent organic aerosols and their internal mixtures with ammonium sulfate, Atmos. Chem. Phys., 16, 4101-4118, https://doi.org/10.5194/acp-164101-2016, 2016.

Jones, S. H., King, M. D., and Ward, A. D.: Atmospherically relevant core-shell aerosol studied using optical trapping and Mie scattering, Chem. Commun., 51, 4914-4917, 2015.

Joshi, N., Romanias, M. N., Riffault, V., and Thevenet, F.: Investigating water adsorption onto natural mineral dust particles: Linking DRIFTS experiments and BET theory, Aeolian Res., 27, 3545, 2017.

Joyner, L. G., Weinberger, E. B., and Montgomery, C. W.: Surface Area Measurements of Activated Carbons, Silica Gel and other Adsorbents, J. Am. Chem. Soc., 67, 2182-2188, 1945.

Jubb, A. M., Hua, W., and Allen, H. C.: Environmental Chemistry at Vapor/Water Interfaces: Insights from Vibrational Sum Frequency Generation Spectroscopy, Annu. Rev. Phys. Chem., 63, 107-130, 2012.

Juranyi, Z., Gysel, M., Duplissy, J., Weingartner, E., Tritscher, T., Dommen, J., Henning, S., Ziese, M., Kiselev, A., Stratmann, F., George, I., and Baltensperger, U.: Influence of gas-to-particle partitioning on the hygroscopic and droplet activation behaviour of alpha-pinene secondary organic aerosol, Phys. Chem. Chem. Phys., 11, 8091-8097, 2009.

Königsberger, E., Königsberger, L.-C., Hefter, G., and May, P. M.: Zdanovskii's Rule and Isopiestic Measurements Applied to Synthetic Bayer Liquors, J. Solution Chem., 36, 1619-1634, 2007.

Kaaden, N., Massling, A., Schladitz, A., Müller, T., Kandler, K., SchüTz, L., Weinzierl, B., Petzold, A., Tesche, M., Leinert, S., Deutscher, C., Ebert, M., Weinbruch, S., and Wiedensohler, A.: State of mixing, shape factor, number size distribution, and hygroscopic growth of the Saharan anthropogenic and mineral dust aerosol at Tinfou, Morocco, Tellus B, 61, 51-63, 2009.

Kanji, Z. A., Ladino, L. A., Wex, H., Boose, Y., Burkert-Kohn, M., Cziczo, D. J., and Krämer, M.: Overview of Ice Nucleating Particles, in: Ice Formation and Evolution in Clouds and Precipitation: Measurement and modeling Challenges, edited by: McFarquhar, G. M., Baumgardner, D., and Heymsfield, A. J., American Meteorological Society, 1.1-1.33, 2017.

Karagulian, F. and Rossi, M. J.: The heterogeneous chemical kinetics of $\mathrm{NO}_{3}$ on atmospheric mineral dust surrogates, Phys. Chem. Chem. Phys., 7, 3150-3162, 2005.

Karagulian, F., Santschi, C., and Rossi, M. J.: The heterogeneous chemical kinetics of $\mathrm{N}_{2} \mathrm{O}_{5}$ on $\mathrm{CaCO}_{3}$ and other atmospheric mineral dust surrogates, Atmos. Chem. Phys., 6, 1373-1388, https://doi.org/10.5194/acp-6-1373-2006, 2006.

Kavouras, A. and Krammer, G.: Ultrasonic levitation for the examination of gas/solid reactions, Rev. Sci. Instrum., 74, 4468-4473, 2003.

Kelly, J. T. and Wexler, A. S.: Thermodynamics of carbonates and hydrates related to heterogeneous reactions involving mineral aerosol, J. Geophys. Res.-Atmos, 110, D11201, https://doi.org/10.1029/2004JD005583, 2005.

Kelly, S. T., Nigge, P., Prakash, S., Laskin, A., Wang, B. B., Tyliszczak, T., Leone, S. R., and Gilles, M. K.: An environmental sample chamber for reliable scanning transmission $\mathrm{x}$-ray mi- 
croscopy measurements under water vapor, Rev. Sci. Instrum., 84, 073708, https://doi.org/10.1063/1.4816649, 2013.

Ketteler, G., Yamamoto, S., Bluhm, H., Andersson, K., Starr, D. E., Ogletree, D. F., Ogasawara, H., Nilsson, A., and Salmeron, M.: The Nature of Water Nucleation Sites on TiO2(110) Surfaces Revealed by Ambient Pressure X-ray Photoelectron Spectroscopy, J. Phys. Chem. C, 111, 8278-8282, 2007.

Khalizov, A. F., Xue, H., Wang, L., Zheng, J., and Zhang, R.: Enhanced Light Absorption and Scattering by Carbon Soot Aerosol Internally Mixed with Sulfuric Acid, J. Phys. Chem. A, 113, 1066-1074, 2009.

Kim, D., Chin, M., Yu, H., Diehl, T., Tan, Q., Kahn, R. A., Tsigaridis, K., Bauer, S. E., Takemura, T., Pozzoli, L., Bellouin, N., Schulz, M., Peyridieu, S., Chédin, A., and Koffi, B.: Sources, sinks, and transatlantic transport of North African dust aerosol: A multimodel analysis and comparison with remote sensing data, J. Geophys. Res.-Atmos, 119, 6259-6277, 2014.

Kim, J. S. and Park, K.: Atmospheric Aging of Asian Dust Particles During Long Range Transport, Aerosol Sci. Technol., 46, 913 924, 2012

Knopf, D. A., Alpert, P. A., and Wang, B.: The Role of Organic Aerosol in Atmospheric Ice Nucleation: A Review, ACS Earth Space Chem., 2, 168-202, 2018.

Knox, K. J. and Reid, J. P.: Ultrasensitive Absorption Spectroscopy of Optically-Trapped Aerosol Droplets, J. Phys. Chem. A, 112, 10439-10441, 2008.

Knox, K. J., Reid, J. P., Hanford, K. L., Hudson, A. J., and Mitchem, L.: Direct measurements of the axial displacement and evolving size of optically trapped aerosol droplets, J. Opt. A-Pure Appl. Op., 9, S180-S188, 2007.

Koehler, K. A., Kreidenweis, S. M., DeMott, P. J., Petters, M. D., Prenni, A. J., and Carrico, C. M.: Hygroscopicity and cloud droplet activation of mineral dust aerosol, Geophys. Res. Lett., 36, L08805, https://doi.org/10.1029/2009GL037348, 2009.

Koloutsou-Vakakis, S., Carrico, C. M., Kus, P., Rood, M. J., Li, Z., Shrestha, R., Ogren, J. A., Chow, J. C., and Watson, J. G.: Aerosol properties at a midlatitude Northern Hemisphere continental site, J. Geophys. Res.-Atmos., 106, 3019-3032, 2001.

Koop, T., Bookhold, J., Shiraiwa, M., and Poschl, U.: Glass transition and phase state of organic compounds: dependency on molecular properties and implications for secondary organic aerosols in the atmosphere, Phys. Chem. Chem. Phys., 13, 19238-19255, 2011.

Kreidenweis, S. M. and Asa-Awuku, A.: 5.13 - Aerosol Hygroscopicity: Particle Water Content and Its Role in Atmospheric Processes, in: Treatise on Geochemistry (Second Edition), edited by: Turekian, K. K., Elsevier, Oxford, 331-361, 2014.

Kreisberg, N. M., Stolzenburg, M. R., Hering, S. V., Dick, W. D., and McMurry, P. H.: A new method for measuring the dependence of particle size distributions on relative humidity, with application to the Southeastern Aerosol and Visibility Study, J. Geophys. Res.-Atmos., 106, 14935-14949, 2001.

Krieger, U. K., Marcolli, C., and Reid, J. P.: Exploring the complexity of aerosol particle properties and processes using single particle techniques, Chem. Soc. Rev., 41, 6631-6662, 2012.

Krueger, B. J., Grassian, V. H., Laskin, A., and Cowin, J. P.: The Transformation of Solid Atmospheric Particles into Liquid Droplets through Heterogeneous Chemistry: Laboratory Insights into the Processing of Calcium Containing Mineral Dust
Aerosol in the Troposphere, Geophys. Res. Lett., 30, 1148, https://doi.org/10.1029/2002GL016563, 2003.

Krueger, B. J., Grassian, V. H., Cowin, J. P., and Laskin, A.: Heterogeneous chemistry of individual mineral dust particles from different dust source regions: the importance of particle mineralogy, Atmos. Environ., 38, 6253-6261, 2004.

Krueger, B. J., Ross, J. L., and Grassian, V. H.: Formation of microcrystals, micropuddles, and other spatial inhomogenieties in surface reactions under ambient conditions: An atomic force microscopy study of water and nitric acid adsorption on $\mathrm{MgO}(100)$ and $\mathrm{CaCO}_{3}$ (1014), Langmuir, 21, 8793-8801, 2005.

Kuang, Y., Zhao, C., Tao, J., Bian, Y., Ma, N., and Zhao, G.: A novel method for deriving the aerosol hygroscopicity parameter based only on measurements from a humidified nephelometer system, Atmos. Chem. Phys., 17, 6651-6662, https://doi.org/10.5194/acp-17-6651-2017, 2017.

Kuang, Y., Zhao, C. S., Zhao, G., Tao, J. C., Xu, W., Ma, N., and Bian, Y. X.: A novel method for calculating ambient aerosol liquid water content based on measurements of a humidified nephelometer system, Atmos. Meas. Tech., 11, 2967-2982, https://doi.org/10.5194/amt-11-2967-2018, 2018.

Kulkarni, P., Baron, P. A., and Willeke, K.: Aerosol Measurement: Principles, Techniques, and Applications (Third edition), ed., John Wiley \& Sons, Inc., Hoboken, New Jersey, 2011.

Kumar, R., Saunders, R. W., Mahajan, A. S., Plane, J. M. C., and Murray, B. J.: Physical properties of iodate solutions and the deliquescence of crystalline $\mathrm{I}_{2} \mathrm{O}_{5}$ and $\mathrm{HIO}_{3}$, Atmos. Chem. Phys., 10, 12251-12260, https://doi.org/10.5194/acp-10-122512010, 2010.

Kuwata, M.: Particle Classification by the Tandem Differential Mobility Analyzer-Particle Mass Analyzer System, Aerosol Sci. Technol., 49, 508-520, 2015.

Kuzmiakova, A., Dillner, A. M., and Takahama, S.: An automated baseline correction protocol for infrared spectra of atmospheric aerosols collected on polytetrafluoroethylene (Teflon) filters, Atmos. Meas. Tech., 9, 2615-2631, https://doi.org/10.5194/amt-92615-2016, 2016.

Lack, D. A., Quinn, P. K., Massoli, P., Bates, T. S., Coffman, D., Covert, D. S., Sierau, B., Tucker, S., Baynard, T., Lovejoy, E., Murphy, D. M., and Ravishankara, A. R.: Relative humidity dependence of light absorption by mineral dust after long-range atmospheric transport from the Sahara, Geophys. Res. Lett., 36, L24805, https://doi.org/10.1029/2009g1041002, 2009

Lack, D. A., Moosmuller, H., McMeeking, G. R., Chakrabarty, R. K., and Baumgardner, D.: Characterizing elemental, equivalent black, and refractory black carbon aerosol particles: a review of techniques, their limitations and uncertainties, Anal. Bioanal. Chem., 406, 99-122, 2014.

Ladino Moreno, L. A., Stetzer, O., and Lohmann, U.: Contact freezing: a review of experimental studies, Atmos. Chem. Phys., 13, 9745-9769, https://doi.org/10.5194/acp-13-9745-2013, 2013.

Lance, S., Medina, J., Smith, J. N., and Nenes, A.: Mapping the operation of the DMT Continuous Flow CCN counter, Aerosol Sci. Technol., 40, 242-254, 2006.

Langridge, J. M., Richardson, M. S., Lack, D., Law, D., and Murphy, D. M.: Aircraft Instrument for Comprehensive Characterization of Aerosol Optical Properties, Part I: Wavelength-Dependent Optical Extinction and Its Relative Humidity Dependence Mea- 
sured Using Cavity Ringdown Spectroscopy, Aerosol Sci. Technol., 45, 1305-1318, 2011.

Langridge, J. M., Richardson, M. S., Lack, D. A., Brock, C. A., and Murphy, D. M.: Limitations of the Photoacoustic Technique for Aerosol Absorption Measurement at High Relative Humidity, Aerosol Sci. Technol., 47, 1163-1173, 2013.

Laskin, A., Iedema, M. J., Ichkovich, A., Graber, E. R., Taraniuk, I., and Rudich, Y.: Direct Observation of Completely Processed Calcium Carbonate Dust Particles, Faraday Discuss., 130, 453468, 2005.

Laskina, O., Morris, H. S., Grandquist, J. R., Estillore, A. D., Stone, E. A., Grassian, V. H., and Tivanski, A. V.: Substrate-Deposited Sea Spray Aerosol Particles: Influence of Analytical Method, Substrate, and Storage Conditions on Particle Size, Phase, and Morphology, Environ. Sci. Technol., 49, 13447-13453, 2015a.

Laskina, O., Morris, H. S., Grandquist, J. R., Estillore, A. D., Stone, E. A., Grassian, V. H., and Tivanski, A. V.: Substrate-Deposited Sea Spray Aerosol Particles: Influence of Analytical Method, Substrate, and Storage Conditions on Particle Size, Phase, and Morphology, Environ. Sci. Technol., 49, 13447-13453, 2015b.

Lathem, T. L. and Nenes, A.: Water Vapor Depletion in the DMT Continuous-Flow CCN Chamber: Effects on Supersaturation and Droplet Growth, Aerosol Sci. Technol., 45, 604-615, 2011.

Lau, N. T., Chan, C. K., Chan, L. I., and Fang, M.: A microscopic study of the effects of particle size and composition of atmospheric aerosols on the corrosion of mild steel, Corros. Sci., 50, 2927-2933, 2008.

Lee, A. K. Y. and Chan, C. K.: Heterogeneous Reactions of Linoleic Acid and Linolenic Acid Particles with Ozone: Reaction Pathways and Changes in Particle Mass, Hygroscopicity, and Morphology, J. Phys. Chem. A, 111, 6285-6295, 2007.

Lee, A. K. Y., Ling, T. Y., and Chan, C. K.: Understanding hygroscopic growth and phase transformation of aerosols using single particle Raman spectroscopy in an electrodynamic balance, Faraday Discuss., 137, 245-263, 2008.

Lee, C. T. and Hsu, W. C.: A novel method to measure aerosol water mass, J. Aerosol. Sci., 29, 827-837, 1998.

Lee, C. T. and Hsu, W. C.: The measurement of liquid water mass associated with collected hygroscopic particles, J. Aerosol. Sci., 31, 189-197, 2000.

Lee, C. T. and Chang, S. Y.: A GC-TCD method for measuring the liquid water mass of collected aerosols, Atmos. Environ., 36, 1883-1894, 2002.

Lehmpuhl, D. W., Ramirez-Aguilar, K. A., Michel, A. E., Rowlen, K. L., and Birks, J. W.: Physical and chemical characterization of atmospheric aerosols by atomic force microscopy, Anal. Chem., 71, 379-383, 1999.

Lehmuskero, A., Johansson, P., Rubinsztein-Dunlop, H., Tong, L. M., and Kall, M.: Laser Trapping of Colloidal Metal Nanoparticles, ACS Nano, 9, 3453-3469, 2015.

Lei, T., Zuend, A., Wang, W. G., Zhang, Y. H., and Ge, M. F.: Hygroscopicity of organic compounds from biomass burning and their influence on the water uptake of mixed organic ammonium sulfate aerosols, Atmos. Chem. Phys., 14, 11165-11183, https://doi.org/10.5194/acp-14-11165-2014, 2014.

Leng, C. B., Pang, S. F., Zhang, Y., Cai, C., Liu, Y., and Zhang, Y. H.: Vacuum FTIR Observation on the Dynamic Hygroscopicity of Aerosols under Pulsed Relative Humidity, Environ. Sci. Technol., 49, 9107-9115, 2015.
Lewis, K. A., Arnott, W. P., Moosmüller, H., Chakrabarty, R. K., Carrico, C. M., Kreidenweis, S. M., Day, D. E., Malm, W. C., Laskin, A., Jimenez, J. L., Ulbrich, I. M., Huffman, J. A., Onasch, T. B., Trimborn, A., Liu, L., and Mishchenko, M. I.: Reduction in biomass burning aerosol light absorption upon humidification: roles of inorganically-induced hygroscopicity, particle collapse, and photoacoustic heat and mass transfer, Atmos. Chem. Phys., 9, 8949-8966, https://doi.org/10.5194/acp-9-89492009, 2009.

Li-Jones, X., Maring, H. B., and Prospero, J. M.: Effect of relative humidity on light scattering by mineral dust aerosol as measured in the marine boundary layer over the tropical Atlantic Ocean, J. Geophys. Res.-Atmos, 103, 31113-31121, 1998.

Li, H. J., Zhu, T., Zhao, D. F., Zhang, Z. F., and Chen, Z. M.: Kinetics and mechanisms of heterogeneous reaction of $\mathrm{NO}_{2}$ on $\mathrm{CaCO}_{3}$ surfaces under dry and wet conditions, Atmos. Chem. Phys., 10, 463-474, https://doi.org/10.5194/acp-10-463-2010, 2010.

Li, K., Ye, X., Pang, H., Lu, X., Chen, H., Wang, X., Yang, $\mathrm{X}$., Chen, J., and Chen, Y.: Temporal variations in the hygroscopicity and mixing state of black carbon aerosols in a polluted megacity area, Atmos. Chem. Phys., 18, 15201-15218, https://doi.org/10.5194/acp-18-15201-2018, 2018.

Li, W., Shao, L., Zhang, D., Ro, C.-U., Hu, M., Bi, X., Geng, H., Matsuki, A., Niu, H., and Chen, J.: A Review of Single Aerosol Particle Studies in the Atmosphere of East Asia: Morphology, Mixing State, Source, and Heterogeneous Reactions, J. Clean. Prod., 112, 1330-1349, 2015.

Li, W. J., Shao, L. Y., Shi, Z. B., Chen, J. M., Yang, L. X., Yuan, Q., Yan, C., Zhang, X. Y., Wang, Y. Q., Sun, J. Y., Zhang, Y. M., Shen, X. J., Wang, Z. F., and Wang, W. X.: Mixing state and hygroscopicity of dust and haze particles before leaving Asian continent, J. Geophys. Res.-Atmos., 119, 1044-1059, 2014.

Li, X. H., Wang, F., Lu, P. D., Dong, J. L., Wang, L. Y., and Zhang, Y. H.: Confocal Raman observation of the efflorescence/deliquescence processes of individual NaNO3 particles on quartz, J. Phys. Chem. B, 110, 24993-24998, 2006.

Li, Y. J., Huang, D. D., Cheung, H. Y., Lee, A. K. Y., and Chan, C. K.: Aqueous-phase photochemical oxidation and direct photolysis of vanillin - a model compound of methoxy phenols from biomass burning, Atmos. Chem. Phys., 14, 2871-2885, https://doi.org/10.5194/acp-14-2871-2014, 2014.

Li, Z., Gu, X., Wang, L., Li, D., Xie, Y., Li, K., Dubovik, O., Schuster, G., Goloub, P., Zhang, Y., Li, L., Ma, Y., and Xu, H.: Aerosol physical and chemical properties retrieved from ground-based remote sensing measurements during heavy haze days in Beijing winter, Atmos. Chem. Phys., 13, 10171-10183, https://doi.org/10.5194/acp-13-10171-2013, 2013.

Li, Z. Y., Hu, R. Z., Xie, P. H., Wang, H. C., Lu, K. D., and Wang, D.: Intercomparison of in situ CRDS and CEAS for measurements of atmospheric N2O5 in Beijing, China, Sci. Total Environ., 613, 131-139, 2018.

Liang, J.-G., Kim, E.-S., Wang, C., Cho, M.-Y., Oh, J.-M., and Kim, N.-Y.: Thickness effects of aerosol deposited hygroscopic films on ultra-sensitive humidity sensors, Sensors Actuat. B, 265, 632643, 2018.

Ling, T. Y. and Chan, C. K.: Formation and transformation of metastable double salts from the crystallization of mixed am- 
monium nitrate and ammonium sulfate particles, Environ. Sci. Technol., 41, 8077-8083, 2007.

Ling, T. Y. and Chan, C. K.: Partial crystallization and deliquescence of particles containing ammonium sulfate and dicarboxylic acids, J. Geophys. Res.-Atmos., 113, D14205, https://doi.org/10.1029/2008JD009779, 2008.

Liu, B. Y. H., Pui, D. Y. H., Whitby, K. T., Kittelson, D. B., Kousaka, Y., and McKenzie, R. L.: The aerosol mobility chromatograph: A new detector for sulfuric acid aerosols, Atmos. Environ., 12, 99104, 1978

Liu, C., Ma, Q. X., He, H., He, G. Z., Ma, J. Z., Liu, Y. C., and Wu, Y.: Structure-activity relationship of surface hydroxyl groups during NO2 adsorption and transformation on TiO2 nanoparticles, Environ. Sci. Nano, 4, 2388-2394, 2017.

Liu, D., Allan, J., Whitehead, J., Young, D., Flynn, M., Coe, H., McFiggans, G., Fleming, Z. L., and Bandy, B.: Ambient black carbon particle hygroscopic properties controlled by mixing state and composition, Atmos. Chem. Phys., 13, 2015-2029, https://doi.org/10.5194/acp-13-2015-2013, 2013a.

Liu, D. F., Ma, G., Xu, M., and Allen, H. C.: Adsorption of Ethylene Glycol Vapor on $\alpha-\mathrm{Al}_{2} \mathrm{O}_{3}(0001)$ and Amorphous $\mathrm{SiO}_{2}$ Surfaces: Observation of Molecular Orientation and Surface Hydroxyl Groups as Sorption Sites, Environ. Sci. Technol., 39, 206212, 2005

Liu, P. F., Li, Y. J., Wang, Y., Gilles, M. K., Zaveri, R. A., Bertram, A. K., and Martin, S. T.: Lability of secondary organic particulate matter, P. Natl. Acad. Sci. USA, 113, 12643-12648, 2016.

Liu, X. G., Zhang, Y. H., Cheng, Y. F., Hu, M., and Han, T. T.: Aerosol hygroscopicity and its impact on atmospheric visibility and radiative forcing in Guangzhou during the 2006 PRIDE-PRD campaign, Atmos. Environ., 60, 59-67, 2012.

Liu, X. G., Gu, J. W., Li, Y. P., Cheng, Y. F., Qu, Y., Han, T. T., Wang, J. L., Tian, H. Z., Chen, J., and Zhang, Y. H.: Increase of aerosol scattering by hygroscopic growth: Observation, modeling, and implications on visibility, Atmos. Res., 132, 91-101, $2013 b$.

Liu, Y. and Laskin, A.: Hygroscopic Properties of CH3SO3Na, $\mathrm{CH} 3 \mathrm{SO} 3 \mathrm{NH} 4,\left(\mathrm{CH}_{3} \mathrm{SO}_{3}\right)(2) \mathrm{Mg}$, and $\left(\mathrm{CH}_{3} \mathrm{SO}_{3}\right)(2) \mathrm{Ca}$ Particles Studied by micro-FTIR Spectroscopy, J. Phys. Chem. A, 113, 1531-1538, 2009.

Liu, Y., Yang, Z., Desyaterik, Y., Gassman, P. L., Wang, H., and Laskin, A.: Hygroscopic behavior of substrate-deposited particles studied by micro-FT-IR spectroscopy and complementary methods of particle analysis, Anal. Chem., 80, 633-642, 2008a.

Liu, Y., Yang, Z., Desyaterik, Y., Gassman, P. L., Wang, H., and Laskin, A.: Hygroscopic behavior of substrate-deposited particles studied by micro-FT-IR spectroscopy and complementary methods of particle analysis, Anal. Chem., 80, 633-642, 2008b.

Liu, Y. J., Zhu, T., Zhao, D. F., and Zhang, Z. F.: Investigation of the hygroscopic properties of $\mathrm{Ca}\left(\mathrm{NO}_{3}\right)_{2}$ and internally mixed $\mathrm{Ca}\left(\mathrm{NO}_{3}\right)_{2} / \mathrm{CaCO}_{3}$ particles by micro-Raman spectrometry, Atmos. Chem. Phys., 8, 7205-7215, https://doi.org/10.5194/acp-87205-2008, 2008c.

Liu, Y. J.: Investigation of the hygroscopic properties of individual aerosol particles by micro-Raman spectrometry, MSc Thesis, Peking University, Beijing, 2008.

Liu, Y., Ma, Q., and He, H.: Comparative study of the effect of water on the heterogeneous reactions of carbonyl sulfide on the surface of $\alpha-\mathrm{Al}_{2} \mathrm{O}_{3}$ and $\mathrm{MgO}$, Atmos. Chem. Phys., 9, 62736286, https://doi.org/10.5194/acp-9-6273-2009, 2009.

Lohmann, U. and Feichter, J.: Global indirect aerosol effects: a review, Atmos. Chem. Phys., 5, 715-737, https://doi.org/10.5194/acp-5-715-2005, 2005.

Lohmann, U., Lüönd, F., and Mahrt, F.: An Introduction to Clouds: From the Microscale to Climate, Cambridge University Press, Cambridge, 2016.

Lopez-Yglesias, X. F., Yeung, M. C., Dey, S. E., Brechtel, F. J., and Chan, C. K.: Performance Evaluation of the Brechtel Mfg. Humidified Tandem Differential Mobility Analyzer (BMI HTDMA) for Studying Hygroscopic Properties of Aerosol Particles, Aerosol Sci. Technol., 48, 969-980, 2014.

Lu, J. W., Rickards, A. M. J., Walker, J. S., Knox, K. J., Miles, R. E. H., Reid, J. P., and Signorell, R.: Timescales of water transport in viscous aerosol: measurements on sub-micron particles and dependence on conditioning history, Phys. Chem. Chem. Phys., 16, 9819-9830, 2014.

Lv, M., Liu, D., Li, Z. Q., Mao, J. T., Sun, Y. L., Wang, Z. Z., Wang, Y. J., and Xie, C. B.: Hygroscopic growth of atmospheric aerosol particles based on lidar, radiosonde, and in situ measurements: Case studies from the Xinzhou field campaign, J. Quant. Spectrosc. Ra., 188, 60-70, 2017.

Ma, G., Liu, D. F., and Allen, H. C.: Piperidine adsorption on hydrated alpha-alumina (0001) surface studied by vibrational sum frequency generation spectroscopy, Langmuir, 20, 11620-11629, 2004.

Ma, Q. and He, H.: Synergistic effect in the humidifying process of atmospheric relevant calcium nitrate, calcite and oxalic acid mixtures, Atmos. Environ., 50, 97-102, 2012.

Ma, Q., He, H., Liu, Y., Liu, C., and Grassian, V. H.: Heterogeneous and multiphase formation pathways of gypsum in the atmosphere, Phys. Chem. Chem. Phys., 15, 19196-19204, 2013.

Ma, Q. X., He, H., and Liu, Y. C.: In Situ DRIFTS Study of Hygroscopic Behavior of Mineral Aerosol, J. Environ. Sci., 22, 555560, 2010a.

Ma, Q. X., Liu, Y. C., and He, H.: The Utilization of Physisorption Analyzer for Studying the Hygroscopic Properties of Atmospheric Relevant Particles, J. Phys. Chem. A, 114, 4232-4237, $2010 b$.

Ma, Q. X., Liu, Y. C., Liu, C., and He, H.: Heterogeneous Reaction of Acetic Acid on $\mathrm{MgO}, \alpha-\mathrm{Al}_{2} \mathrm{O}_{3}$, and $\mathrm{CaCO}_{3}$ and the Effect on the Hygroscopic Behavior of These Particles, Phys. Chem. Chem. Phys., 14, 8403-8409, 2012a.

Ma, Q. X., Liu, Y. C., Liu, C., Ma, J. Z., and He, H.: A case study of Asian dust storm particles: Chemical composition, reactivity to SO2 and hygroscopic properties, J. Environ. Sci., 24, 62-71, 2012b.

Ma, Q. X., Ma, J. Z., Liu, C., Lai, C. Y., and He, H.: Laboratory Study on the Hygroscopic Behavior of External and Internal C2-C-4 Dicarboxylic Acid-NaCl Mixtures, Environ. Sci. Technol., 47, 10381-10388, 2013.

Maffia, M. C. and Meirelles, A. J. A.: Water activity and $\mathrm{pH}$ in aqueous polycarboxylic acid systems, J. Chem. Eng. Data, 46, 582-587, 2001.

Magome, N., Kohira, M. I., Hayata, E., Mukai, S., and Yoshikawa, K.: Optical trapping of a growing water droplet in air, J. Phys. Chem. B, 107, 3988-3990, 2003. 
Mahowald, N.: Aerosol Indirect Effect on Biogeochemical Cycles and Climate, Science, 334, 794-796, 2011.

Mahowald, N., Ward, D. S., Kloster, S., Flanner, M. G., Heald, C. L., Heavens, N. G., Hess, P. G., Lamarque, J.-F., and Chuang, P. Y.: Aerosol Impacts on Climate and Biogeochemistry, Annu. Rev. Environ. Resour., 36, 45-74, 2011.

Malm, W. C. and Day, D. E.: Estimates of aerosol species scattering characteristics as a function of relative humidity, Atmos. Environ., 35, 2845-2860, 2001.

Malm, W. C., Day, D. E., and Kreidenweis, S. M.: Light scattering characteristics of aerosols as a function of relative humidity: Part I - A comparison of measured scattering and aerosol concentrations using the theoretical models, J. Air Waste Manage., 50, 686-700, 2000a.

Malm, W. C., Day, D. E., and Kreidenweis, S. M.: Light scattering characteristics of aerosols at ambient and as a function of relative humidity: Part II - A comparison of measured scattering and aerosol concentrations using statistical models, J. Air Waste Manage., 50, 701-709, 2000b.

Marcolli, C., Luo, B. P., and Peter, T.: Mixing of the organic aerosol fractions: Liquids as the thermodynamically stable phases, J. Phys. Chem. A, 108, 2216-2224, 2004.

Maria, S. F., Russell, L. M., Turpin, B. J., and Porcja, R. J.: FTIR measurements of functional groups and organic mass in aerosol samples over the Caribbean, Atmos. Environ., 36, 5185-5196, 2002.

Martin, S. T.: Phase transitions of aqueous atmospheric particles, Chem. Rev., 100, 3403-3453, 2000.

Martin-Torres, F. J., Zorzano, M. P., Valentin-Serrano, P., Harri, A. M., Genzer, M., Kemppinen, O., Rivera-Valentin, E. G., Jun, I., Wray, J., Madsen, M. B., Goetz, W., McEwen, A. S., Hardgrove, C., Renno, N., Chevrier, V. F., Mischna, M., Navarro-Gonzalez, R., Martinez-Frias, J., Conrad, P., McConnochie, T., Cockell, C. S., Berger, G., Vasavada, A. R., Sumner, D., and Vaniman, D.: Transient liquid water and water activity at Gale crater on Mars, Nat. Geosci., 8, 357-361, 2015.

Mason, N. J., Drage, E. A., Webb, S. M., Dawes, A., McPheat, R., and Hayes, G.: The spectroscopy and chemical dynamics of microparticles explored using an ultrasonic trap, Faraday Discuss., 137, 367-376, 2008.

Massling, A., Leinert, S., Wiedensohler, A., and Covert, D.: Hygroscopic growth of sub-micrometer and one-micrometer aerosol particles measured during ACE-Asia, Atmos. Chem. Phys., 7, 3249-3259, https://doi.org/10.5194/acp-7-3249-2007, 2007.

Massling, A., Niedermeier, N., Hennig, T., Fors, E. O., Swietlicki, E., Ehn, M., Hämeri, K., Villani, P., Laj, P., Good, N., McFiggans, G., and Wiedensohler, A.: Results and recommendations from an intercomparison of six Hygroscopicity-TDMA systems, Atmos. Meas. Tech., 4, 485-497, https://doi.org/10.5194/amt-4485-2011, 2011.

Massoli, P., Lambe, A. T., Ahern, A. T., Williams, L. R., Ehn, M., Mikkila, J., Canagaratna, M. R., Brune, W. H., Onasch, T. B., Jayne, J. T., Petaja, T., Kulmala, M., Laaksonen, A., Kolb, C. E., Davidovits, P., and Worsnop, D. R.: Relationship between aerosol oxidation level and hygroscopic properties of laboratory generated secondary organic aerosol (SOA) particles, Geophys. Res. Lett., 37, L24801, https://doi.org/10.1029/2010GL045258, 2010.
Matsuki, A., Iwasaka, Y., Shi, G. Y., Zhang, D. Z., Trochkine, D., Yamada, M., Kim, Y. S., Chen, B., Nagatani, T., Miyazawa, T., Nagatani, M., and Nakata, H.: Morphological and chemical modification of mineral dust: Observational insight into the heterogeneous uptake of acidic gases, Geophys. Res. Lett., 32, L22806, https://doi.org/10.1029/2005GL024176, 2005.

Matsumura, T. and Hayashi, M.: Hygroscopic growth of an (NH4)(2)SO4 aqueous solution droplet measured using an environmental scanning electron microscope (ESEM), Aerosol Sci. Technol., 41, 770-774, 2007.

Mauer, L. J. and Taylor, L. S.: Deliquescence of pharmaceutical systems, Pharm. Dev. Technol., 15, 582-594, 2010a.

Mauer, L. J. and Taylor, L. S.: Water-Solids Interactions: Deliquescence, Annu. Rev. Food Sci. Technol., 1, 41-63, 2010 b.

McFiggans, G., Artaxo, P., Baltensperger, U., Coe, H., Facchini, M. C., Feingold, G., Fuzzi, S., Gysel, M., Laaksonen, A., Lohmann, U., Mentel, T. F., Murphy, D. M., O’Dowd, C. D., Snider, J. R., and Weingartner, E.: The effect of physical and chemical aerosol properties on warm cloud droplet activation, Atmos. Chem. Phys., 6, 2593-2649, https://doi.org/10.5194/acp-6-25932006, 2006.

McGloin, D.: Optical tweezers: 20 years on, Philos. T. Roy. Soc. A, 364, 3521-3537, 2006

McInnes, L. M., Quinn, P. K., Covert, D. S., and Anderson, T. L.: Gravimetric analysis, ionic composition, and associated water mass of the marine aerosol, Atmos. Environ., 30, 869-884, 1996.

McMeeking, G. R., Good, N., Petters, M. D., McFiggans, G., and Coe, H.: Influences on the fraction of hydrophobic and hydrophilic black carbon in the atmosphere, Atmos. Chem. Phys., 11, 5099-5112, https://doi.org/10.5194/acp-115099-2011, 2011.

McMurry, P. H.: A review of atmospheric aerosol measurements, Atmos. Environ., 34, 1959-1999, 2000.

McMurry, P. H. and Stolzenburg, M. R.: On the sensitivity of particle size to relative humidity for Los Angeles aerosols, Atmos. Environ., 23, 497-507, 1989.

Mikhailov, E., Vlasenko, S., Martin, S. T., Koop, T., and Pöschl, U.: Amorphous and crystalline aerosol particles interacting with water vapor: conceptual framework and experimental evidence for restructuring, phase transitions and kinetic limitations, Atmos. Chem. Phys., 9, 9491-9522, https://doi.org/10.5194/acp-9-94912009, 2009.

Mikhailov, E., Vlasenko, S., Rose, D., and Pöschl, U.: Mass-based hygroscopicity parameter interaction model and measurement of atmospheric aerosol water uptake, Atmos. Chem. Phys., 13, $717-$ 740, https://doi.org/10.5194/acp-13-717-2013, 2013.

Mikhailov, E. F., Merkulov, V. V., Vlasenko, S. S., Ryshkevich, T. I., and Pöschl, U. J.: Filter-based differential hygroscopicity analyzer of aerosol particles, Izvestiya, Atmos. Ocean. Phys. 47, 747-759, 2011.

Mikhailov, E. F., Mironov, G. N., Pöhlker, C., Chi, X., Krüger, M. L., Shiraiwa, M., Förster, J.-D., Pöschl, U., Vlasenko, S. S., Ryshkevich, T. I., Weigand, M., Kilcoyne, A. L. D., and Andreae, M. O.: Chemical composition, microstructure, and hygroscopic properties of aerosol particles at the Zotino Tall Tower Observatory (ZOTTO), Siberia, during a summer campaign, Atmos. Chem. Phys., 15, 8847-8869, https://doi.org/10.5194/acp15-8847-2015, 2015. 
Miranda, P. B., Xu, L., Shen, Y. R., and Salmeron, M.: Icelike water monolayer adsorbed on mica at room temperature, Phys. Rev. Lett., 81, 5876-5879, 1998.

Mitchem, L. and Reid, J. P.: Optical manipulation and characterisation of aerosol particles using a single-beam gradient force optical trap, Chem. Soc. Rev., 37, 756-769, 2008.

Mitchem, L., Buajarern, J., Hopkins, R. J., Ward, A. D., Gilham, R. J. J., Johnston, R. L., and Reid, J. P.: Spectroscopy of growing and evaporating water droplets: Exploring the variation in equilibrium droplet size with relative humidity, J. Phys. Chem. A, 110, 8116-8125, 2006a.

Mitchem, L., Buajarern, J., Ward, A. D., and Reid, J. P.: A strategy for characterizing the mixing state of immiscible aerosol components and the formation of multiphase aerosol particles through coagulation, J. Phys. Chem. B, 110, 13700-13703, 2006b.

Montgomery, J. F., Rogak, S. N., Green, S. I., You, Y., and Bertram, A. K.: Structural Change of Aerosol Particle Aggregates with Exposure to Elevated Relative Humidity, Environ. Sci. Technol., 49, 12054-12061, 2015.

Moosmuller, H., Chakrabarty, R. K., and Arnott, W. P.: Aerosol light absorption and its measurement: A review, J. Quant. Spectrosc. Ra., 110, 844-878, 2009.

Morris, H. S., Grassian, V. H., and Tivanski, A. V.: Humiditydependent surface tension measurements of individual inorganic and organic submicrometre liquid particles, Chem. Sci., 6, 32423247, 2015.

Morris, H. S., Estillore, A. D., Laskina, O., Grassian, V. H., and Tivanski, A. V.: Quantifying the Hygroscopic Growth of Individual Submicrometer Particles with Atomic Force Microscopy, Anal. Chem., 88, 3647-3654, 2016.

Moteki, N. and Kondo, Y.: Dependence of Laser-Induced Incandescence on Physical Properties of Black Carbon Aerosols: Measurements and Theoretical Interpretation, Aerosol Sci. Technol., 44, 663-675, 2010.

Mu, Q., Shiraiwa, M., Octaviani, M., Ma, N., Ding, A. J., Su, H., Lammel, G., Poeschl, U., and Cheng, Y. F.: Temperature effect on phase state and reactivity controls atmospheric multiphase chemistry and transport of PAHs, Scie. Adv., 4, UNSP eaap7314, https://doi.org/10.1126/sciadv.aap7314, 2018.

Murray, B. J., O'Sullivan, D., Atkinson, J. D., and Webb, M. E.: Ice nucleation by particles immersed in supercooled cloud droplets, Chem. Soc. Rev., 41, 6519-6554, 2012.

Najera, J. J., Percival, C. J., and Horn, A. B.: Infrared spectroscopic studies of the heterogeneous reaction of ozone with dry maleic and fumaric acid aerosol particles, Phys. Chem. Chem. Phys., 11, 9093-9103, 2009.

Navea, J. G., Chen, H. H., Huang, M., Carmichael, G. R., and Grassian, V. H.: A comparative evaluation of water uptake on several mineral dust sources, Environ. Chem., 7, 162-170, 2010.

Navea, J. G., Richmond, E., Stortini, T., and Greenspan, J.: Water Adsorption Isotherms on Fly Ash from Several Sources, Langmuir, 33, 10161-10171, 2017.

Nenes, A., Chuang, P. Y., Flagan, R. C., and Seinfeld, J. H.: A theoretical analysis of cloud condensation nucleus (CCN) instruments, J. Geophys. Res.-Atmos., 106, 3449-3474, 2001.

Newman, A. W., Reutzel-Edens, S. M., and Zografi, G.: Characterization of the "Hygroscopic" properties of active pharmaceutical ingredients, J. Pharm. Sci., 97, 1047-1059, 2008.
Niedermeier, D., Wex, H., Voigtländer, J., Stratmann, F., Brüggemann, E., Kiselev, A., Henk, H., and Heintzenberg, J.: LACISmeasurements and parameterization of sea-salt particle hygroscopic growth and activation, Atmos. Chem. Phys., 8, 579-590, https://doi.org/10.5194/acp-8-579-2008, 2008.

Ohata, S., Schwarz, J. P., Moteki, N., Koike, M., Takami, A., and Kondo, Y.: Hygroscopicity of materials internally mixed with black carbon measured in Tokyo, J. Geophys. Res.-Atmos., 121, 362-381, 2016.

Olfert, J. S. and Collings, N.: New method for particle mass classification - the Couette centrifugal particle mass analyzer, J. Aerosol. Sci., 36, 1338-1352, 2005.

Onasch, T. B., Siefert, R. L., Brooks, S. D., Prenni, A. J., Murray, B., Wilson, M. A., and Tolbert, M. A.: Infrared spectroscopic study of the deliquescence and efflorescence of ammonium sulfate aerosol as a function of temperature, J. Geophys Res.-Atmos., 104, 21317-21326, 1999.

Pöhlker, C., Saturno, J., Krüger, M. L., Förster, J.-D., Weigand, M., Wiedemann, K. T., Bechtel, M., Artaxo, P., and Andreae, M. O.: Efflorescence upon humidification? X-ray microspectroscopic in situ observation of changes in aerosol microstructure and phase state upon hydration, Geophys. Res. Lett., 41, 3681-3689, 2014.

Pöschl, U.: Atmospheric Aerosols: Composition, Transformation, Climate and Health Effects, Angew. Chem.-Int. Edit., 44, 7520 7540, 2005.

Pöschl, U. and Shiraiwa, M.: Multiphase Chemistry at the Atmosphere-Biosphere Interface Influencing Climate and Public Health in the Anthropocene, Chem. Rev., 115, 4440-4475, 2015.

Pahlow, M., Feingold, G., Jefferson, A., Andrews, E., Ogren, J. A., Wang, J., Lee, Y. N., Ferrare, R. A., and Turner, D. D.: Comparison between lidar and nephelometer measurements of aerosol hygroscopicity at the Southern Great Plains Atmospheric Radiation Measurement site, J. Geophys. Res.-Atmos., 111, D05S15, https://doi.org/10.1029/2004JD005646, 2006.

Pant, A., Fok, A., Parsons, M. T., Mak, J., and Bertram, A. K.: Deliquescence and crystallization of ammonium sulfate-glutaric acid and sodium chloride-glutaric acid particles, Geophys. Res. Lett., 31, L12111, https://doi.org/10.1029/2004g1020025, 2004.

Pant, A., Parsons, M. T., and Bertram, A. K.: Crystallization of aqueous ammonium sulfate particles internally mixed with soot and kaolinite: Crystallization relative humidities and nucleation rates, J. Phys. Chem. A, 110, 8701-8709, 2006.

Parsons, M. T., Knopf, D. A., and Bertram, A. K.: Deliquescence and Crystallization of Ammonium Sulfate Particles Internally Mixed with Water-Soluble Organic Compounds, J. Phys. Chem. A, 108, 11600-11608, 2004a.

Parsons, M. T., Mak, J., Lipetz, S. R., and Bertram, A. K.: Deliquescence of malonic, succinic, glutaric, and adipic acid particles, J. Geophys. Res.-Atmos., 109, D06212, https://doi.org/10.1029/2003JD004075, 2004b.

Parsons, M. T., Riffell, J. L., and Bertram, A. K.: Crystallization of aqueous inorganic-malonic acid particles: Nucleation rates, dependence on size, and dependence on the ammonium-to-sulfate, J. Phys. Chem. A, 110, 8108-8115, 2006.

Patashnick, H. and Rupprecht, E. G.: Continuous PM-10 measurement using the tapered element oscillating microbalance, J. Air Waste Manage., 41, 1079-1083, 1991. 
Patterson, J. P., Collins, D. B., Michaud, J. M., Axson, J. L., Sultana, C. M., Moser, T., Dommer, A. C., Conner, J., Grassian, V. H., Stokes, M. D., Deane, G. B., Evans, J. E., Burkart, M. D., Prather, K. A., and Gianneschi, N. C.: Sea Spray Aerosol Structure and Composition Using Cryogenic Transmission Electron Microscopy, ACS Central Science, 2, 40-47, 2016.

Peng, C. and Chan, C. K.: The water cycles of water-soluble organic salts of atmospheric importance, Atmos. Environ., 35, 11831192, 2001a.

Peng, C. G. and Chan, C. K.: The water cycles of water-soluble organic salts of atmospheric importance, Atmos. Environ., 35, 1183-1192, 2001b.

Peng, C., Chan, M. N., and Chan, C. K.: The hygroscopic properties of dicarboxylic and multifunctional acids: Measurements and UNIFAC predictions, Environ. Sci. Technol., 35, 4495-4501, 2001.

Peng, C., Wang, W. G., Li, K., Li, J. L., Zhou, L., Wang, L. S., and Ge, M. F.: The Optical Properties of Limonene Secondary Organic Aerosols: The Role of NO3, OH, and O-3 in the Oxidation Processes, J. Geophys. Res.-Atmos., 123, 3292-3303, 2018.

Peng, C. G., Chow, A. H. L., and Chan, C. K.: Study of the hygroscopic properties of selected pharmaceutical aerosols using single particle levitation, Pharm. Res., 17, 1104-1109, 2000.

Perring, A. E., Schwarz, J. P., Markovic, M. Z., Fahey, D. W., Jimenez, J. L., Campuzano-Jost, P., Palm, B. D., Wisthaler, A., Mikoviny, T., Diskin, G., Sachse, G., Ziemba, L., Anderson, B., Shingler, T., Crosbie, E., Sorooshian, A., Yokelson, R., and Gao, R. S.: In situ measurements of water uptake by black carboncontaining aerosol in wildfire plumes, J. Geophys. Res.-Atmos., 122, 1086-1097, 2017.

Petters, M. D. and Kreidenweis, S. M.: A single parameter representation of hygroscopic growth and cloud condensation nucleus activity, Atmos. Chem. Phys., 7, 1961-1971, https://doi.org/10.5194/acp-7-1961-2007, 2007.

Petters, M. D., Prenni, A. J., Kreidenweis, S. M., and DeMott, P. J.: On measuring the critical diameter of cloud condensation nuclei using mobility selected aerosol, Aerosol Sci. Technol., 41, 907913, 2007.

Petters, M. D., Wex, H., Carrico, C. M., Hallbauer, E., Massling, A., McMeeking, G. R., Poulain, L., Wu, Z., Kreidenweis, S. M., and Stratmann, F.: Towards closing the gap between hygroscopic growth and activation for secondary organic aerosol - Part 2: Theoretical approaches, Atmos. Chem. Phys., 9, 3999-4009, https://doi.org/10.5194/acp-9-3999-2009, 2009.

Piens, D. S., Kelly, S. T., Harder, T. H., Petters, M. D., O’Brien, R. E., Wang, B. B., Teske, K., Dowell, P., Laskin, A., and Gilles, M. K.: Measuring Mass-Based Hygroscopicity of Atmospheric Particles through in Situ Imaging, Environ. Sci. Technol., 50, 51725180, 2016.

Pilat, M. J. and Charlson, R. J.: Theoretical and optical studies of humidity effects on the size distribution of a hygroscopic aerosol, J. Rech. Atmos., 1, 165-170, 1966.

Pinterich, T., Spielman, S. R., Hering, S., and Wang, J.: A waterbased fast integrated mobility spectrometer (WFIMS) with enhanced dynamic size range, Aerosol Sci. Technol., 51, 12121222, 2017a.

Pinterich, T., Spielman, S. R., Wang, Y., Hering, S. V., and Wang, J.: A humidity-controlled fast integrated mobility spectrometer (HFIMS) for rapid measurements of parti- cle hygroscopic growth, Atmos. Meas. Tech., 10, 4915-4925, https://doi.org/10.5194/amt-10-4915-2017, 2017b.

Pitzer, K. S.: Activity Coefficients in Electrolyte Solutions, CRC Press, Boca Raton, Florida, USA, 1991.

Platt, U., Meinen, J., Pöhler, D., and Leisner, T.: Broadband Cavity Enhanced Differential Optical Absorption Spectroscopy (CEDOAS) - applicability and corrections, Atmos. Meas. Tech., 2, 713-723, https://doi.org/10.5194/amt-2-713-2009, 2009.

Pomorska, A., Shchukin, D., Hammond, R., Cooper, M. A., Grundmeier, G., and Johannsmann, D.: Positive Frequency Shifts Observed Upon Adsorbing Micron-Sized Solid Objects to a Quartz Crystal Microbalance from the Liquid Phase, Anal. Chem., 82, 2237-2242, 2010.

Pope, F. D.: Pollen grains are efficient cloud condensation nuclei, Environ. Res. Lett., 5, 044015, https://doi.org/10.1088/17489326/5/4/044015, 2010.

Pope, F. D., Dennis-Smither, B. J., Griffiths, P. T., Clegg, S. L., and Cox, R. A.: Studies of Single Aerosol Particles Containing Malonic Acid, Glutaric Acid, and Their Mixtures with Sodium Chloride. I. Hygroscopic Growth, J. Phys. Chem. A, 114, 5335-5341, 2010a.

Pope, F. D., Gallimore, P. J., Fuller, S. J., Cox, R. A., and Kalberer, M.: Ozonolysis of Maleic Acid Aerosols: Effect upon Aerosol Hygroscopicity, Phase and Mass, Environ. Sci. Technol., 44, 6656-6660, 2010b.

Popovicheva, O., Persiantseva, N. M., Shonija, N. K., DeMott, P., Koehler, K., Petters, M., Kreidenweis, S., Tishkova, V., Demirdjian, B., and Suzanne, J.: Water interaction with hydrophobic and hydrophilic soot particles, Phys. Chem. Chem. Phys., 10, 2332 2344, 2008a.

Popovicheva, O. B., Persiantseva, N. M., Tishkova, V., Shonija, N. K., and Zubareva, N. A.: Quantification of water uptake by soot particles, Environ. Res. Lett., 3, 025009, https://doi.org/10.1088/1748-9326/3/2/025009, 2008b.

Popovitcheva, O. B., Trukhin, M. E., Persiantseva, N. M., and Shonija, N. K.: Water adsorption on aircraft-combustor soot under young plume conditions, Atmos. Environ., 35, 1673-1676, 2001

Posfai, M. and Buseck, P. R.: Nature and Climate Effects of Individual Tropospheric Aerosol Particles, Annu. Rev. Earth Planet. Sci., 38, 17-43, 2010.

Posfai, M., Xu, H. F., Anderson, J. R., and Buseck, P. R.: Wet and dry sizes of atmospheric aerosol particles: An AFM-TEM study, Geophys. Res. Lett., 25, 1907-1910, 1998.

Power, R. M., Simpson, S. H., Reid, J. P., and Hudson, A. J.: The transition from liquid to solid-like behaviour in ultrahigh viscosity aerosol particles, Chem. Sci., 4, 2597-2604, 2013.

Prather, K. A., Hatch, C. D., and Grassian, V. H.: Analysis of Atmospheric Aerosols, Annu. Rev. Phys. Chem., 1, 485-514, 2008.

Prenni, A. J., Petters, M. D., Kreidenweis, S. M., DeMott, P. J., and Ziemann, P. J.: Cloud droplet activation of secondary organic aerosol, J. Geophys. Res.-Atmos., 112, D10223, https://doi.org/10.1029/2006JD007963, 2007.

Pruppacher, H. R. and Klett, J. D.: Microphysics of Clouds and Precipitation, 2nd ed., Kluwer Academic Publishers, Dordrecht, Netherlands 1997.

Quinn, P. K., Bates, T. S., Baynard, T., Clarke, A. D., Onasch, T. B., Wang, W., Rood, M. J., Andrews, E., Allan, J., Carrico, C. M., Coffman, D., and Worsnop, D.: Impact of particulate organic matter on the relative humidity dependence of light scattering: 
A simplified parameterization, Geophys. Res. Lett., 32, L22809, https://doi.org/10.1029/2005GL024322, 2005.

Quinn, P. K., Collins, D. B., Grassian, V. H., Prather, K. A., and Bates, T. S.: Chemistry and Related Properties of Freshly Emitted Sea Spray Aerosol, Chem. Rev., 115, 4383-4399, 2015.

Raatikainen, T., Vaattovaara, P., Tiitta, P., Miettinen, P., Rautiainen, J., Ehn, M., Kulmala, M., Laaksonen, A., and Worsnop, D. R.: Physicochemical properties and origin of organic groups detected in boreal forest using an aerosol mass spectrometer, Atmos. Chem. Phys., 10, 2063-2077, https://doi.org/10.5194/acp10-2063-2010, 2010.

Rader, D. J. and McMurry, P. H.: Application of the tandem differential mobility analyzer to studies of droplet growth or evaporation, J. Aerosol. Sci., 17, 771-787, 1986.

Rard, J. A. and Miller, D. G.: Isopiestic determination of the osmotic and activity coefficients of aqueous magnesium chloride solutions at $25^{\circ} \mathrm{C}$, J. Chem. Eng. Data, 26, 38-43, 1981.

Rard, J. A. and Clegg, S. L.: Critical Evaluation of the Thermodynamic Properties of Aqueous Calcium Chloride. 1. Osmotic and Activity Coefficients of 0-10.77 moløkg-1 Aqueous Calcium Chloride Solutions at 298.15 K and Correlation with Extended Pitzer Ion-Interaction Models, J. Chem. Eng. Data, 42, 819-849, 1997.

Redemann, J., Russell, P. B., and Hamill, P.: Dependence of aerosol light absorption and single-scattering albedo on ambient relative humidity for sulfate aerosols with black carbon cores, J. Geophys. Res.-Atmos., 106, 27485-27495, 2001.

Reid, J. P. and Sayer, R. M.: Heterogeneous atmospheric aerosol chemistry: laboratory studies of chemistry on water droplets, Chem. Soc. Rev., 32, 70-79, 2003.

Reid, J. P., Meresman, H., Mitchem, L., and Symes, R.: Spectroscopic studies of the size and composition of single aerosol droplets, Int. Rev. Phys. Chem., 26, 139-192, 2007.

Reid, J. P., Bertram, A. K., Topping, D. O., Laskin, A., Martin, S. T., Petters, M. D., Pope, F. D., and Rovelli, G.: The viscosity of atmospherically relevant organic particles, Nat. Commun., 9, 956, https://doi.org/10.1038/s41467-018-03027-z, 2018.

Renbaum-Wolff, L., Grayson, J. W., Bateman, A. P., Kuwata, M., Sellier, M., Murray, B. J., Shilling, J. E., Martin, S. T., and Bertram, A. K.: Viscosity of alpha-pinene secondary organic material and implications for particle growth and reactivity, P. Natl. Acad. Sci. USA, 110, 8014-8019, 2013.

Reutter, P., Su, H., Trentmann, J., Simmel, M., Rose, D., Gunthe, S. S., Wernli, H., Andreae, M. O., and Pöschl, U.: Aerosol- and updraft-limited regimes of cloud droplet formation: influence of particle number, size and hygroscopicity on the activation of cloud condensation nuclei (CCN), Atmos. Chem. Phys., 9, 70677080, https://doi.org/10.5194/acp-9-7067-2009, 2009.

Rissler, J., Pagels, J., Swietlicki, E., Wierzbicka, A., Strand, M., Lillieblad, L., Sanati, M., and Bohgard, M.: Hygroscopic behavior of aerosol particles emitted from biomass fired grate boilers, Aerosol Sci. Technol., 39, 919-930, 2005.

Rissler, J., Nordin, E. Z., Eriksson, A. C., Nilsson, P. T., Frosch, M., Sporre, M. K., Wierzbicka, A., Svenningsson, B., Londahl, J., Messing, M. E., Sjogren, S., Hemmingsen, J. G., Loft, S., Pagels, J. H., and Swietlicki, E.: Effective Density and Mixing State of Aerosol Particles in a Near-Traffic Urban Environment, Environ. Sci. Technol., 48, 6300-6308, 2014.
Rkiouak, L., Tang, M. J., Camp, J. C. J., McGregor, J., Watson, I. M., Cox, R. A., Kalberer, M., Ward, A. D., and Pope, F. D.: Optical trapping and Raman Spectroscopy of solid aerosol particles, Phys. Chem. Chem. Phys., 16, 11426-11434, 2014.

Roberts, G. C. and Nenes, A.: A continuous-flow streamwise thermal-gradient $\mathrm{CCN}$ chamber for atmospheric measurements, Aerosol Sci. Technol., 39, 206-221, 2005.

Robinson, C. B., Schill, G. P., Zarzana, K. J., and Tolbert, M. A.: Impact of Organic Coating on Optical Growth of Ammonium Sulfate Particles, Environ. Sci. Technol., 47, 13339-13346, 2013.

Robinson, C. B., Schill, G. P., and Tolbert, M. A.: Optical growth of highly viscous organic/sulfate particles, J. Atmos. Chem., 71, 145-156, 2014.

Robinson, R. J. and Yu, C. P.: Theoretical analysis of hygroscopic growth rate of mainstream and sidestream cigarette smoke particles in the human respiratory tract, Aerosol Sci. Technol., 28, 21-32, 1998.

Rodahl, M., and Kasemo, B.: On the measurement of thin liquid overlayers with the quartz-crystal microbalance, Sensor. Actuator., 54, 448-456, 1996.

Rogaski, C. A., Golden, D. M., and Williams, L. R.: Reactive uptake and hydration experiments on amorphous carbon treated with NO2, SO2, O3, HNO3, and H2SO4, Geophys. Res. Lett., 24, 381-384, 1997.

Rogers, C. F., Watson, J. G., Day, D., and Oraltay, R. G.: Real-time liquid water mass measurement for airborne particulates, Aerosol Sci. Technol., 29, 557-562, 1998.

Rood, M. J., Larson, T. V., Covert, D. S., and Ahlquist, N. C.: Measurement of laboratory and ambient aerosols with temperature and humidity controlled nephelometry, Atmos. Environ., 19, 1181-1190, 1985.

Rosenberger, T., Münzer, A., Kiesler, D., Wiggers, H., and Kruis, F. E.: Ejector-based sampling from low-pressure aerosol reactors, J. Aerosol. Sci., 123, 105-115, 2018.

Rubasinghege, G. and Grassian, V. H.: Role(s) of Adsorbed Water in the Surface Chemistry of Environmental Interfaces, Chem. Commun., 49, 3071-3094, 2013.

Russell, L. M., Bahadur, R., and Ziemann, P. J.: Identifying organic aerosol sources by comparing functional group composition in chamber and atmospheric particles, P. Natl. Acad. Sci. USA, 108, 3516-3521, 2011.

Sadeghi, R. and Shahebrahimi, Y.: Vapor-Liquid Equilibria of Aqueous Polymer Solutions from Vapor-Pressure Osmometry and Isopiestic Measurements, J. Chem. Eng. Dara, 56, 789-799, 2011.

Salcedo, D.: Equilibrium Phase Diagrams of Aqueous Mixtures of Malonic Acid and Sulfate/Ammonium Salts, J. Phys. Chem. A, 110, 12158-12165, 2006.

Salmeron, M. and Schlogl, R.: Ambient pressure photoelectron spectroscopy: A new tool for surface science and nanotechnology, Surf. Sci. Rep., 63, 169-199, 2008.

Santarpia, J. L., Li, R., and Collins, D. R.: Direct measurement of the hydration state of ambient aerosol populations, J. Geophys. Res.-Atmos, 109, D18209, https://doi.org/10.1029/2004JD004653, 2004.

Sarangi, B., Ramachandran, S., Rajesh, T. A., and Dhaker, V. K.: Black carbon linked aerosol hygroscopic growth: Size and mixing state are crucial, Atmos. Environ., 200, 110-118, 2019. 
Sauerbrey, G.: Verwendung von schwingquarzen zur wagung dunner schichten und zur mikrowagung, Z. Phys., 155, 206-222, 1959.

Schenk, J., Panne, U., and Albrecht, M.: Interaction of Levitated Ionic Liquid Droplets with Water, J. Phys. Chem. B, 116, 1417114177, 2012.

Schilling, C. and Winterer, M.: Preserving Particle Characteristics at Increasing Production Rate of ZnO Nanoparticles by Chemical Vapor Synthesis, Chem. Vapor Depos., 20, 138-145, 2014.

Schindelholz, E., Risteen, B. E., and Kelly, R. G.: Effect of Relative Humidity on Corrosion of Steel under Sea Salt Aerosol Proxies: I. NaCl, J. Electrochem. Soc., 161, C450-C459, 2014a.

Schindelholz, E., Risteen, B. E., and Kelly, R. G.: Effect of Relative Humidity on Corrosion of Steel under Sea Salt Aerosol Proxies: II. $\mathrm{MgCl} 2$, Artificial Seawater, J. Electrochem. Soc., 161, C460C470, 2014b.

Schindelholz, E., Tsui, L. K., and Kelly, R. G.: Hygroscopic Particle Behavior Studied by Interdigitated Array Microelectrode Impedance Sensors, J. Phys. Chem. A, 118, 167-177, $2014 \mathrm{c}$.

Schladitz, A., Müller, Thomas, Nowak, A., Kandler, K., Lieke, K., Massling, A., and Wiedensohler, A.: In situ aerosol characterization at Cape Verde. Part 1: particle number size distributions, hygroscopic growth and state of mixing of the marine and Saharan dust aerosol, Tellus B, 63, 531-548, 2011.

Schmid, O., Artaxo, P., Arnott, W. P., Chand, D., Gatti, L. V., Frank, G. P., Hoffer, A., Schnaiter, M., and Andreae, M. O.: Spectral light absorption by ambient aerosols influenced by biomass burning in the Amazon Basin. I: Comparison and field calibration of absorption measurement techniques, Atmos. Chem. Phys., 6, 3443-3462, https://doi.org/10.5194/acp-6-3443-2006, 2006.

Schroeder, J. R. and Beyer, K. D.: Deliquescence Relative Humidities of Organic and Inorganic Salts Important in the Atmosphere, J. Phys. Chem. A, 120, 9948-9957, 2016.

Schurman, M. I., Kim, J. Y., Cheung, H. H. Y., and Chan, C. K.: Atmospheric particle composition-hygroscopic growth measurements using an in-series hybrid tandem differential mobility analyzer and aerosol mass spectrometer, Aerosol Sci. Technol., 51, 694-703, 2017.

Schuster, G. L., Lin, B., and Dubovik, O.: Remote sensing of aerosol water uptake, Geophys. Res. Lett., 36, L03814, https://doi.org/10.1029/2008GL036576, 2009.

Schuttlefield, J., Al-Hosney, H., Zachariah, A., and Grassian, V. H.: Attenuated Total Reflection Fourier Transform Infrared Spectroscopy to Investigate Water Uptake and Phase Transitions in Atmospherically Relevant Particles, Appl. Spectrosc., 61, 283292, 2007a.

Schuttlefield, J. D., Cox, D., and Grassian, V. H.: An investigation of water uptake on clays minerals using ATRFTIR spectroscopy coupled with quartz crystal microbalance measurements, J. Geophys. Res.-Atmos., 112, D21303, https://doi.org/10.1029/2007JD008973, 2007b.

Schwarz, J. P., Gao, R. S., Spackman, J. R., Watts, L. A., Thomson, D. S., Fahey, D. W., Ryerson, T. B., Peischl, J., Holloway, J. S., Trainer, M., Frost, G. J., Baynard, T., Lack, D. A., de Gouw, J. A., Warneke, C., and Del Negro, L. A.: Measurement of the mixing state, mass, and optical size of individual black carbon particles in urban and biomass burning emissions, Geophys. Res. Lett., 35, L13810, https://doi.org/10.1002/2016GL071042, 2008.
Schwarz, J. P., Spackman, J. R., Gao, R. S., Watts, L. A., Stier, P., Schulz, M., Davis, S. M., Wofsy, S. C., and Fahey, D. W.: Global-scale black carbon profiles observed in the remote atmosphere and compared to models, Geophys. Res. Lett., 37, L18812, https://doi.org/10.1029/2010GL044372, 2010.

Schwarz, J. P., Perring, A. E., Markovic, M. Z., Gao, R. S., Ohata, S., Langridge, J., Law, D., McLaughlin, R., and Fahey, D. W.: Technique and theoretical approach for quantifying the hygroscopicity of black-carbon-containing aerosol using a single particle soot photometer, J. Aerosol. Sci., 81, 110-126, 2015.

Sedlacek, A. and Lee, J.: Photothermal interferometric aerosol absorption spectrometry, Aerosol Sci. Technol., 41, 1089-1101, 2007.

Seinfeld, J. H. and Pandis, S. N.: Atmospheric Chemistry and Physics: From Air Pollution to Climate Change (Third edition), Wiley Interscience, New York, 2016.

Seisel, S., Lian, Y., Keil, T., Trukhin, M. E., and Zellner, R.: Kinetics of the interaction of water vapour with mineral dust and soot surfaces at $\mathrm{T}=298 \mathrm{~K}$, Phys. Chem. Chem. Phys., 6, 1926-1932, 2004.

Seisel, S., Pashkova, A., Lian, Y., and Zellner, R.: Water uptake on mineral dust and soot: A fundamental view of the hydrophilicity of atmospheric particles?, Faraday Discuss., 130, 437-451, 2005.

Semeniuk, T. A., Wise, M. E., Martin, S. T., Russell, L. M., and Buseck, P. R.: Hygroscopic behavior of aerosol particles from biomass fires using environmental transmission electron microscopy, J. Atmos. Chem., 56, 259-273, 2007a.

Semeniuk, T. A., Wise, M. E., Martin, S. T., Russell, L. M., and Buseck, P. R.: Water uptake characteristics of individual atmospheric particles having coatings, Atmos. Environ., 41, 62256235, $2007 \mathrm{~b}$.

Shi, Z., Zhang, D., Hayashi, M., Ogata, H., Ji, H., and Fujiie, W.: Influences of sulfate and nitrate on the hygroscopic behaviour of coarse dust particles, Atmos. Environ., 42, 822-827, 2008.

Shiraiwa, M., Ammann, M., Koop, T., and Poschl, U.: Gas uptake and chemical aging of semisolid organic aerosol particles, P. Natl. Acad. Sci. USA, 108, 11003-11008, 2011.

Shiraiwa, M., Li, Y., Tsimpidi, A. P., Karydis, V. A., Berkemeier, T., Pandis, S. N., Lelieveld, J., Koop, T., and Pöschl, U.: Global distribution of particle phase state in atmospheric secondary organic aerosols, Nat. Commun., 8, 15002, https://doi.org/10.1038/ncomms15002, 2017a.

Shiraiwa, M., Ueda, K., Pozzer, A., Lammel, G., Kampf, C. J., Fushimi, A., Enami, S., Arangio, A. M., Frohlich-Nowoisky, J., Fujitani, Y., Furuyama, A., Lakey, P. S. J., Lelieveld, J., Lucas, K., Morino, Y., Poschl, U., Takaharna, S., Takami, A., Tong, H. J., Weber, B., Yoshino, A., and Sato, K.: Aerosol Health Effects from Molecular to Global Scales, Environ. Sci. Technol., 51, 13545-13567, 2017b.

Slowik, J. G., Cross, E. S., Han, J. H., Davidovits, P., Onasch, T. B., Jayne, J. T., WilliamS, L. R., Canagaratna, M. R., Worsnop, D. R., Chakrabarty, R. K., Moosmuller, H., Arnott, W. P., Schwarz, J. P., Gao, R. S., Fahey, D. W., Kok, G. L., and Petzold, A.: An inter-comparison of instruments measuring black carbon content of soot particles, Aerosol Sci. Technol., 41, 295-314, 2007.

Snider, J. R. and Petters, M. D.: Optical particle counter measurement of marine aerosol hygroscopic growth, Atmos. Chem. Phys., 8, 1949-1962, https://doi.org/10.5194/acp-8-1949-2008, 2008. 
Sobanski, N., Schuladen, J., Schuster, G., Lelieveld, J., and Crowley, J. N.: A five-channel cavity ring-down spectrometer for the detection of $\mathrm{NO}_{2}, \mathrm{NO}_{3}, \mathrm{~N}_{2} \mathrm{O}_{5}$, total peroxy nitrates and total alkyl nitrates, Atmos. Meas. Tech., 9, 5103-5118, https://doi.org/10.5194/amt-9-5103-2016, 2016.

Solomon, P. A. and Sioutas, C.: Continuous and semicontinuous monitoring techniques for particulate matter mass and chemical components: A synthesis of findings from EPA's particulate matter supersites program and related studies, J. Air Waste Manage., 58, 164-195, 2008.

Song, M., Liu, P., Martin, S. T., and Bertram, A. K.: Liquid-liquid phase separation in particles containing secondary organic material free of inorganic salts, Atmos. Chem. Phys., 17, 1126111271, https://doi.org/10.5194/acp-17-11261-2017, 2017.

Song, M., Ham, S., Andrews, R. J., You, Y., and Bertram, A. K.: Liquid-liquid phase separation in organic particles containing one and two organic species: importance of the average O : C, Atmos. Chem. Phys., 18, 12075-12084, https://doi.org/10.5194/acp-18-12075-2018, 2018.

Song, X. W. and Boily, J. F.: Water Vapor Adsorption on Goethite, Environ. Sci. Technol., 47, 7171-7177, 2013.

Song, Y. C., Haddrell, A. E., Bzdek, B. R., Reid, J. P., Bannan, T., Topping, D. O., Percival, C., and Cai, C.: Measurements and Predictions of Binary Component Aerosol Particle Viscosity, J. Phys. Chem. A, 120, 8123-8137, 2016.

Sorooshian, A., Hersey, S., Brechtel, F. J., Corless, A., Flagan, R. C., and Seinfeld, J. H.: Rapid, size-resolved aerosol hygroscopic growth measurements: Differential aerosol sizing and hygroscopicity spectrometer probe (DASH-SP), Aerosol Sci. Technol., 42, 445-464, 2008.

Sorooshian, A., Shingler, T., Crosbie, E., Barth, M. C., Homeyer, C. R., Campuzano-Jost, P., Day, D. A., Jimenez, J. L., Thornhill, K. L., Ziemba, L. D., Blake, D. R., and Fried, A.: Contrasting aerosol refractive index and hygroscopicity in the inflow and outflow of deep convective storms: Analysis of airborne data from DC3, J. Geophys. Res.-Atmos., 122, 4565-4577, 2017.

Spedding, F. H., Weber, H. O., Saeger, V. W., Petheram, H. H., Rard, J. A., and Habenschuss, A.: Isopiestic determination of the activity coefficients of some aqueous rare earth electrolyte solutions at $25{ }^{\circ} \mathrm{C}$. 1 . The rare earth chlorides, J. Chem. Eng. Dara, 21, 341-360, 1976.

Speer, R. E., Barnes, H. M., and Brown, R.: An instrument for measuring the liquid water content of aerosols, Aerosol Sci. Technol., 27, 50-61, 1997.

Spesyvtseva, S. E. S. and Dholakia, K.: Trapping in a Material World, ACS Photonics, 3, 719-736, 2016.

Steimer, S. S., Krieger, U. K., Te, Y.-F., Lienhard, D. M., Huisman, A. J., Luo, B. P., Ammann, M., and Peter, T.: Electrodynamic balance measurements of thermodynamic, kinetic, and optical aerosol properties inaccessible to bulk methods, Atmos. Meas. Tech., 8, 2397-2408, https://doi.org/10.5194/amt-8-2397-2015, 2015.

Stokes, R. H. and Robinson, R. A.: Ionic Hydration and Activity in Electrolyte Solutions, J. Am. Chem. Soc., 70, 1870-1878, 1948.

Stratmann, F., Kiselev, A., Wurzler, S., Wendisch, M., Heintzenberg, J., Charlson, R. J., Diehl, K., Wex, H., and Schmidt, S.: Laboratory Studies and Numerical Simulations of Cloud Droplet Formation under Realistic Supersaturation Conditions, J. Atmos. Ocean. Tech., 21, 876-887, 2004.
Su, H., Rose, D., Cheng, Y. F., Gunthe, S. S., Massling, A., Stock, M., Wiedensohler, A., Andreae, M. O., and Pöschl, U.: Hygroscopicity distribution concept for measurement data analysis and modeling of aerosol particle mixing state with regard to hygroscopic growth and CCN activation, Atmos. Chem. Phys., 10, 7489-7503, https://doi.org/10.5194/acp-10-7489-2010, 2010.

Sun, J. X., Liu, L., Xu, L., Wang, Y. Y., Wu, Z. J., Hu, M., Shi, Z. B., Li, Y. J., Zhang, X. Y., Chen, J. M., and Li, W. J.: Key Role of Nitrate in Phase Transitions of Urban Particles: Implications of Important Reactive Surfaces for Secondary Aerosol Formation, J. Geophys. Res.-Atmos., 123, 1234-1243, 2018.

Swietlicki, E., Zhou, J. C., Berg, O. H., Martinsson, B. G., Frank, G., Cederfelt, S. I., Dusek, U., Berner, A., Birmili, W., Wiedensohler, A., Yuskiewicz, B., and Bower, K. N.: A closure study of sub-micrometer aerosol particle hygroscopic behaviour, Atmos. Res., 50, 205-240, 1999.

Swietlicki, E., Hansson, H. C., Hameri, K., Svenningsson, B., Massling, A., McFiggans, G., McMurry, P. H., Petaja, T., Tunved, P., Gysel, M., Topping, D., Weingartner, E., Baltensperger, U., Rissler, J., Wiedensohler, A., and Kulmala, M.: Hygroscopic properties of submicrometer atmospheric aerosol particles measured with H-TDMA instruments in various environments - a review, Tellus B, 60, 432-469, 2008.

Tabazadeh, A. and Toon, O. B.: The role of ammoniated aerosols in cirrus cloud nucleation, Geophys. Res. Lett., 25, 1379-1382, 1998.

Takahama, S., Johnson, A., and Russell, L. M.: Quantification of Carboxylic and Carbonyl Functional Groups in Organic Aerosol Infrared Absorbance Spectra, Aerosol Sci. Technol., 47, 310325, 2013.

Takahama, S., Ruggeri, G., and Dillner, A. M.: Analysis of functional groups in atmospheric aerosols by infrared spectroscopy: sparse methods for statistical selection of relevant absorption bands, Atmos. Meas. Tech., 9, 3429-3454, https://doi.org/10.5194/amt-9-3429-2016, 2016.

Takahama, S., Dillner, A. M., Weakley, A. T., Reggente, M., Bürki, C., Lbadaoui-Darvas, M., Debus, B., Kuzmiakova, A., and Wexler, A. S.: Atmospheric particulate matter characterization by Fourier transform infrared spectroscopy: a review of statistical calibration strategies for carbonaceous aerosol quantification in US measurement networks, Atmos. Meas. Tech., 12, 525-567, https://doi.org/10.5194/amt-12-525-2019, 2019.

Tan, F., Tong, S., Jing, B., Hou, S., Liu, Q., Li, K., Zhang, Y., and Ge, M.: Heterogeneous reactions of $\mathrm{NO}_{2}$ with $\mathrm{CaCO}_{3}-$ $\left(\mathrm{NH}_{4}\right)_{2} \mathrm{SO}_{4}$ mixtures at different relative humidities, Atmos. Chem. Phys., 16, 8081-8093, https://doi.org/10.5194/acp-168081-2016, 2016.

Tang, I. N.: Thermodynamic and optical properties of mixed-salt aerosols of atmospheric importance, J. Geophys. Res.-Atmos., 102, 1883-1893, 1997.

Tang, I. N. and Fung, K. H.: Hydration and Raman scattering studies of levitated microparticles: $\mathrm{Ba}\left(\mathrm{NO}_{3}\right)_{2}, \mathrm{Sr}\left(\mathrm{NO}_{3}\right)_{2}$, and $\mathrm{Ca}\left(\mathrm{NO}_{3}\right)_{2}$, J. Chem. Phys., 106, 1653-1660, 1997.

Tang, I. N. and Munkelwitz, H. R.: Water activities, densities, and refractive indices of aqueous sulfates and sodium nitrate droplets of atmospheric importance, J. Geophys. Res.-Atmos, 99, 1880118808, 1994. 
Tang, I. N., Fung, K. H., Imre, D. G., and Munkelwitz, H. R.: Phase transformation and metastability of hygroscopic microparticles, Aerosol Sci. Technol., 23, 443-453, 1995.

Tang, I. N., Tridico, A. C., and Fung, K. H.: Thermodynamic and optical properties of sea salt aerosols, J. Geophys. Res.-Atmos., 102, 23269-23275, 1997.

Tang, M. J., Camp, J. C. J., Rkiouak, L., McGregor, J., Watson, I. M., Cox, R. A., Kalberer, M., Ward, A. D., and Pope, F. D.: Heterogeneous Interaction of $\mathrm{SiO}_{2}$ with $\mathrm{N}_{2} \mathrm{O}_{5}$ : Aerosol Flow Tube and Single Particle Optical Levitation-Raman Spectroscopy Studies, J. Phys. Chem. A, 118, 8817-8827, 2014.

Tang, M. J., Cziczo, D. J., and Grassian, V. H.: Interactions of Water with Mineral Dust Aerosol: Water Adsorption, Hygroscopicity, Cloud Condensation and Ice Nucleation, Chem. Rev., 116, 42054259, 2016a.

Tang, M. J., Larish, W., Fang, Y., Gankanda, A., and Grassian, V. H.: Heterogeneous Reactions of Acetic Acid with Oxide Surfaces: Effects of Mineralogy and Relative Humidity, J. Phys. Chem. A, 120, 5609-5616, 2016b.

Tang, M., Huang, X., Lu, K., Ge, M., Li, Y., Cheng, P., Zhu, T., Ding, A., Zhang, Y., Gligorovski, S., Song, W., Ding, X., Bi, X., and Wang, X.: Heterogeneous reactions of mineral dust aerosol: implications for tropospheric oxidation capacity, Atmos. Chem. Phys., 17, 11727-11777, https://doi.org/10.5194/acp-17-117272017, 2017.

Tang, M. J., Chen, J., and Wu, Z. J.: Ice nucleating particles in the troposphere: Progresses, challenges and opportunities, Atmos. Environ., 192, 206-208, 2018.

Tang, M., Gu, W., Ma, Q., Li, Y. J., Zhong, C., Li, S., Yin, X., Huang, R.-J., He, H., and Wang, X.: Water adsorption and hygroscopic growth of six anemophilous pollen species: the effect of temperature, Atmos. Chem. Phys., 19, 2247-2258, https://doi.org/10.5194/acp-19-2247-2019, 2019.

Thomas, E., Rudich, Y., Trakhtenberg, S., and Ussyshkin, R.: Water adsorption by hydrophobic organic surfaces: Experimental evidence and implications to the atmospheric properties of organic aerosols, J. Geophys. Res.-Atmos., 104, 16053-16059, 1999.

Thomas, S., Cole, M., Villa-Lopez, F. H., and Gardner, J. W.: High frequency surface acoustic wave resonator-based sensor for particulate matter detection, Sensor. Actuat. A, 244, 138-145, 2016.

Titos, G., Cazorla, A., Zieger, P., Andrews, E., Lyamani, H., Granados-Munoz, M. J., Olmo, F. J., and Alados-Arboledas, L.: Effect of hygroscopic growth on the aerosol light-scattering coefficient: A review of measurements, techniques and error sources, Atmos. Environ., 141, 494-507, 2016.

Tobo, Y., Zhang, D., Matsuki, A., and Iwasaka, Y.: Asian Dust Particles Converted into Aqueous Droplets under Remote Marine Atmospheric Conditions, P. Natl. Acad. Sci. USA, 107, 1790517910, 2010.

Tobo, Y., DeMott, P. J., Raddatz, M., Niedermeier, D., Hartmann, S., Kreidenweis, S. M., Stratmann, F., and Wex, H.: Impacts of chemical reactivity on ice nucleation of kaolinite particles: A case study of levoglucosan and sulfuric acid, Geophys. Res. Lett., 39, L19803, https://doi.org/10.1029/2012GL053007, 2012.

Tong, H. H. Y., Chow, A. S. F., Chan, H. M., Chow, A. H. L., Wan, Y. K. Y., Williams, I. D., Shek, F. L. Y., and Chan, C. K.: ProcessInduced Phase Transformation of Berberine Chloride Hydrates, J. Pharm. Sci., 99, 1942-1954, 2010a.
Tong, H. J., Reid, J. P., Dong, J. L., and Zhang, Y. H.: Observation of the Crystallization and Supersaturation of Mixed Component NaNO3-Na2SO4 Droplets by FTIR-ATR and Raman Spectroscopy, J. Phys. Chem. A, 114, 12237-12243, 2010 b.

Tong, H.-J., Reid, J. P., Bones, D. L., Luo, B. P., and Krieger, U. K.: Measurements of the timescales for the mass transfer of water in glassy aerosol at low relative humidity and ambient temperature, Atmos. Chem. Phys., 11, 4739-4754, https://doi.org/10.5194/acp-11-4739-2011, 2011.

Tong, H.-J., Ouyang, B., Nikolovski, N., Lienhard, D. M., Pope, F. D., and Kalberer, M.: A new electrodynamic balance (EDB) design for low-temperature studies: application to immersion freezing of pollen extract bioaerosols, Atmos. Meas. Tech., 8, 11831195, https://doi.org/10.5194/amt-8-1183-2015, 2015.

Torrent, J., Barron, V., and Schwertmann, U.: Phosphate Adsorption and Desorption by Goethites Differing in Crystal Morphology, Soil Sci. S. Am. J., 54, 1007-1012, 1990.

Treuel, L., Butler, J. R., Hargreaves, G., and Reid, J. P.: Probing the Equilibrium Size and Hydrogen Bonding Structure in Aqueous Aerosol Droplets, Z. Phys. Chem., 224, 1185-1204, 2010.

Tritscher, T., Juranyi, Z., Martin, M., Chirico, R., Gysel, M., Heringa, M. F., DeCarlo, P. F., Sierau, B., Prevot, A. S. H., Weingartner, E., and Baltensperger, U.: Changes of hygroscopicity and morphology during ageing of diesel soot, Environ. Res. Lett., 6, 034026, https://doi.org/10.1088/1748-9326/6/3/034026, 2011.

Trunk, M., Lubben, J. F., Popp, J., Schrader, B., and Kiefer, W.: Investigation of a phase transition in a single optically levitated microdroplet by Raman-Mie scattering, Appl. Optics, 36, 3305 3309, 1997.

Tsionsky, V. and Gileadi, E.: Use of the Quartz Crystal Microbalance for the Study of Adsorption from the Gas Phase, Langmuir, 10, 2830-2835, 1994.

Twomey, S.: The identification of individual hygroscopic particles in the atmosphere by a phase-transition method, J. Appl. Phys., 24, 1099-1102, 1953.

Twomey, S.: The composition of hygroscopic particles in the atmosphere, J. Meteorol., 11, 334-338, 1954.

Vainio, E., Kinnunen, H., Lauren, T., Brink, A., Yrjas, P., DeMartini, N., and Hupa, M.: Low-temperature corrosion in cocombustion of biomass and solid recovered fuels, Fuel, 184, 957965, 2016.

Vali, G., DeMott, P. J., Möhler, O., and Whale, T. F.: Technical Note: A proposal for ice nucleation terminology, Atmos. Chem. Phys., 15, 10263-10270, https://doi.org/10.5194/acp-15-102632015, 2015.

Varma, R. M., Ball, S. M., Brauers, T., Dorn, H.-P., Heitmann, U., Jones, R. L., Platt, U., Pöhler, D., Ruth, A. A., Shillings, A. J. L., Thieser, J., Wahner, A., and Venables, D. S.: Light extinction by secondary organic aerosol: an intercomparison of three broadband cavity spectrometers, Atmos. Meas. Tech., 6, 3115-3130, https://doi.org/10.5194/amt-6-3115-2013, 2013.

Veghte, D. P., Bittner, D. R., and Freedman, M. A.: CryoTransmission Electron Microscopy Imaging of the Morphology of Submicrometer Aerosol Containing Organic Acids and Ammonium Sulfate, Anal. Chem., 86, 2436-2442, 2014.

Virtanen, A., Joutsensaari, J., Koop, T., Kannosto, J., Yli-Pirila, P., Leskinen, J., Makela, J. M., Holopainen, J. K., Poschl, U., Kulmala, M., Worsnop, D. R., and Laaksonen, A.: An amorphous 
solid state of biogenic secondary organic aerosol particles, Nature, 467, 824-827, 2010.

Vittorias, E., Kappl, M., Butt, H. J., and Johannsmann, D.: Studying mechanical microcontacts of fine particles with the quartz crystal microbalance, Powder Technology, 203, 489-502, 2010.

Vlasenko, A., Sjogren, S., Weingartner, E., Gaggeler, H. W., and Ammann, M.: Generation of submicron Arizona test dust aerosol: Chemical and hygroscopic properties, Aerosol Sci. Technol., 39, 452-460, 2005.

Vlasenko, S. S., Su, H., Pöschl, U., Andreae, M. O., and Mikhailov, E. F.: Tandem configuration of differential mobility and centrifugal particle mass analysers for investigating aerosol hygroscopic properties, Atmos. Meas. Tech., 10, 1269-1280, https://doi.org/10.5194/amt-10-1269-2017, 2017.

Wagner, C., Hanisch, F., Holmes, N., de Coninck, H., Schuster, G., and Crowley, J. N.: The interaction of $\mathrm{N}_{2} \mathrm{O}_{5}$ with mineral dust: aerosol flow tube and Knudsen reactor studies, Atmos. Chem. Phys., 8, 91-109, https://doi.org/10.5194/acp-8-91-2008, 2008.

Walker, J. S., Wills, J. B., Reid, J. P., Wang, L. Y., Topping, D. O., Butler, J. R., and Zhang, Y. H.: Direct Comparison of the Hygroscopic Properties of Ammonium Sulfate and Sodium Chloride Aerosol at Relative Humidities Approaching Saturation, J. Phys. Chem. A, 114, 12682-12691, 2010.

Wang, F., Zhang, Y. H., Li, S. H., Wang, L. Y., and Zhao, L. J.: A strategy for single supersaturated droplet analysis: Confocal Raman investigations on the complicated hygroscopic properties of individual $\mathrm{MgSO} 4$ droplets on the quartz substrate, Anal. Chem., 77, 7148-7155, 2005.

Wang, G. H., Zhang, R. Y., Gomez, M. E., Yang, L. X., Zamora, M. L., Hu, M., Lin, Y., Peng, J. F., Guo, S., Meng, J. J., Li, J. J., Cheng, C. L., Hu, T. F., Ren, Y. Q., Wang, Y. S., Gao, J., Cao, J. J., An, Z. S., Zhou, W. J., Li, G. H., Wang, J. Y., Tian, P. F., Marrero-Ortiz, W., Secrest, J., Du, Z. F., Zheng, J., Shang, D. J., Zeng, L. M., Shao, M., Wang, W. G., Huang, Y., Wang, Y., Zhu, Y. J., Li, Y. X., Hu, J. X., Pan, B., Cai, L., Cheng, Y. T., Ji, Y. M., Zhang, F., Rosenfeld, D., Liss, P. S., Duce, R. A., Kolb, C. E., and Molina, M. J.: Persistent sulfate formation from London Fog to Chinese haze, P. Natl. Acad. Sci. USA, 113, 13630-13635, 2016.

Wang, H., Chen, J., and Lu, K.: Development of a portable cavityenhanced absorption spectrometer for the measurement of ambient $\mathrm{NO}_{3}$ and $\mathrm{N}_{2} \mathrm{O}_{5}$ : experimental setup, lab characterizations, and field applications in a polluted urban environment, Atmos. Meas. Tech., 10, 1465-1479, https://doi.org/10.5194/amt10-1465-2017, 2017a.

Wang, L., Huang, D. D., Chan, C. K., Li, Y. J., and Xu, X. J. G.: Nanoscale spectroscopic and mechanical characterization of individual aerosol particles using peak force infrared microscopy, Chem. Commun., 53, 7397-7400, 2017b.

Wang, Q. Q., Jacob, D. J., Spackman, J. R., Perring, A. E., Schwarz, J. P., Moteki, N., Marais, E. A., Ge, C., Wang, J., and Barrett, S. R. H.: Global budget and radiative forcing of black carbon aerosol: Constraints from pole-to-pole (HIPPO) observations across the Pacific, J. Geophys. Res.-Atmos., 119, 195-206, 2014.

Wang, X., Ye, X., Chen, H., Chen, J., Yang, X., and Gross, D. S.: Online hygroscopicity and chemical measurement of urban aerosol in Shanghai, China, Atmos. Environ., 95, 318-326, 2014.
Wang, X. M., Ye, X. N., Chen, H., Chen, J. M., Yang, X., and Gross, D. S.: Online hygroscopicity and chemical measurement of urban aerosol in Shanghai, China, Atmos. Environ., 95, 318-326, 2014.

Wang, Y., Zheng, G., Spielman, S. R., Pinterich, T., Hering, S. V., and Wang, J.: Retrieval of high time resolution growth factor probability density function from a humidity-controlled fast integrated mobility spectrometer, Aerosol Sci. Technol., 53, 10921106, 2019.

Ward, A. D., Zhang, M., and Hunt, O.: Broadband Mie scattering from optically levitated aerosol droplets using a white LED, Optics Express, 16, 16390-16403, 2008.

Washenfelder, R. A., Flores, J. M., Brock, C. A., Brown, S. S., and Rudich, Y.: Broadband measurements of aerosol extinction in the ultraviolet spectral region, Atmos. Meas. Tech., 6, 861-877, https://doi.org/10.5194/amt-6-861-2013, 2013.

Washenfelder, R. A., Attwood, A. R., Flores, J. M., Zarzana, K. J., Rudich, Y., and Brown, S. S.: Broadband cavity-enhanced absorption spectroscopy in the ultraviolet spectral region for measurements of nitrogen dioxide and formaldehyde, Atmos. Meas. Tech., 9, 41-52, https://doi.org/10.5194/amt-9-41-2016, 2016.

Wasisto, H. S., Uhde, E., and Peiner, E.: Enhanced performance of pocket-sized nanoparticle exposure monitor for healthy indoor environment, Build. Environ., 95, 13-20, 2016.

Weingartner, E., Burtscher, H., and Baltensperger, U.: Hygroscopic properties of carbon and diesel soot particles, Atmos. Environ., 31, 2311-2327, 1997.

Weingartner, E., Gysel, M., and Baltensperger, U.: Hygroscopicity of Aerosol Particles at Low Temperatures. 1. New LowTemperature H-TDMA Instrument:? Setup and First Applications, Environ. Sci. Technol., 36, 55-62, 2002.

Wendt, S., Matthiesen, J., Schaub, R., Vestergaard, E. K., Laegsgaard, E., Besenbacher, F., and Hammer, B.: Formation and splitting of paired hydroxyl groups on reduced TiO2(110), Phys. Rev. Lett., 96, 066107, https://doi.org/10.1103/PhysRevLett.96.066107, 2006.

Wex, H., Kiselev, A., Stratmann, F., Zoboki, J., and Brechtel, F.: Measured and modeled equilibrium sizes of $\mathrm{NaCl}$ and (NH4)2SO4 particles at relative humidities up to $99.1 \%$, J. Geophys. Res.-Atmos, 110, D21212, https://doi.org/10.1029/2004JD005507, 2005.

Wex, H., Petters, M. D., Carrico, C. M., Hallbauer, E., Massling, A., McMeeking, G. R., Poulain, L., Wu, Z., Kreidenweis, S. M., and Stratmann, F.: Towards closing the gap between hygroscopic growth and activation for secondary organic aerosol: Part 1 - Evidence from measurements, Atmos. Chem. Phys., 9, 3987-3997, https://doi.org/10.5194/acp-9-3987-2009, 2009.

Wex, H., Augustin-Bauditz, S., Boose, Y., Budke, C., Curtius, J., Diehl, K., Dreyer, A., Frank, F., Hartmann, S., Hiranuma, N., Jantsch, E., Kanji, Z. A., Kiselev, A., Koop, T., Möhler, O., Niedermeier, D., Nillius, B., Rösch, M., Rose, D., Schmidt, C., Steinke, I., and Stratmann, F.: Intercomparing different devices for the investigation of ice nucleating particles using Snomax ${ }^{\circledR}$ as test substance, Atmos. Chem. Phys., 15, 14631485, https://doi.org/10.5194/acp-15-1463-2015, 2015.

Whitehead, J. D., Irwin, M., Allan, J. D., Good, N., and McFiggans, G.: A meta-analysis of particle water uptake reconciliation studies, Atmos. Chem. Phys., 14, 11833-11841, https://doi.org/10.5194/acp-14-11833-2014, 2014. 
Wills, J. B., Knox, K. J., and Reid, J. P.: Optical control and characterisation of aerosol, Chem. Phys. Lett., 481, 153-165, 2009.

Winkler-Heil, R., Ferron, G., and Hofmann, W.: Calculation of hygroscopic particle deposition in the human lung, Inhal. Toxicol., 26, 193-206, 2014.

Winkler-Heil, R., Pichelstorfer, L., and Hofmann, W.: Aerosol dynamics model for the simulation of hygroscopic growth and deposition of inhaled $\mathrm{NaCl}$ particles in the human respiratory tract, J. Aerosol. Sci., 113, 212-226, 2017.

Wise, M. E., Surratt, J. D., Curtis, D. B., Shilling, J. E., and Tolbert, M. A.: Hygroscopic growth of ammonium sulfate/dicarboxylic acids, J. Geophys. Res.-Atmos., 108, 4638, https://doi.org/10.1029/2003JD003775, 2003.

Wise, M. E., Biskos, G., Martin, S. T., Russell, L. M., and Buseck, P. R.: Phase transitions of single salt particles studied using a transmission electron microscope with an environmental cell, Aerosol Sci. Technol., 39, 849-856, 2005.

Wise, M. E., Semeniuk, T. A., Bruintjes, R., Martin, S. T., Russell, L. M., and Buseck, P. R.: Hygroscopic behavior of NaClbearing natural aerosol particles using environmental transmission electron microscopy, J. Geophys. Res.-Atmos., 112, D10224, https://doi.org/10.1029/2006JD007678TS62, 2007.

Wittmaack, K. and Strigl, M.: Novel Approach to Identifying Supersaturated Metastable Ambient Aerosol Particles, Environ. Sci. Technol., 39, 8177-8184, 2005.

Wu, H. B., Chan, M. N., and Chan, C. K.: FTIR Characterization of Polymorphic Transformation of Ammonium Nitrate, Aerosol Sci. Technol., 41, 581-588, 2007.

Wu, Z. J., Nowak, A., Poulain, L., Herrmann, H., and Wiedensohler, A.: Hygroscopic behavior of atmospherically relevant water-soluble carboxylic salts and their influence on the water uptake of ammonium sulfate, Atmos. Chem. Phys., 11, 1261712626, https://doi.org/10.5194/acp-11-12617-2011, 2011.

Wu, Z. J., Poulain, L., Henning, S., Dieckmann, K., Birmili, W., Merkel, M., van Pinxteren, D., Spindler, G., Müller, K., Stratmann, F., Herrmann, H., and Wiedensohler, A.: Relating particle hygroscopicity and $\mathrm{CCN}$ activity to chemical composition during the HCCT-2010 field campaign, Atmos. Chem. Phys., 13, 79837996, https://doi.org/10.5194/acp-13-7983-2013, 2013.

Wu, Z. J., Zheng, J., Shang, D. J., Du, Z. F., Wu, Y. S., Zeng, L. M., Wiedensohler, A., and Hu, M.: Particle hygroscopicity and its link to chemical composition in the urban atmosphere of Beijing, China, during summertime, Atmos. Chem. Phys., 16, 11231138, https://doi.org/10.5194/acp-16-1123-2016, 2016.

Wu, Z. J., Wang, Y., Tan, T. Y., Zhu, Y. S., Li, M. R., Shang, D. J., Wang, H. C., Lu, K. D., Guo, S., Zeng, L. M., and Zhang, Y. H.: Aerosol Liquid Water Driven by Anthropogenic Inorganic Salts: Implying Its Key Role in Haze Formation over the North China Plain, Environ. Sci. Tech. Lett., 5, 160-166, 2018.

Xue, H., Khalizov, A. F., Wang, L., Zheng, J., and Zhang, R.: Effects of dicarboxylic acid coating on the optical properties of soot, Phys. Chem. Chem. Phys., 11, 7869-7875, 2009.

Yamamoto, S., Kendelewicz, T., Newberg, J. T., Ketteler, G., Starr, D. E., Mysak, E. R., Andersson, K. J., Ogasawara, H., Bluhm, H., Salmeron, M., Brown, G. E., and Nilsson, A.: Water Adsorption on $\alpha$-Fe2O3(0001) at near Ambient Conditions, J. Phys. Chem. C, 114, 2256-2266, 2010a.

Yamamoto, S., Kendelewicz, T., Newberg, J. T., Ketteler, G., Starr, D. E., Mysak, E. R., Andersson, K. J., Ogasawara, H., Bluhm,
H., Salmeron, M., Brown, G. E., and Nilsson, A.: Water Adsorption on alpha-Fe2O3(0001) at near Ambient Conditions, J. Phys. Chem. C, 114, 2256-2266, 2010 b.

Yang, L. T., Pabalan, R. T., and Juckett, M. R.: Deliquescence relative humidity measurements using an electrical conductivity method, J. Solution Chem., 35, 583-604, 2006.

Ye, X., Tang, C., Yin, Z., Chen, J., Ma, Z., Kong, L., Yang, X., Gao, W., and Geng, F.: Hygroscopic growth of urban aerosol particles during the 2009 Mirage-Shanghai Campaign, Atmos. Environ., 64, 263-269, 2013.

Ye, X. N., Ma, Z., Hu, D. W., Yang, X., and Chen, J. M.: Sizeresolved hygroscopicity of submicrometer urban aerosols in Shanghai during wintertime, Atmos. Res., 99, 353-364, 2011.

Yeşilbaş, M. and Boily, J.-F.: Particle Size Controls on Water Adsorption and Condensation Regimes at Mineral Surfaces, Sci. Rep., 6, 32136, https://doi.org/10.1038/srep32136, 2016.

Yeung, M. C. and Chan, C. K.: Water Content and Phase Transitions in Particles of Inorganic and Organic Species and their Mixtures Using Micro-Raman Spectroscopy, Aerosol Sci. Technol., 44, 269-280, 2010.

Yeung, M. C., Lee, A. K. Y., and Chan, C. K.: Phase Transition and Hygroscopic Properties of Internally Mixed Ammonium Sulfate and Adipic Acid (AS-AA) Particles by Optical Microscopic Imaging and Raman Spectroscopy, Aerosol Sci. Technol., 43, 387-399, 2009.

Yeung, M. C., Ling, T. Y., and Chan, C. K.: Effects of the Polymorphic Transformation of Glutaric Acid Particles on Their Deliquescence and Hygroscopic Properties, J. Phys. Chem. A, 114, 898-903, 2010.

Yeung, M. C., Lee, B. P., Li, Y. J., and Chan, C. K.: Simultaneous HTDMA and HR-ToF-AMS measurements at the HKUST Supersite in Hong Kong in 2011, J. Geophys. Res.-Atmos., 119, 9864-9883, 2014a.

Yeung, M. C., Lee, B. P., Li, Y. J., and Chan, C. K.: Simultaneous HTDMA and HR-ToF-AMS measurements at the HKUST Supersite in Hong Kong in 2011, J. Geophys. Res.-Atmos, 119, 9864-9883, 2014b.

You, Y., Renbaum-Wolff, L., Carreras-Sospedra, M., Hanna, S. J., Hiranuma, N., Kamal, S., Smith, M. L., Zhang, X. L., Weber, R. J., Shilling, J. E., Dabdub, D., Martin, S. T., and Bertram, A. K.: Images reveal that atmospheric particles can undergo liquidliquid phase separations, P. Natl. Acad. Sci. USA, 109, 1318813193, 2012.

You, Y., Smith, M. L., Song, M. J., Martin, S. T., and Bertram, A. K.: Liquid-liquid phase separation in atmospherically relevant particles consisting of organic species and inorganic salts, Int. Rev. Phys. Chem., 33, 43-77, 2014.

Zardini, A. A., Sjogren, S., Marcolli, C., Krieger, U. K., Gysel, M., Weingartner, E., Baltensperger, U., and Peter, T.: A combined particle trap/HTDMA hygroscopicity study of mixed inorganic/organic aerosol particles, Atmos. Chem. Phys., 8, 55895601, https://doi.org/10.5194/acp-8-5589-2008, 2008.

Zawadowicz, M. A., Proud, S. R., Seppalainen, S. S., and Cziczo, D. J.: Hygroscopic and phase separation properties of ammonium sulfate/organics/water ternary solutions, Atmos. Chem. Phys., 15, 8975-8986, https://doi.org/10.5194/acp-158975-2015, 2015.

Zelenay, V., Ammann, M., Krepelova, A., Birrer, M., Tzvetkov, G., Vernooij, M. G. C., Raabe, J., and Huthwelker, T.: Direct obser- 
vation of water uptake and release in individual submicrometer sized ammonium sulfate and ammonium sulfate/adipic acid particles using X-ray microspectroscopy, J. Aerosol. Sci., 42, 38-51, 2011a.

Zelenay, V., Huthwelker, T., Krepelova, A., Rudich, Y., and Ammann, M.: Humidity driven nanoscale chemical separation in complex organic matter, Environ. Chem., 8, 450-460, $2011 \mathrm{~b}$.

Zeng, G., Kelley, J., Kish, J. D., and Liu, Y.: TemperatureDependent Deliquescent and Efflorescent Properties of Methanesulfonate Sodium Studied by ATR-FTIR Spectroscopy, J. Phys. Chem. A, 118, 583-591, 2014.

Zhang, L., Sun, J. Y., Shen, X. J., Zhang, Y. M., Che, H., Ma, Q. L., Zhang, Y. W., Zhang, X. Y., and Ogren, J. A.: Observations of relative humidity effects on aerosol light scattering in the Yangtze River Delta of China, Atmos. Chem. Phys., 15, 84398454, https://doi.org/10.5194/acp-15-8439-2015, 2015.

Zhang, Q., Jimenez, J. L., Canagaratna, M. R., Allan, J. D., Coe, H., Ulbrich, I., Alfarra, M. R., Takami, A., Middlebrook, A. M., Sun, Y. L., Dzepina, K., Dunlea, E., Docherty, K., DeCarlo, P. F., Salcedo, D., Onasch, T., Jayne, J. T., Miyoshi, T., Shimono, A., Hatakeyama, S., Takegawa, N., Kondo, Y., Schneider, J., Drewnick, F., Borrmann, S., Weimer, S., Demerjian, K., Williams, P., Bower, K., Bahreini, R., Cottrell, L., Griffin, R. J., Rautiainen, J., Sun, J. Y., Zhang, Y. M., and Worsnop, D. R.: Ubiquity and dominance of oxygenated species in organic aerosols in anthropogenically-influenced Northern Hemisphere midlatitudes, Geophys. Res. Lett., 34, L13801, https://doi.org/10.1029/2007GL029979, 2007.

Zhang, Q. N., Zhang, Y., Cai, C., Guo, Y. C., Reid, J. P., and Zhang, Y. H.: In Situ Observation on the Dynamic Process of Evaporation and Crystallization of Sodium Nitrate Droplets on a ZnSe Substrate by FTIR-ATR, J. Phys. Chem. A, 118, 2728-2737, 2014.

Zhang, X. L., Massoli, P., Quinn, P. K., Bates, T. S., and Cappa, C. D.: Hygroscopic growth of submicron and supermicron aerosols in the marine boundary layer, J. Geophys. Res.-Atmos., 119, 8384-8399, https://doi.org/10.1002/2013JD021213, 2014.

Zhang, Y. H. and Chan, C. K.: Study of contact ion pairs of supersaturated magnesium sulfate solutions using raman scattering of levitated single droplets, J. Phys. Chem. A, 104, 9191-9196, 2000.

Zhang, Y.-H. and Chan, C. K.: Understanding the Hygroscopic Properties of Supersaturated Droplets of Metal and Ammonium Sulfate Solutions Using Raman Spectroscopy, J. Phys. Chem. A, 106, 285-292, 2002a.

Zhang, Y. H. and Chan, C. K.: Understanding the hygroscopic properties of supersaturated droplets of metal and ammonium sulfate solutions using Raman spectroscopy, J. Phys. Chem. A, 106, 285-292, 2002b.

Zhang, Y. H. and Chan, C. K.: Observations of water monomers in supersaturated $\mathrm{NaClO} 4, \mathrm{LiClO} 4$, and $\mathrm{Mg}(\mathrm{ClO} 4) 2$ droplets using Raman spectroscopy, J. Phys. Chem. A, 107, 5956-5962, 2003.

Zhang, Y. X., Yuan, Q., Huang, D., Kong, S. F., Zhang, J., Wang, X. F., Lu, C. Y., Shi, Z. B., Zhang, X. Y., Sun, Y. L., Wang, Z. F., Shao, L. Y., Zhu, J. H., and Li, W. J.: Direct Observations of Fine Primary Particles From Residential Coal Burning: Insights Into Their Morphology, Composition, and Hygroscopicity, J. Geophys. Res.-Atmos, 123, 12964-12979, 2018.
Zhao, D. F.: Gas-aqueous-solid Multiphase Reaction of $\mathrm{NO}_{2}$ with Individual $\mathrm{CaCO}_{3}$ Particles and relevant hygroscopicity and CCN activity, PhD Thesis, Peking University, Beijing, 2010.

Zhao, D. F., Buchholz, A., Kortner, B., Schlag, P., Rubach, F., Fuchs, H., Kiendler-Scharr, A., Tillmann, R., Wahner, A., Watne, Å. K., Hallquist, M., Flores, J. M., Rudich, Y., Kristensen, K., Hansen, A. M. K., Glasius, M., Kourtchev, I., Kalberer, M., and Mentel, Th. F.: Cloud condensation nuclei activity, droplet growth kinetics, and hygroscopicity of biogenic and anthropogenic secondary organic aerosol (SOA), Atmos. Chem. Phys., 16, 1105-1121, https://doi.org/10.5194/acp16-1105-2016, 2016.

Zhao, H., Liu, X. F., and Tse, S. D.: Effects of pressure and precursor loading in the flame synthesis of titania nanoparticles, J. Aerosol. Sci., 40, 919-937, 2009.

Zhao, L. J., Zhang, Y. H., Wei, Z. F., Cheng, H., and Li, X. H.: Magnesium sulfate aerosols studied by FTIR spectroscopy: Hygroscopic properties, supersaturated structures, and implications for seawater aerosols, J. Phys. Chem. A, 110, 951-958, 2006.

Zhao, W., Xu, X., Dong, M., Chen, W., Gu, X., Hu, C., Huang, Y., Gao, X., Huang, W., and Zhang, W.: Development of a cavityenhanced aerosol albedometer, Atmos. Meas. Tech., 7, 25512566, https://doi.org/10.5194/amt-7-2551-2014, 2014.

Zhao, W. X., Xu, X. Z., Fang, B., Zhang, Q. L., Qian, X. D., Wang, S., Liu, P., Zhang, W. J., Wang, Z. Z., Liu, D., Huang, Y. B., Venables, D. S., and Chen, W. D.: Development of an incoherent broad-band cavity-enhanced aerosol extinction spectrometer and its application to measurement of aerosol optical hygroscopicity, Appl. Optics, 56, E16-E22, 2017.

Zhou, L., Wang, W. G., and Ge, M. F.: Temperature Dependence of Heterogeneous Uptake of Hydrogen Peroxide on Silicon Dioxide and Calcium Carbonate, J. Phys. Chem. A, 116, 7959-7964, 2012.

Zieger, P., Fierz-Schmidhauser, R., Gysel, M., Ström, J., Henne, S., Yttri, K. E., Baltensperger, U., and Weingartner, E.: Effects of relative humidity on aerosol light scattering in the Arctic, Atmos. Chem. Phys., 10, 3875-3890, https://doi.org/10.5194/acp10-3875-2010, 2010.

Zieger, P., Fierz-Schmidhauser, R., Weingartner, E., and Baltensperger, U.: Effects of relative humidity on aerosol light scattering: results from different European sites, Atmos. Chem. Phys., 13, 10609-10631, https://doi.org/10.5194/acp-13-106092013, 2013.

Zieger, P., Vaisanen, O., Corbin, J. C., Partridge, D. G., Bastelberger, S., Mousavi-Fard, M., Rosati, B., Gysel, M., Krieger, U. K., Leck, C., Nenes, A., Riipinen, I., Virtanen, A., and Salter, M. E.: Revising the hygroscopicity of inorganic sea salt particles, Nat. Commun., 8, 15883, https://doi.org/10.1038/ncomms15883, 2017.

Zielinski, A. T., Gallimore, P. J., Griffiths, P. T., Jones, R. L., Seshia, A. A., and Kalberer, M.: Measuring Aerosol Phase Changes and Hygroscopicity with a Microresonator Mass Sensor, Anal. Chem., 90, 9716-9724, 2018.

Zobrist, B., Soonsin, V., Luo, B. P., Krieger, U. K., Marcolli, C., Peter, T., and Koop, T.: Ultra-slow water diffusion in aqueous sucrose glasses, Phys. Chem. Chem. Phys., 13, 3514-3526, 2011.

Zuberi, B., Johnson, K. S., Aleks, G. K., Molina, L. T., and Laskin, A.: Hydrophilic properties of aged soot, Geophys. Res. Lett., 32, L01807, https://doi.org/10.1029/2004GL021496, 2005. 
Zuend, A., Marcolli, C., Booth, A. M., Lienhard, D. M., Soonsin, V., Krieger, U. K., Topping, D. O., McFiggans, G., Peter, T., and Seinfeld, J. H.: New and extended parameterization of the thermodynamic model AIOMFAC: calculation of activity coefficients for organic-inorganic mixtures containing carboxyl, hydroxyl, carbonyl, ether, ester, alkenyl, alkyl, and aromatic functional groups, Atmos. Chem. Phys., 11, 9155-9206, https://doi.org/10.5194/acp-11-9155-2011, 2011. 